\title{
Mad2/2 as a safeguard for open chromatin in embryonic stem cells
}

\author{
Dissertation \\ for the award of the degree \\ "Doctor rerum naturalium." \\ Of the Georg-August-Universität Göttingen \\ within the doctoral program (Genes and Development) \\ of the Georg-August University School of Science (GAUSS)
}

Submitted by:

Ali Rahjouei

From: Iran

Göttingen, 2016 


\section{Members of the Thesis Committee}

\section{Reviewer 1: Professor Dr. Michael Kessel}

Developmental Biology Group, Max Planck Institute for Biophysical Chemistry

Reviewer 2: Professor Dr. Wolfgang Fischle

Biological and Environmental Sciences \& Engineering Division, King Abdullah University of Science and Technology

Professor Dr. Tomas Pieler

Department of Developmental Biochemistry, University Medical Center Göttingen

\section{Members of the Extended Thesis Committee}

\section{Professor Dr. Ahmed Mansouri}

Molecular Cell Differentiation Group, Max Planck Institute for Biophysical Chemistry

Professor Dr. Detlef Doenecke

Department of Molecular Biology, University Medical Center Göttingen

\section{Dr. Halyna Shcherbata}

Gene expression and signaling Biology Group, Max Planck Institute for Biophysical Chemistry 


\section{Affirmation:}

Here I declare that my doctoral thesis entitled "Mad2/2 as a safeguard for open chromatin in embryonic stem cells" has been written independently with no other sources and aids than quoted.

Ali Rahjouei, Goettingen, April 2016 


\section{Contents}

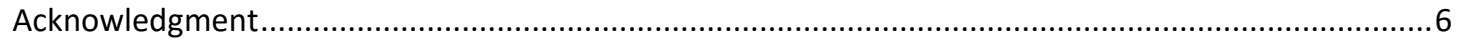

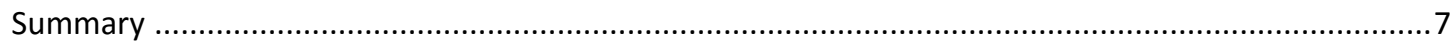

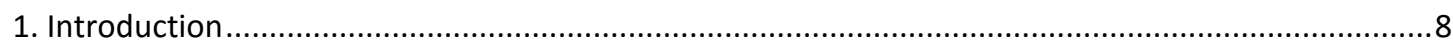

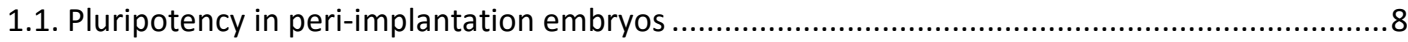

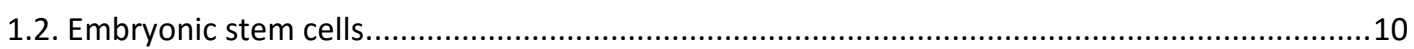

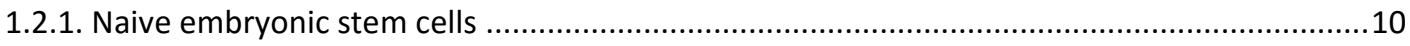

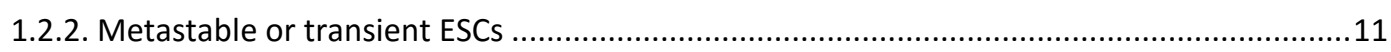

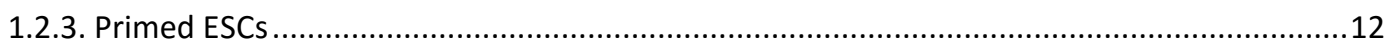

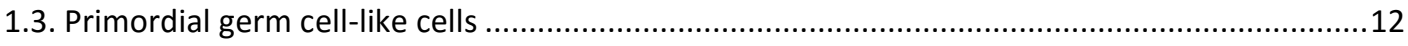

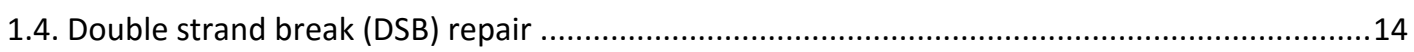

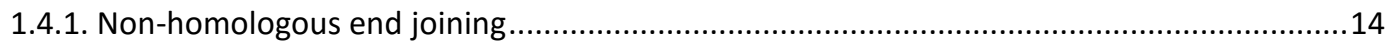

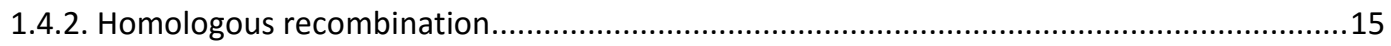

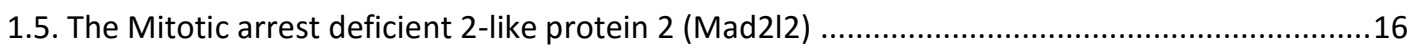

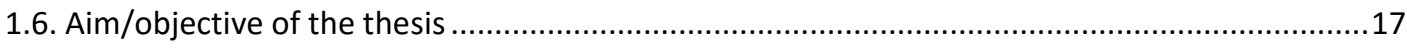

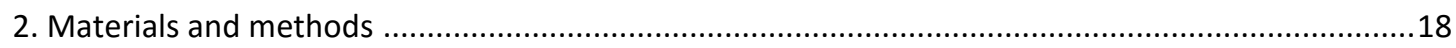

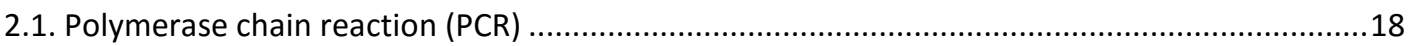

2.2. Reverse transcriptase - polymerase chain reaction (RT-PCR) ….........................................18

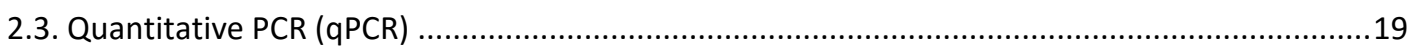

2.4.1- MEF (isolation, expansion, freezing, thawing) ...............................................................21

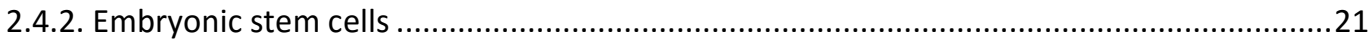

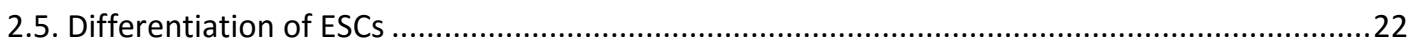

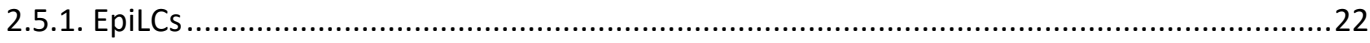

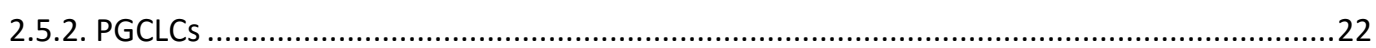

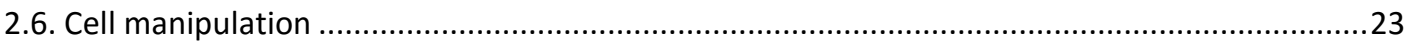

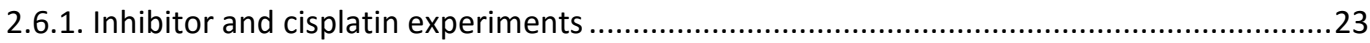

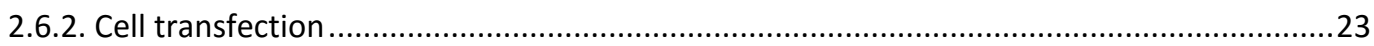

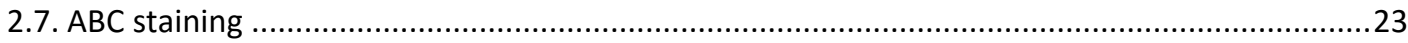

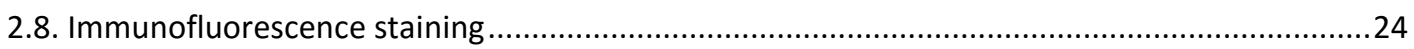

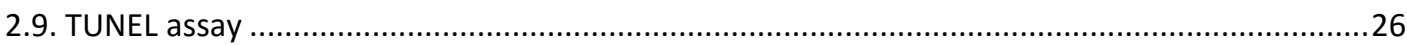

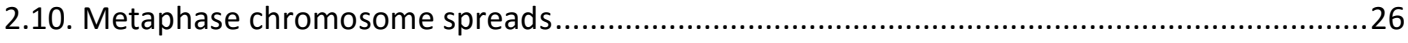

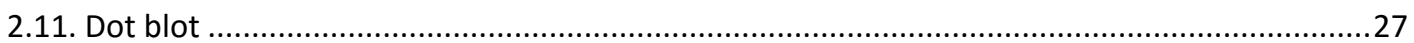

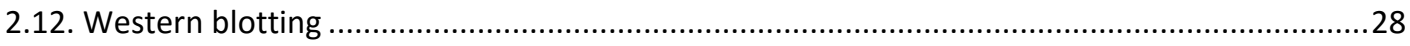

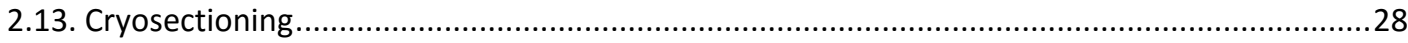

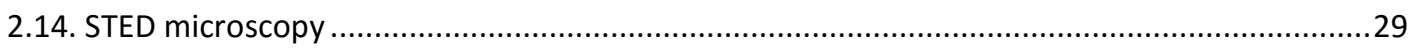

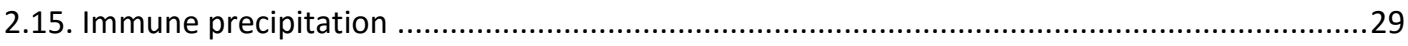

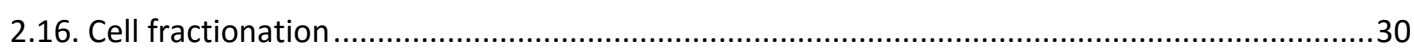

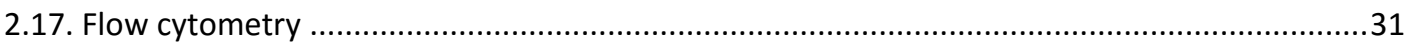

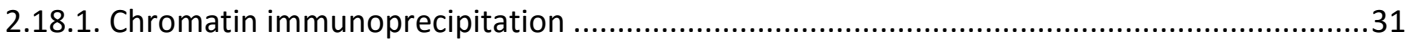

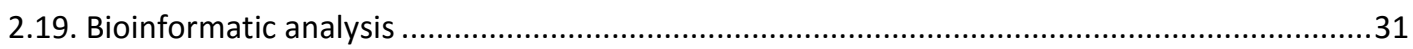

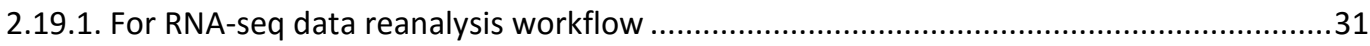


2.19.2. ChIP-seq

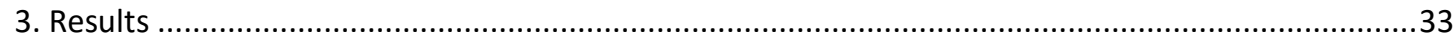

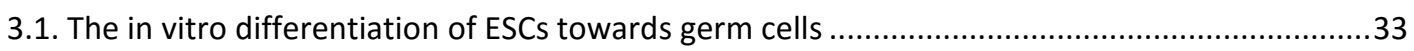

3.1.1 Mad212-deficient EpiLCs resemble wild-type EpiLCs ..................................................35

3.1.2 The differentiation of ESCS under PGCLC-inducing conditions in the presence or absence of

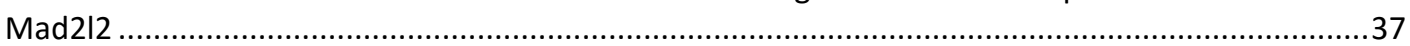

3.2. DDR in Mad2/2-deficient murine embryonic fibroblasts..........................................................46

3.2.1. Mad212-deficiency leads to activation of a DDR. .........................................................46

3.2.2. Cell proliferation is decreased in Mad2I2-deficient MEFs ................................................47

3.2.3. Histone modifications were misregulated in Mad2/2-deficient MEFs after DNA damage...48

3.3. Characterization of Wild-type and Mad2/2-deficient ESCs ..................................................49

3.3.1. Mad2I2 is highly expressed in the euchromatin of ESCS .................................................49

3.3.2. Comparison histone 3 modifications in wild-type and mutant ESCs.................................51

3.3.3. No evidence for DNA damage in Mad212-deficient ESCs ...................................................53

3.3.4. Comparison of transcriptomes from wild-type and Mad2/2-deficient ESCs ......................54

3.3.5. Dppa3 is downregulated in Mad212-deficient ESCs..............................................................57

3.3.6. Increase of DNA methylation in Mad2/2-deficient ESCs....................................................60

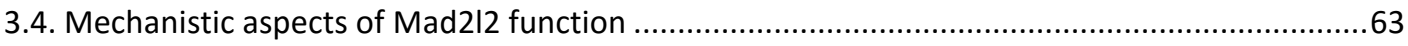

3.4.1. Absence of Mad212 from meiotic testicular cells ...........................................................63

3.4.2. Mad2/2 interacts with DDR factors directly .....................................................................64

3.4.3. Inhibition of histone or DNA modifications by small inhibitors in Mad2/2-deficient ESCs....65

3.4.4. ATM cascade in the maintenance of pluripotency .........................................................67

3.4.5. Colocalization of 53BP1 and H3K27me3 in the ESCs nucleus........................................69

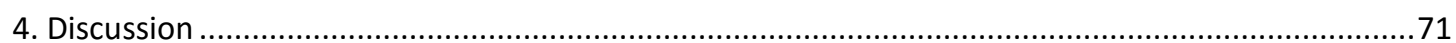

4.1. Failure of germ cell differentiation in the absence of Mad2/2 _............................................71

4.2. Prolongation of the cell cycle and spontaneous differentiation of Mad2/2-deficient ESCs........72

4.3. A function of Mad2/2 role in heterochromatin replication ....................................................... 72

4.4. Accumulation of damaged DNA in Mad2/2-deficient MEFs, but not ESCs .............................. 73

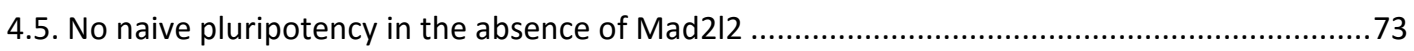

4.6. Promotion of open chromatin versus suppression of heterochromatin by Mad2/2 .................74

4.7. Mad2I2: an epigenetic regulator in pluripotency and DNA damage .....................................75

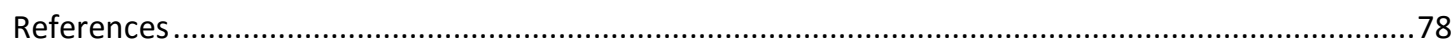

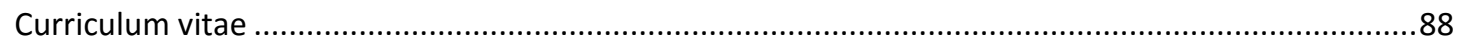




\section{Acknowledgment}

I would like to thank my supervior Prof. Dr. Michael Kessel for giving me the opportunity to work in his laboratory on this interesting project. His continuous support, guidance and the many helpful discussions are the cornerstones of this work and have added value to my scientific and personal development.

I am thankful to Prof. Dr. Tomas Pieler and Prof. Dr. Wolfgang Fischle, the members of my thesis committee. The thesis committee meetings are a central feature of the graduate program "Genes and development" and the additional advice, guidance and critical comments I received during these meetings were very helpful. I would like to thank the coordination office of the "Genes and development" program for their helpfulness and untiring dedication and Dr. Dirk Kamin for his collaboration.

I am grateful to my former colleagues for their continuous support. My special thanks go to Prof. Dr. Ahmed Mansouri, Dr. Alexander Klimke, and Dr. Golnaz Tabrizi for helpful discussions and advice. I would like to thank Sabine Geisendorf and Sharif Mahsur for their helps. Also, this work was not possible without Dr. Mehdi Pirouz supports and his efforts on Mad2I2 research. I would like to thank Dr. Ulrike Teichmann for her help and advice concerning the mice. I would like to thank Prof. Dr. Mitinori Saitou from Anatomy and Cell Biology, Kyoto University and Prof. Dr. Frederick W. Alt from Boston Children's Hospital for donation of Cells.

Finally, I would like to thank my parents for allowing me to follow my ambitions throughout my life and my wife, which supports me all the time with her kindness and patience. 


\section{Summery}

Mad2/2 as a safeguard for open chromatin in embryonic stem cells

Ali Rahjouei

Research Group Developmental Biology, Max Planck Institute for Biophysical Chemistry, Goettingen

Open chromatin is induced locally during the repair of DNA double strand breaks, when a cascade of protein recruitments and modifications is triggered. This "ATM cascade" includes components like the Mrn complex, ATM kinase, phosphorylated histon variant $\mathrm{YH} 2 \mathrm{AX}, \mathrm{MDC1}$, E3 ligases RNF 8 and RNF8, 53BP1, and Rif1. Recent investigations have shown that also the Mad2/2 protein is a downstream effector of the ATM cascade during DNA repair. It was first described as an accessory subunit during translesion DNA repair, and more recently as a key factor inhibiting the resection of DNA 5 'ends, thus promoting non-homologous end joining, and repressing homologous recombination.

Naive embryonic stem cells (ESCS) have a globally open chromatin. A preliminary study from this laboratory has demonstrated that ESCs require the presence of the Mad2I2 protein for the maintenance of their transcriptional and epigenetic profiles, and thus for the stability of pluripotency (Pirouz et al., Cell Cycle $14,1596,2015)$. The aim of the present study was to correlate Mad2/2 with the ATM cascade and the chromatin status in ESCs.

Mad2I2 as well as several other components of the ATM cascade are expressed at extraordinary high levels in the euchromatin of ESCs. High-resolution microscopy revealed that the localization of heterochromatin markers (H3K9me2 and H3K27me3) and Mad2/2 were mutually exclusive. In the absence of Mad2/2 the methylation of DNA and the amount of heterochromatin increased significantly. Comparative gene expression profiling indicated a striking, activating effect of Mad2I2 on the expression of Dppa3, a common marker of naive ESCs and primordial germ cells. Mass spectrometry identified Mad2l2 partners as a direct interactor of ATM cascade proteins, and DNA methyltransferase I (Dnmt1) in the ESC chromatin. Mad2/2 interaction with Dnmt1 had a substantial impact on the expression of imprinted genes in ESCs, which were downregulated in mutant ESCs. Inhibition of ATM, ATR and DNA-PK kinases supported the position of Mad2I2 as a downstream effector in the ATM cascade, just upstream of a DNA-Pk mediated Dppa3 activity. The suppression of Dppa3 in the absence of Mad2/2 was at least partially achieved by an occupation of the promoter with $\mathrm{H} 3 \mathrm{~K} 9 \mathrm{me} 2$. Further epigenetic effects related to Mad212 were the loss of the mutually exclusive localization of 53BP1 and H3K27me, and the necessity of Mad2I2 for the epigenetic reprogramming of ESCs into germ cells in vitro.

In conclusion, this study provides evidence for the function of Mad212 as a downstream effector in the constitutive ATM cascade in ESCs. This implies that the importance of Mad212 for DNA repair, germ cell development and ESC stability lies in the epigenetic regulation of the chromatin status. 


\section{Introduction}

\subsection{Pluripotency in peri-implantation embryos}

The fusion of haploid egg and sperm results in the formation of a diploid, one-cell embryo, or the zygote. In mammals, this single cell is capable of developing into all embryonic and extraembryonic tissues. It shares this "totipotency" with its daughter cells during the next cleavage divisions. The first divisions lead to a compact, round shaped embryo with 8 or 16 cells, the morula, which is surrounded by a cell-free membrane, the zona pellucida. Morula cells have to make a first developmental decision, to become either extraembryonal trophectoderm or inner cell mass (ICM) (Frum and Ralston, 2015; Zernicka-Goetz, 2005).

By embryonic day E3.5 the early blastocyst consists of 32 cells in the ICM, surrounded by the trophectoderm, also called trophoblast. ICM cells lack the potential to generate a trophectoderm, but retain the remarkable developmental potential to develop into all other cell types of the body, including germ cells. This potential has been defined as pluripotency (De Los Angeles et al.; Frum and Ralston, 2015). Pluripotent cells are characterized by the homogeneous expression of three core transcription factors, namely Oct4, Sox2 and Nanog (Ohnishi et al., 2014). Epigenetically, ICM cells in early blastocyst have high levels of activating histone 3 modifications around transcription start sites (H3K4me1, H3K4me2, and H3K4me3). Their DNA is significantly hypomethylated, and both $\mathrm{X}$ chromosomes are active (Li et al., 2012). The mid blastocyst ICM consists of a heterogeneous cell population, with fluctuating levels of Nanog and other pluripotency related markers (Xenopoulos et al., 2015). Several regulatory genes bear at the same time activating and repressive epigenetic signatures (Vastenhouw and Schier, 2012). For example, genes like Gata4 and Sox17 are characterized simultaneously by H3K4me3 and H3K27me3 histones. This epigenetic configuration termed bivalency is typical for pluripotent cells. It maintains lineage commitment in a poised state (Li et al., 2012).

The late blastocyst containing more than 64 ICM cells implants into the uterus. Now the ICM cells are ready to make a second fundamental decision, namely between an embryonic and an extra-embryonic fate. The embryonic cells, now designated the epiblast, maintain their pluripotent potential, including the 
expression of Oct4 and Sox2, while Nanog expression is downregulated, and early ICM markers such as Dppa3 (formerly Stella) and Zfp42 (formerly Rex1) are completely silenced (Joo et al., 2014). Prospective extra-embryonic, visceral endoderm cells are distinguished from epiblast cells by their peripheral location, and by the expression of Gata4 and Sox17 (Bao et al., 2009). The pluripotent potential of the early post-implantation epiblast is quickly lost upon further development towards gastrulation. Now the embryo will develop the three germ layers, acquire a cylinder shape ("egg cylinder"), and become asymmetric along the proximal-distal as well as the anterior-posterior axis (Stower and Srinivas, 2014).

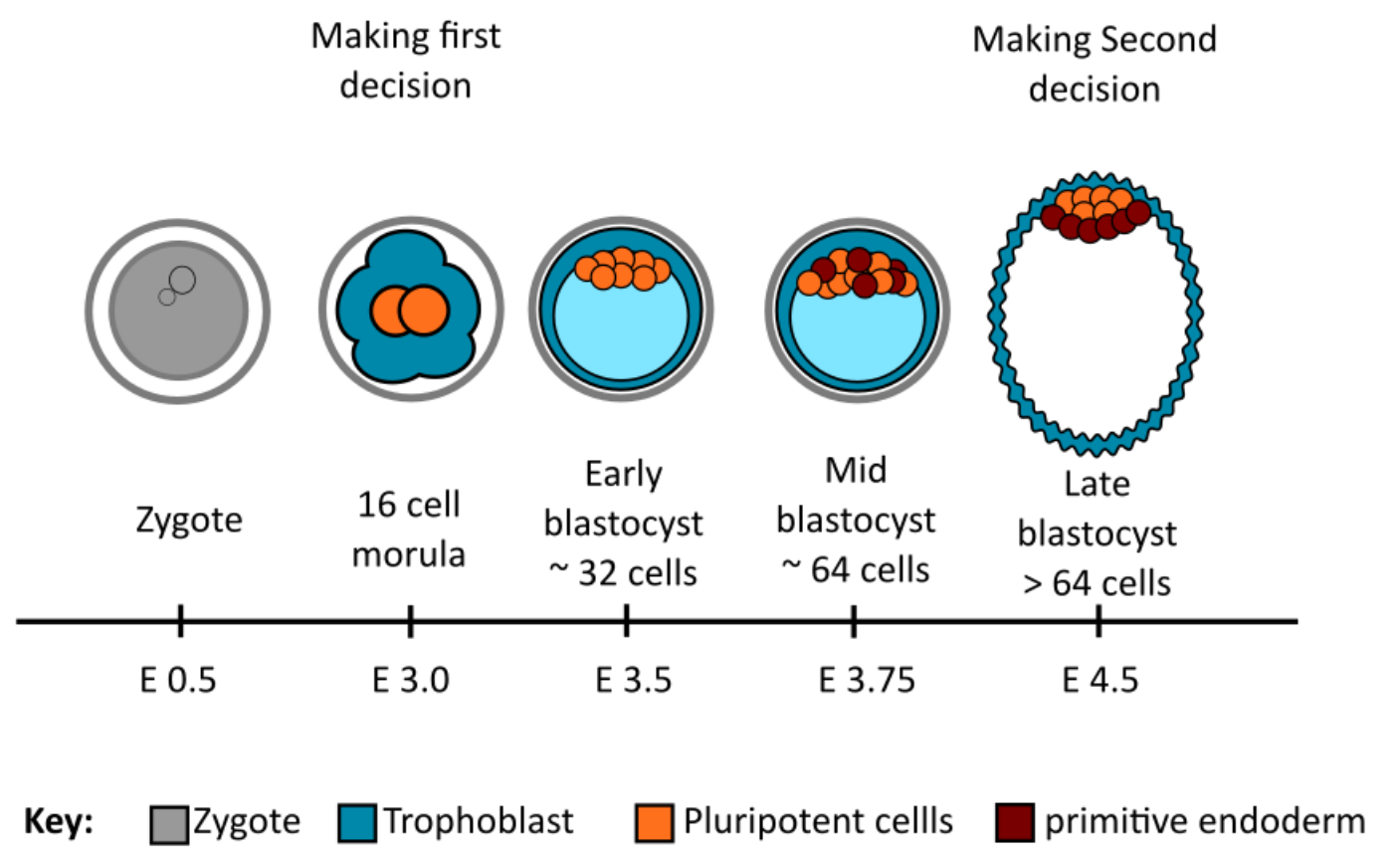

Figure 1: Early embryonic development from zygote to late blastocyst.

Mouse embryonic development starts with the formation of the zygote, in which the paternal and the maternal pronuclei initially are not fused yet. It takes three days for a zygote to develop into a morula, a condensed sphere of 16 cells. Around E3.5, a hollow ball of cells, the blastocyst, has formed. The cells in outer layer represent the trophoblast, and the cells inside the inner cell mass (ICM). Blastocyst development occurs in three stages, so that early, mid and late blastocysts are observed on E3.5, E3.75 and E4.5, respectively.

On day E6 around 20 somatic cells at the interface between extra embryonic and embryonic mesoderm become induced by BMP signaling, and acquire a specific fate as primordial germ cells (PGCs) (Lawson et al., 1999; Okamura et al., 2005). They are identified by expression of the marker genes Prdm1 (Blimp1) and Nanos3. After 
one day other PGC-related markers are detectable, including several typical pluripotency-related markers such as also Dppa3 (Saitou and Yamaji, 2012). Between E8 and E9 early PGCs become epigenetically reprogrammed, most significantly by a global reduction of histone 3 lysine 9 dimethylation (H3K9me2) and an increase of histone 3 lysine 27 trimethylation (H3K27me3), while DNA methylation becomes globally reduced (Kurimoto et al., 2015; Seki et al., 2007).

\subsection{Embryonic stem cells}

Embryonic stem cells (ESCs) can be derived from the ICM of early or late blastocysts before implantation (De Los Angeles et al., 2015). ESCs are characterized by their potential for unlimited self-renewal in culture and can differentiate into almost any ectodermal, mesodermal and endodermal cell lineage (De Los Angeles et al., 2015). Their specific pluripotent potential and their distinct functional properties depend not only on their embryonic origin, but significantly also on culture conditions. Thus, they may differ with respect to epigenetic profiles (DNA methylation patterns, histone modifications) and transcriptional profiles. Based on such parameters ESCs have been categorized into naive, metastable or transient, and primed subtypes (De Los Angeles et al., 2015).

\subsubsection{Naive embryonic stem cells}

Naive ESCs are cultured in a medium containing serum, and leukemia inhibitory factor (LIF), supplemented with two inhibitors (2i) directed against MEK and GSK3 signaling (De Los Angeles et al., 2015). MEK inhibition blocks differentiation pathways triggered by tyrosine kinase inducing factors, and GSK3 inhibition supports ESCs proliferation. 2i propagated ESCs resemble ICM cells of early blastocysts (Ying et al., 2008). Naive pluripotency is considered to represent a developmental ground state, as opposed to transient and primed pluripotency as defined below (Marks et al., 2012; Tosolini and Jouneau, 2016). The epigenetic landscape of naive ESCs is similar to the early inner cell mass, with a high level of H3K4me3 associated with both pluripotency and lineage specification marker genes, and a low number of bivalent loci (Marks et al., 2012). Their DNA is globally 
hypomethylated and both X chromosomes are reactivated (Marks et al., 2012; Singer et al., 2014). Naive ESC cultures display a homogeneous expression of pluripotencyassociated factors (Oct4, Sox2, KIf3), and are further characterized by naive ESC markers such as Dppa3, Zfp42, Prdm14, KIf2, and Esrrb, whereas early lineage specification markers are completely silenced (Kolodziejczyk et al., 2015; Marks et al., 2012; Singer et al., 2014). There are just few markers to distinguish naive ESCS from other ESCs. One of these is Dppa3, a highly specific marker for naive ESCs and for primordial germ cells. Dppa3 is also expressed in those 20 percent of metastable ESCs which are in a naive state at the time of observation (see below). Dppa3 is completely suppressed in primed ESCs. Overexpression of Dppa3 in combination with Oct4, Sox2, and KIf3 enhances the induction of pluripotency in mouse embryonic fibroblasts (MEFs), at least partially via promotion of global DNA demethylation (Funaki et al., 2014; Xu et al., 2015b). Dppa3-deficient mice develop normally in the first generation, but the second generation does not survive the 4cell stage (Bortvin et al., 2004). In the zygote, Dppa3 is unequally distributed between the paternal and maternal pronucleus (Bian and $Y u, 2014$ ). It binds to methylated DNA and protects the methylation state of e.g. imprinted loci by the inhibition of Tet1 and 2 (Kolodziejczyk et al., 2015; Marks et al., 2012; Singer et al., 2014).

\subsubsection{Metastable or transient ESCs}

Metastable or transient ESCs can be isolated from ICMs of both early and mid-blastocysts, but resemble more closely the mid-blastocyst on E4.5 (De Los Angeles et al., 2015). They are established in culture medium containing LIF and serum, on a feeder layer of mitotically inactive mouse embryonic fibroblasts (MEFs). LIF supports pluripotency by activation of the signal transducer STAT3 and consequently the induction of several pluripotency related transcription factors, especially Nanog (Stuart et al., 2014). Bone morphogenesis protein 4 (BMP4) in the presence of LIF is another extrinsic factor necessary for the culture of metastable mESCs. BMP4 induces expression of the Id gene (inhibition of differentiation) family, and inhibition of MAP kinase activity (Stuart et al., 2014). The epigenome of 
metastable ESCs is characterized by an increased number of bivalent loci, which keep lineage specification markers under negative control. Metastable ESCs oscillate between a naive and a primed state of pluripotency, which is documented by the heterogeneous expression of pluripotency-associated regulatory genes such as Prdm14, Dppa3, Zfp42, Pecam1, Nanog and SSEA1 in metastable ESC colonies, three different groups of ESCs can be recognized (Singer et al., 2014). One group expresses high levels of pluripotency related markers including Dppa3, and low levels of keratin and actins. The second group is highly positive for Oct4 and Sox2, but Dppa3 and Nanog levels are reduced. Finally, a third group expresses significant levels of differentiation related markers including cytoskeletal proteins (Kolodziejczyk et al., 2015; Marks et al., 2012; Singer et al., 2014).

\subsubsection{Primed ESCs}

Primed ESCs correlate with ICM cells from late blastocysts (De Los Angeles et al., 2015). They grow in the presence of Activin, and bFGF, and have a unique epigenetic and transcriptional signature. Promoters of early lineage specification markers are enriched with activating histone modifications such as H3K4me3. In contrast, the promoters of pluripotency related markers are suppressed both by de novo DNA methylation and by an increase of H3K27me3 and H3K9me3 levels. One of the $X$ chromosomes is inactivated (Guyochin et al., 2014). Expression of Oct4, Sox2 and other pluripotency related factors is still characteristic for primed ESCs, even if the Oct4 genes is regulated by a different enhancer (Pan et al., 2002). Nanog expression is low and typical pre-implantation factors such as Dppa3 and Zfp42 are silenced. Genes related to differentiation such as Gata4, Gata6, Sox17, Otx2, and FGF5 become transcribed in colonies of primed ESCs (Iwafuchi-Doi et al., 2012; Kojima et al., 2014).

\subsection{Primordial germ cell-like cells}

In 2011, Mitinori Saitou's laboratory introduced a new protocol for the differentiation of ESCs into primordial germ cell-like cells (PGCLCs) (Hayashi et al., 2011). This protocol was unique because it involved an intermediate cell type, the epiblast-like cells (EpiLCs). These intermediate cells express low levels of primitive 
endoderm marks such as Sox17 and Gata4/6 (Padua et al., 2014), and therefore they are different from epiblast stem cells (Hayashi et al., 2011). EpiLCs can be induced by BMPs into PGCLCs, which possess a transcriptional profile highly related to migratory PGCs in vivo (Saitou and Yamaji, 2012). PGCLCs have undergone an extensive epigenetic reprogramming, which includes the increase of H3K27me3 and a simultaneous decrease of H3K9me2 histone modifications (Hayashi et al., 2011). Thus, the in vitro differentiation of ESCs via EpiLCs into PGCCLs mimics closely the in vivo induction of PGCs at the beginning of gastrulation (Hayashi et al., 2011).

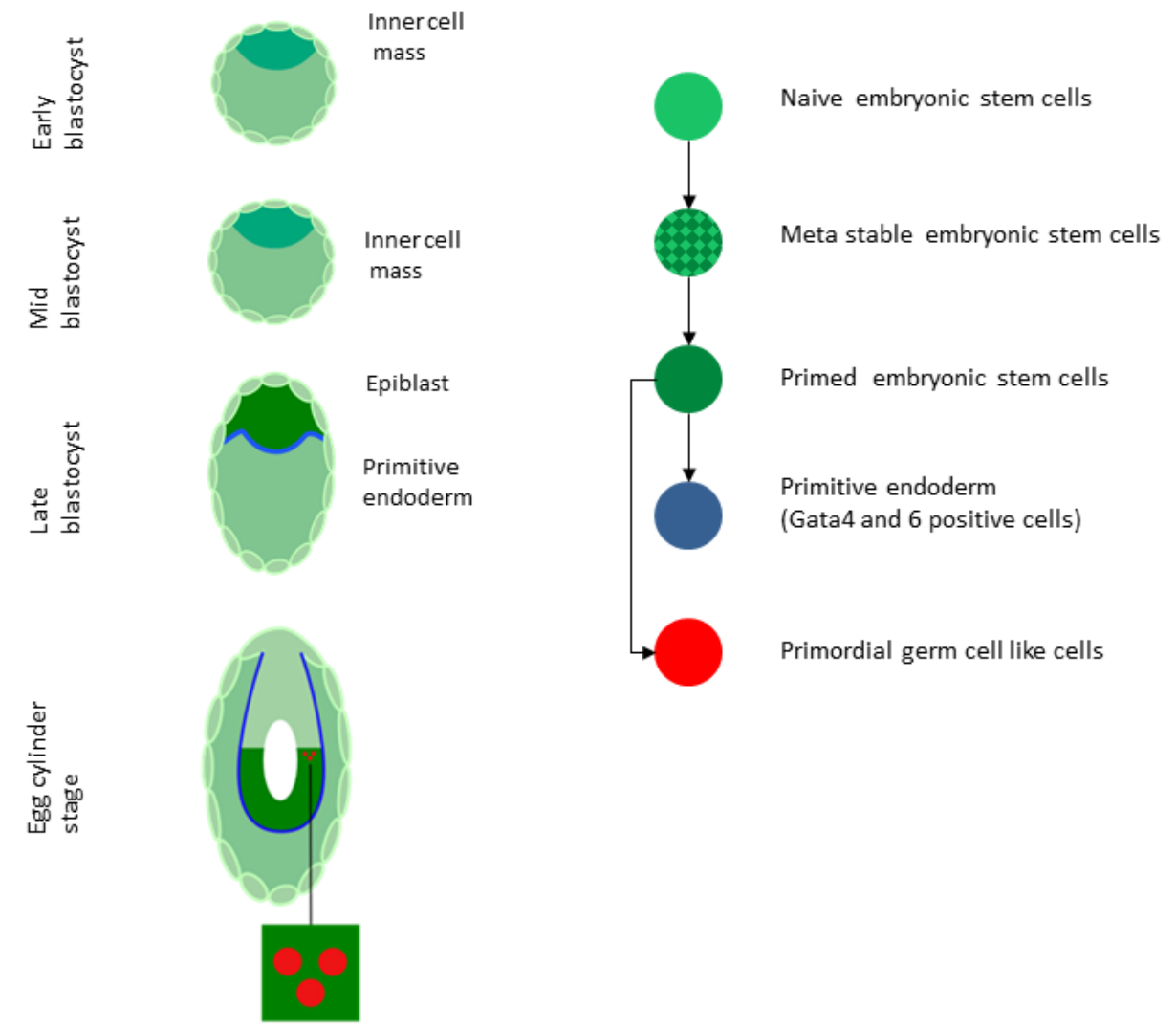

Figure 2: Correspondence between embryonic stage and ESC categories.

Naive ESCs correspond to the ICM of early blastocysts. These cells have low levels of suppressive histone modifications and DNA methylation. Metastable ESCs correspond to an ICM in mid blastocysts. They fluctuate characteristically between naive and primed status. Primed ESCs correspond to the ICM of late blastocysts. These cells are committed to differentiation and have stochastic expression of early lineage specification genes such as Gata4 and 6. PGCLCs correspond to PGCs are induced in egg cylinder stage embryo at the onset of gastrulation. 


\subsection{Double strand break (DSB) repair}

DNA damage can be induced by physical forces or chemical components. Cells possess a wide repertoire of mechanisms to respond to such defects, depending on the specific type of damage, and on parameters such as chromatin status (euchromatin, heterochromatin) or cell cycle phase. Double strand breaks (DSBs) are recognized by the MRN complex (Mer11, Rad50 and Nbs1), which acts as a platform for further proteins required for DSB repair (Lamarche et al., 2010). A key role is played by the ATM (Ataxia telangiectasia mutated) kinase, which phosphorylates $\mathrm{H} 2 \mathrm{AX}$ and the mediator of DNA damage checkpoint protein 1 (MDC1) (Alvarez-Quilon et al., 2014). The latter, recruits a number of other proteins including the two E3 ligases RNF8 and RNF168, which ubiquitinate histone H1, and H2A respectively (Thorslund et al., 2015; Zimmermann and de Lange, 2014). This initiates an opening of the chromatin at sites of damage, allowing the interaction with the DNA repair machinery (Zimmermann and de Lange, 2014). The two main pathways for DSB repair are non-homologous end joining (NHEJ) or homologous recombination (HR) (Fig. 3). Their choice strongly depends on the phase of the cell cycle, and thus the presence or absence of Cyclin-dependent kinase 1 (CDK1).

\subsubsection{Non-homologous end joining}

NHEJ is the dominant DSB repair pathway in the G1 phase, when there is no replicated DNA to be used as a template (Mao et al., 2008). Since the DNA ends are ligated after removal of one or two nucleotides, NHEJ is not precise and introduces mutations (Deriano and Roth, 2013). The chromatin at a DSB is characterized by three histone modifications, namely $\mathrm{H} 4$ di-methylated on residue $\mathrm{K} 2 \mathrm{O}, \mathrm{H} 2 \mathrm{~A}$ ubiquitinated on $\mathrm{K} 12$, and H2AX phosphorylated on S139 (Baldock et al., 2015). The large protein 53BP1 recognizes these modifications via its Tudor, UDR and BRCT domains, respectively (Figure 4). It promotes chromatin relaxation, and RIF1 and Mad2I2 are downstream effectors (Boersma et al., 2015; Xu et al., 2015a). Together, these proteins inhibit DNA $5^{\prime}$ end resection, and thus promote NHEJ while antagonizing HR. Mechanistically, NHEJ relies on heterodimers of the highly abundant Ku70 and Ku80 proteins which have a high affinity for DNA ends after a 
DSB, but only if the $5^{\prime}$ ends are not resected (Deriano and Roth, 2013). The Ku70/Ku80/DNA complex is first recognized by DNA-dependent protein kinase (DNAPKc), and then by the Artemis protein, which leads to DNA-PKc auto-phosphorylation and Artemis phosphorylation (Moshous et al., 2001). A conformational change then allows to bring the broken DNA ends close to each other, so that they can be joined by ligase IV and XRCC4 (Collis et al., 2005)

\subsubsection{Homologous recombination}

In the S/G2 phase of the cell cycle, DSBs are preferentially repaired by HR (Mao et al., 2008). Cdk1 phosphorylates CtIP, one of the early recruited proteins to the damage site, which then recruits breast cancer 1 (BRCA1) (Peterson et al., 2011). This complex inhibits the interaction of 53BP1/RIF1 and thus antagonizes NHEJ (Escribano-Diaz et al., 2013). Additionally, CDK1 activity is essential for DNA 5' end resection by activation of Exonulease1 (Exo1) (Tomimatsu et al., 2014). Singlestranded DNA is recognized by replication protein A (RPA) which is essential for recruitment of other factors and finally for HR (Moynahan and Jasin, 2010; Sung and Klein, 2006).

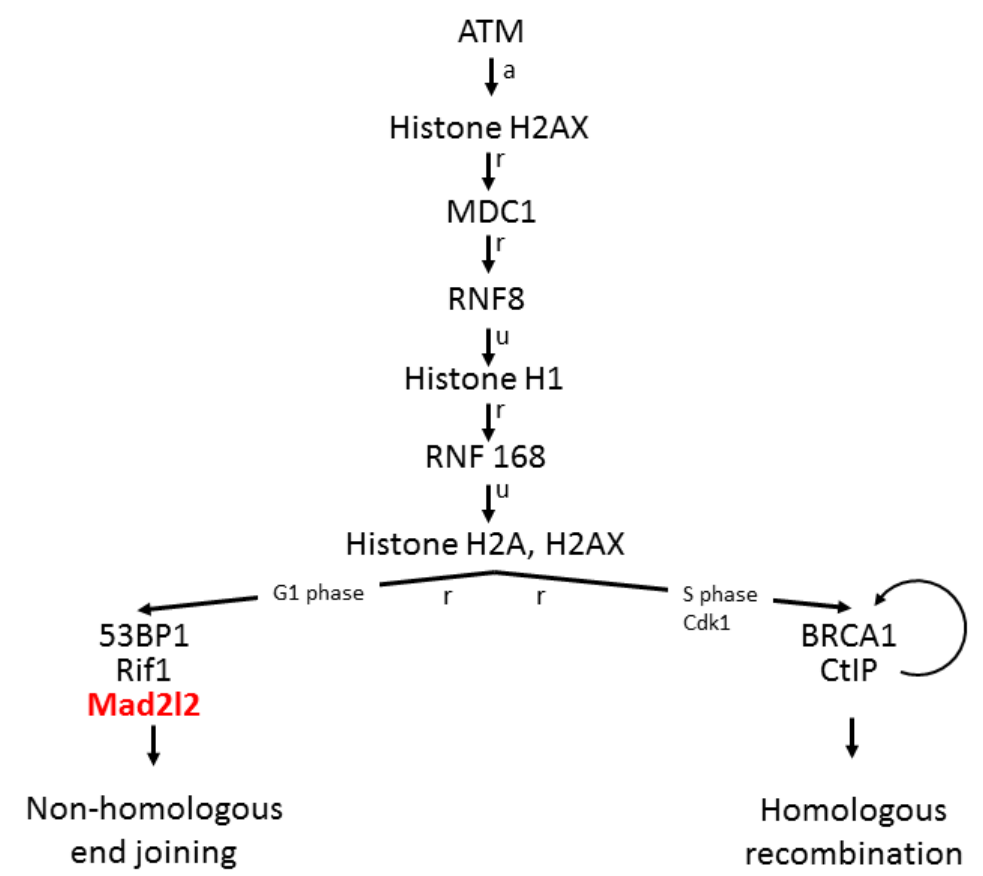

Figure 3: ATM cascade. DNA damage response after DSB and the decision between HR and NHEJ. a, activation; $p$, phosphorylation; $r$, recruitment; $u$, ubiquitylation; For explanation see 1.4.1. 


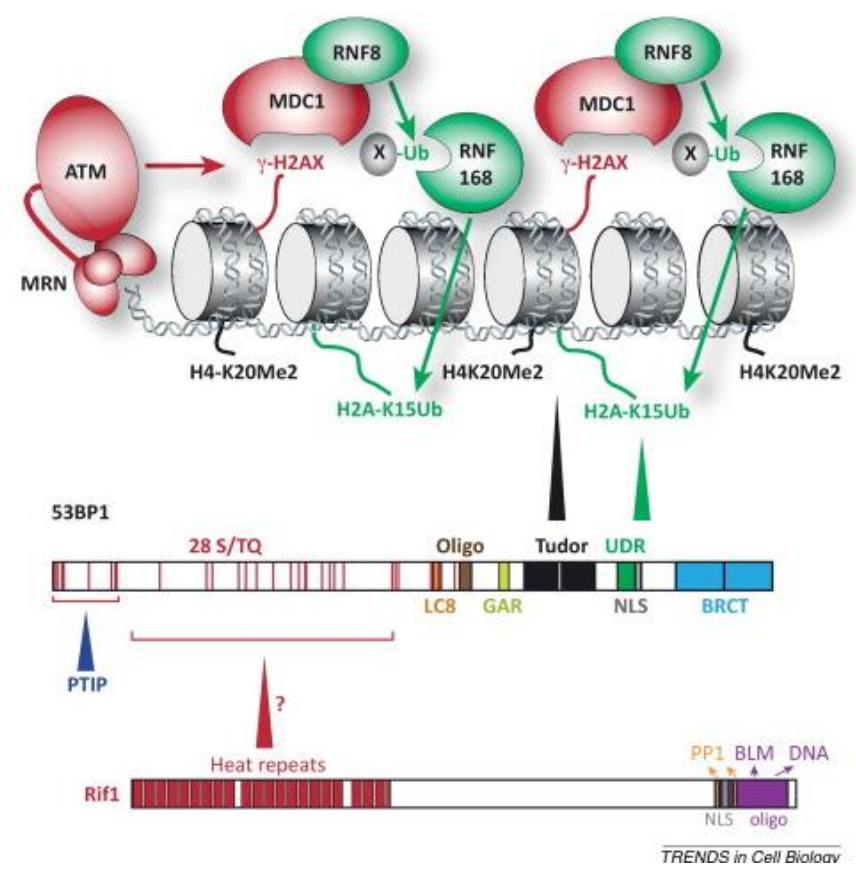

Figure 4: 53BP1 and RIF1 are recruitment of DSBs. For explanation see 1.4. Figure is taken from (Zimmermann and de Lange, 2014).

\subsection{The Mitotic arrest deficient 2 -like protein $2(\operatorname{Mad} 2 / 2)$}

The Mad2l2 (Rev7) protein consists of 211 amino acids, adding up to a molecular weight of $24,334 \mathrm{Da}$. It is structurally related to the mitotic arrestdeficient protein 2 (MAD2), with which it shares 26\% identical and 54\% similar amino acids. Mad2/2 has a protein-protein interaction sequence known as a HORMA (Hop1, Rev7 and Mad2) domain, and interactions with numerous, at first sight unrelated proteins were described (UniProtKB-Q9D752). However, postulated functions Mad2/2 in cell cycle control or transcription factor regulation mostly based on interactions with Cdc20, Cdh1, TCF4 have remained functionally unclear or contradictory (Chen and Fang, 2001; Chun et al., 2013; Hong et al., 2009; Iwai et al., 2007). Much better understood is a role for Mad2/2 in DNA damage repair. Mad2/2 was described as an accessory subunit of translesion polymerase $\zeta$, forming a ternary complex with Rev1 and Rev3. Translesion DNA repair is a highly error-prone mechanism increasing the rate of mutagenesis significantly (Iwai et al., 2007). Mad2/2-deficient cells are hypersensitive to DNA damage induced by DNA crosslinkers such as cisplatin (Niimi et al., 2014). The observed increase of $\mathrm{\gamma H} 2 \mathrm{AX}$ foci is catalyzed by one of the three kinases DNA-PK, ATM or ATR (Wang et al., 2005; Ward 
and Chen, 2001). It indicates an accumulation of DSBs, which are not efficiently repaired in the absence of Mad2I2 (Cheung et al., 2006).

Mad2l2 protein is not generally necessary for mouse development but it is specifically required for PGC development (Khalaj et al., 2014; Pirouz et al., 2013; Watanabe et al., 2013). Mad2/2-deficient PGCs are properly induced, but disappear shortly after, without undergoing the obligatory epigenetic reprogramming from a H3K9me2 to a H3K27me3 chromatin configuration (Pirouz et al., 2013). For the molecular function of Mad2/2 it was previously suggested that it would antagonize the methylation of $\mathrm{H} 3$ on the $\mathrm{K} 9$ residue via interaction with the methyltransferases Ehmt2 and Ehmt1 (Pirouz et al., 2013). On the other hand it was shown that Mad2/2 binds and inhibits Cdk1, and thus might maintain methyltransferase Ezh2 in an active state, which would then result in the methylation of $\mathrm{H} 3$ on residue $\mathrm{K} 27$ residue (Pirouz et al., 2013).

Mad2I 2 is an essential factor for the stable maintenance of pluripotency of ESCs in LIF/Serum medium. Mad2/2-deficient ESCs heterogeneously express primitive endoderm markers such as Sox17 and Gata4, since the MAPK signaling pathway is hypersensitive and several of its components are misregulated. In these cells the Nanog promoter was occupied with a silencing epigenetically mark and the Gata4 promoter had lost its bivalent status. In the absence of Mad2I2, a global increase of heterochromatin markers was observed (Pirouz et al., 2015). Expression of primitive endoderm markers were rescued by ERK signaling pathway inhibition, which, however, did not replace the epigenetic regulatory roles of Mad2l2 (Pirouz et al., 2015).

\subsection{Aim of the thesis}

The aim of the submitted thesis was to understand the role of epigenetic programming and reprogramming in PGCs and ESCs, in comparison to related processes occurring in response to the damage of DNA. At the core of the work stood the Mad2/2 protein and its function in development and epigenetics. 


\section{Materials and methods}

If experiment procedure is not mentioned here, standard protocols and materials were applied as summarized in current protocols in molecular biology (Ausubel, 2002).

\subsection{Polymerase chain reaction (PCR)}

DNA fragments were amplified by PCR. For each primer annealing temperature was identified by gradient PCR with respect to each primer melting temperature. Expansion time was calculated based on amplification size (1 min per 1 kb). The GoTaq $^{\circledR}$ DNA polymerase (Promega) was applied according to the instructions of the manufacturer. Materials are listed in Table 1. The amplification program (Table 2) was executed using the Mastercycler ${ }^{\circledR}$ Gradient (Eppendorf).

Table 1. List of materials used for PCR

\begin{tabular}{lll}
\hline Name & Company & Catalog number \\
\hline GoTaq G2 polymerase & Promega & M7841 \\
GoTaq G2 polymerase & Promega & M7822 \\
GoTaq G2 Green Master & Promega & C1141 \\
Mix & & \\
PCR Nucleotide Mix & Promega & P1193 \\
Nuclease-Free Water & Promega & P1193 \\
dNTP Solution Mix & Promega & N0447S \\
Nuclease-Free Water & NEB & M7841 \\
\hline
\end{tabular}

Table 2. Standard amplification program

\begin{tabular}{llll}
\hline Step & Number of cycles & Temperature & time \\
\hline 1) Initial denaturation & 1 & $94^{\circ} \mathrm{C}$ & $2 \mathrm{~min}$ \\
2) Denaturation & $30-40$ & $94^{\circ} \mathrm{C}$ & $45 \mathrm{sec}$ \\
3) Annealing & & $55-65^{\circ} \mathrm{C}$ & $45 \mathrm{sec}$ \\
4) Elongation & & $72^{\circ} \mathrm{C}$ & $1 \mathrm{~min}$ per $1 \mathrm{~kb}$ \\
5) Final elongation & 1 & $72^{\circ} \mathrm{C}$ & $19 \mathrm{~min}$ \\
\hline
\end{tabular}

\subsection{Reverse transcriptase - polymerase chain reaction (RT-PCR)}

The QIAGEN ${ }^{\circledR}$ Omniscript kit (QIAGEN-205110) was used to make complementary DNA from RNA templates. The enzyme mix contains the Ominscript, 10X RT buffer, dNTP mix, Oligo-dT primer, RNase inhibitor (Promega-N2511), and RTenzyme (Table 3). One $\mu \mathrm{g}$ isolated RNA was used for each reaction. Master Mix and 
templates were incubated in for $30 \mathrm{~min}$ at $37^{\circ} \mathrm{C}$ by the Mastercycler ${ }^{\circledR}$ Gradient (Eppendorf).

Table 3. List of materials and final concentration for RT-PCR

\begin{tabular}{lll}
\hline Component & Volume & Final Concentration \\
\hline 10x Buffer RT & $2 \mu \mathrm{l}$ & $1 \mathrm{x}$ \\
dNTP Mix & $2 \mu \mathrm{l}$ & $0.5 \mathrm{mM}$ each dNTP \\
Oligo-dT primer & $2 \mu \mathrm{l}$ & $1 \mu \mathrm{M}$ \\
RNase inhibitor & $1 \mu \mathrm{l}$ & 10 units (per $20 \mu$ l reaction) \\
Omniscript & $1 \mu \mathrm{l}$ & 4 units (per $20 \mu \mathrm{l}$ reaction) \\
\hline
\end{tabular}

\subsection{Quantitative PCR (qPCR)}

Total RNA was extracted from LIF/2i expanded ESCs by RNeasy kit (Qiagen) according to manufacturer standard protocol. cDNA was synthesized as described earlier (2.2). For each reaction $25 \mathrm{ng} c D N A, 10 \mathrm{mM}$ primers, and $10 \mu \mathrm{l}$ from KAPA SYBR $^{\circledR}$ FAST qPCR Master Mix (KAPA biosystems-KK4600) were mixed. The amplification program (Table 4) was executed using the Biosystems 7300 Sequence Detection system. The expression levels based on Ct values after normalization with GAPDH.

Table 4. Standard amplification program for qPCR

\begin{tabular}{llll}
\hline Step & Number of cycles & Temperature & Time \\
\hline 1) Initial denaturation & 1 & $95^{\circ} \mathrm{C}$ & $3 \mathrm{~min}$ \\
2) Denaturation & $30-40$ & $95^{\circ} \mathrm{C}$ & $1-3 \mathrm{sec}$ \\
3) Annealing & & $55-65^{\circ} \mathrm{C}$ & $20 \mathrm{sec}$ \\
4) Elongation & & $72^{\circ} \mathrm{C}$ & $20 \mathrm{sec}$ \\
5) Data acquisition & 1 & $72^{\circ} \mathrm{C}$ & $30 \mathrm{~min}$ \\
\hline
\end{tabular}

Primers were designed by primer-blast tools from NCBI and amplification size was restricted to 100-200 bp (http://www.ncbi.nlm.nih.gov/tools/primer-blast/) (Table 5). 
Table 5. List of RT-qPCR primers

\begin{tabular}{|c|c|c|}
\hline Name & Sequence & $\mathrm{Tm}$ \\
\hline Dnm3b-F & GCCAGACCTTGGAAACCTCA & $59.89^{\circ} \mathrm{C}$ \\
\hline Dnm3b-R & GCTGGCACCCTCTTCTTCAT & $60.03^{\circ} \mathrm{C}$ \\
\hline Wnt3-F & GCGTGGCCAACCTAACTCTT & $60.61^{\circ} \mathrm{C}$ \\
\hline Wnt3-R & ATTCACGGGTGGCAGTCATT & $59.96^{\circ} \mathrm{C}$ \\
\hline Sox17-F & CAGGGTCTGGCCTGAATGTT & $59.96^{\circ} \mathrm{C}$ \\
\hline Sox17-R & GCTCTTTCCAGTCCCTGGTC & $60.04^{\circ} \mathrm{C}$ \\
\hline Hoxb1-F & TCAGCCTACGACCTCCTCTC & $60.11^{\circ} \mathrm{C}$ \\
\hline Hoxb1-R & CGGACACCTTCGCTGTCTTA & $59.76^{\circ} \mathrm{C}$ \\
\hline Klf4-F & TACCCCTACACTGAGTCCCG & $60.03^{\circ} \mathrm{C}$ \\
\hline Klf4-R & GGAAAGGAGGGTAGTTGGGC & $60.03^{\circ} \mathrm{C}$ \\
\hline FGF5-F & CGGCTCGGAACATAGCAGTT & $60.46^{\circ} \mathrm{C}$ \\
\hline FGF5-R & AATTTGGCTTAACACACTGGC & $57.61^{\circ} \mathrm{C}$ \\
\hline Nanog-F & CACCCACCCATGCTAGTCTT & $59.38^{\circ} \mathrm{C}$ \\
\hline Nanog-R & АСССТCAAACTCCTGGTCCT & $60.10^{\circ} \mathrm{C}$ \\
\hline Oct4-F & CTGAGGGCCAGGCAGGAGCACGAG & $60.83^{\circ} \mathrm{C}$ \\
\hline Oct4-R & CTGTAGGGAGGGCTTCGGGACTT & $60.87^{\circ} \mathrm{C}$ \\
\hline Sox2-F & TAGAGCTAGACTCCGGGCGATGA & $64.27^{\circ} \mathrm{C}$ \\
\hline Sox2-R & TTGCCTTAAACAAGACCACGAAA & $59.30^{\circ} \mathrm{C}$ \\
\hline Prdm14-F & CGGCTTCAACTTCACAGAGG & $58.85^{\circ} \mathrm{C}$ \\
\hline Prdm14-R & AAGATGATTAGACCCAGAACTCTC & $57.52^{\circ} \mathrm{C}$ \\
\hline Zfp42-F & TCCATGGCATAGTTCCAACAG & $58.00^{\circ} \mathrm{C}$ \\
\hline Zfp42-R & TAACTGATTTTCTGCCGTATGC & $57.12^{\circ} \mathrm{C}$ \\
\hline Gata6-F & GTCTCTACAGCAAGATGAATGG & $56.60^{\circ} \mathrm{C}$ \\
\hline Gata6-R & CATAAGGTAGTGGTTGTGGTG & $56.25^{\circ} \mathrm{C}$ \\
\hline Gata4-F & CCATCCAGTGCTGTCTGCTCT & $61.12^{\circ} \mathrm{C}$ \\
\hline Gata4-R & ACTTTGCTGGCCCCCACGTC & $65.46^{\circ} \mathrm{C}$ \\
\hline Gapdh-F & GTCGTGGAGTCTACTGGTGTC & $59.80^{\circ} \mathrm{C}$ \\
\hline Gapdh-R & GAGCCCTTCCACAATGCCAAA & $61.44^{\circ} \mathrm{C}$ \\
\hline Blimp1_Venus_F & ACTCATCTCAGAAGAGGATCTG & $59.00^{\circ} \mathrm{C}$ \\
\hline Blimp1_Venus_R & CACAGTCGAGGCTGATCTCG & $66.30^{\circ} \mathrm{C}$ \\
\hline Dppa3_ECFP_F & CGACTCTAGATCATAATCAGCC & $59.40^{\circ} \mathrm{C}$ \\
\hline Dppa3_ECFP_R & TAAGATACATTGATGAGTTTGGAC & $58.60^{\circ} \mathrm{C}$ \\
\hline Dppa3-F & CGTCCTACAACCAGAAACAC & $59.70^{\circ} \mathrm{C}$ \\
\hline Dppa3-R & CTGCTCAATCCGAACAAGTC & $62.40^{\circ} \mathrm{C}$ \\
\hline Mad2I2-F & GTTGCCTTGAGTCCCTACAG & $61.30^{\circ} \mathrm{C}$ \\
\hline Mad212-R & TCCACATCGTTCTTCTCCAG & $62.90^{\circ} \mathrm{C}$ \\
\hline Tet1-F & CAGACCCAGCATCAATCCTC & $64.70^{\circ} \mathrm{C}$ \\
\hline Tet1-R & TACCTCCATCACAGTCACAG & $58.70^{\circ} \mathrm{C}$ \\
\hline Tet2-F & CGATGTTTCAGAATCAGATACTCC & $62.60^{\circ} \mathrm{C}$ \\
\hline Tet2-R & TCTCCGATATACCCATTTAGCA & $62.10^{\circ} \mathrm{C}$ \\
\hline Tet3-F & GACTGTGCTCTCAACTACCT & $56.00^{\circ} \mathrm{C}$ \\
\hline Tet3-R & TTCTCCATACCGATCCTCCA & $64.40^{\circ} \mathrm{C}$ \\
\hline Mad2I2_Genotyping P1 & GCTCTTATTGCCTTGACATGTGGCTGC & $65.00^{\circ} \mathrm{C}$ \\
\hline Mad2I2_Genotyping P2 & GGACACTCAGTTCTGGAAAGGCTGG & $65.00^{\circ} \mathrm{C}$ \\
\hline Mad2|2_Genotyping P3 & CTGCAGCCCAATTCCGATCATATTCAATAAC & $65.00^{\circ} \mathrm{C}$ \\
\hline
\end{tabular}




\subsection{Cell culture}

\subsection{1- MEF (isolation, expansion, freezing, thawing)}

Mating was arranged between two $\mathrm{Mad}_{2} 12^{+/-}$male and $\mathrm{Mad} 212^{+/-}$female animals and pregnancy time was identified by the formation of vaginal plaque (Pirouz et al., 2015). Pregnant females on E13.5 were sacrificed by exposing to carbon dioxide. Uterine horns were removed from body and placed into a $50 \mathrm{ml}$ falcon tube containing PBS. Each embryo was separated from placenta and transferred to distinct wells. Brain and dark red organs were removed and remains transferred in to fresh PBS filled plates. Tissue was suspended with $2 \mathrm{ml}$ of trypsinEDTA (Gibco $25300-096$ ) and incubated with gentle shaking at $37^{\circ} \mathrm{C}$ for $15 \mathrm{~min}$. For further dissociation, cell suspension was transfered from a syringe with gage 18 needle. Trypsin was neutralized with DMED medium supplemented with $10 \%$ FBS (Table 6).

Table 6. List of materials for MEF culture

\begin{tabular}{lll}
\hline Name & Company & Catalog Number \\
\hline DMEM (High Glucose) & Gibco & $41966-052$ \\
FBS & Biochrom & S0115 \\
L-glutamine & Gibco, & $25030-024$ \\
Penicillin-streptomycin & Gibco, & $15140-122$ \\
DMSO & Sigma & D2650 \\
Knockout DMEM & Gibco & $10829-018$ \\
Knockout Serum Replacement & Gibco & $10828-028$ \\
Non-Essential Amino Acids & Gibco & $11140-035$ \\
beta-Mercapto-ethanol & Sigma & M7522 \\
DNase I & Sigma & D4527 \\
Mitomycin C & Roche & 10107409001 \\
Basic Fibroblast Growth Factor & PeproTech & $100-18 B$ \\
Gelatin & Sigma & G9391 \\
0.05\% Trypsin-EDTA & Gibco, & $25300-054$ \\
\hline
\end{tabular}

\subsubsection{Embryonic stem cells}

ESCs were cultured by a standard protocol in DMEM: $10 \%$ serum and LIF (1000 u/ml) on inactive MEFs (Ying et al., 2008). Wild-type and Mad2l2-deficient ESCs establishment and was previously established by Pirouz et al., 2015 (Pirouz et 
al., 2015). ESCs were cultured by a standard procedure in N2B27 medium with $2 \mathrm{i}$ (PD0325901, 0.4 M: Stemgent, San Diego, CA; CHIR99021, $3 \mu \mathrm{M}$ : Stemgent) and LIF (1000 u/ml) on gelatin-coated plate (Pirouz et al., 2015; Ying et al., 2008). BVSC ESCS were donated by Mitinori Saitou (Ohinata et al., 2008). These ESCs have eCFP and mVenus reporter between Dppa3 promoter and transcription starting site and between Prdm1 (formerly Blimp1) and transcription starting site, respectively. $\mathrm{H} 2 \mathrm{AX}$, DNA-PK and ATM deficient ESCs were donated by Frederick W. Alt (Bassing et al., 2003; Gao et al., 1998; Zha et al., 2008). Growth condition for these cells was equal with wild-type ESCs.

\subsection{Differentiation of ESCs}

\subsubsection{EpiLCs}

This protocol was previously described by Hayashi et al., (Hayashi et al., 2011) 6-well pates were coated with human plasma fibronectin $(16.7 \mu \mathrm{g} / \mathrm{ml})$ and incubated overnight at $37 \mathrm{C}$. ESCs $\left(2.0 \times 10^{5}\right)$ were seeded on the coated palates in N2B27 medium containing activin $\mathrm{A}(20 \mathrm{ng} / \mathrm{ml}), \operatorname{bFGF}(12 \mathrm{ng} / \mathrm{ml})$, and $\mathrm{KSR}(1 \%)$ and the medium was changed every day.

\subsubsection{PGCLCs}

This protocol is a modified version of Hayashi et al (Hayashi et al., 2011). EpiLCs were trypsinized and $2.0 \times 10^{3}$ were counted and plated on a low-cell-binding U-bottom 96-well plate in a serum-free medium (GK15; GMEM [Invitrogen] with 15\% KSR, $0.1 \mathrm{mM}$ NEAA, $1 \mathrm{mM}$ sodium pyruvate, $0.1 \mathrm{mM}$ 2-mercaptoethanol, $100 \mathrm{U} / \mathrm{ml}$ penicillin, $0.1 \mathrm{mg} / \mathrm{ml}$ streptomycin, and $2 \mathrm{mM}$ L-glutamine) in the presence of the cytokines BMP4 (500 ng/ml; Peprotech), LIF (1000 u/ml; Invitrogen), SCF (100 ng/ml; Peprotech), and EGF (50 ng/ml; R\&D Systems). After 24 h, aggregates were shacken gently for elimination of death cells. Two days after PGCLC induction cells were transferred to a five-centimeter plate in the old medium. Aggregates were cultured in five-centimeter plates for four more days. 


\subsection{Cell manipulation}

\subsubsection{Inhibitor and cisplatin experiments}

ESCs cells were grown in LIF/2i medium to $40 \%$ confluency in 6 -well plates. Inhibitors were mixed with fresh LIF/2i medium (Table 6). ESCs were culture for defined times (Table 7) under standard growing conditions, and ESCs were harvested after washing with PBS.

Table 7. List of used inhibitors

\begin{tabular}{llll}
\hline Name & Cat.Num & Final concentration & Treatment time \\
\hline Trichostatin A & T8552 SIGMA & $250 \mathrm{nM}, 4000 \mathrm{x}$ & $8 \mathrm{~h}$ \\
SAHA & SML0061 SIGMA & $10 \mathrm{um}, 1000 \mathrm{x}$ & $8 \mathrm{~h}$ \\
5-Azacytidine & A2385 SIGMA & $70 \mathrm{uM}, 1000 \mathrm{x}$ & $48 \mathrm{~h}$ \\
GSK126 & 500580 Millipore & $10 \mathrm{mM}, 5000 \mathrm{x}$ & $24 \mathrm{~h}$ \\
BIX 01294 & B9311 SIGMA & $4.1 \mathrm{mM} 4000 \mathrm{x}$ & $24 \mathrm{~h}$ \\
KU-55933 & SML1109 SIGMA & $10 \mathrm{uM}, 1000 \mathrm{x}$ & $24 \mathrm{~h}$ \\
VE-821 & SML1415 SIGMA & $5 \mathrm{uM}, 1000 \mathrm{x}$ & $24 \mathrm{~h}$ \\
NU-7441 & CAS 503468-95-9 & $5 \mathrm{uM}, 1000 \mathrm{x}$ & $24 \mathrm{~h}$ \\
\hline
\end{tabular}

\subsubsection{Cell transfection}

Cells were transfected with Lipofectamine 2000 (cat. 11668500) based on theprotocol recommended by the manufacturer. CMV-GFP-Md2I2 plasmid was purified by phenol extraction and ethanol precipitation. Details about plasmid werepublished previously (Pirouz et al., 2013).

\subsection{ABC staining}

Cryo-section slides were prepared according to 2.12. Slides were washed 3 times for 5 minutes with PBS. Samples were encircled with fat pen and covered with block solution for 30 minutes at RT. Dppa3 antibody was applied and incubated overnight at $4{ }^{\circ} \mathrm{C}$.

Table 8. Solutions and components for ABC staining

\begin{tabular}{ll}
\hline Name & Components \\
\hline $\begin{array}{l}\text { Phosphate-buffered } \\
\text { Saline (PBS) } \\
\text { Blocking Buffer }\end{array}$ & $0.1 \mathrm{M}$ phosphate, 0.15M NaCl, pH 7.5 \\
& $\begin{array}{l}\text { Add 3 drops of normal serum from the ABC Staining Kit to } 10 \mathrm{~mL} \text { of PBS. } \\
\text { Alternatively, 1\% BSA in PBS may be used }\end{array}$ \\
\hline
\end{tabular}




\begin{tabular}{|c|c|}
\hline Primary Antibody & Dppa3 (Santa Cruz, cat no. sc-19878) \\
\hline Biotinylated Secondary & Add 3 drops $(135 \mu \mathrm{L})$ of normal serum and 1 drop $(45 \mu \mathrm{L})$ of the \\
\hline Antibody & $\begin{array}{l}\text { Biotinylated Secondary Antibody from the ABC Staining Kit to } 10 \mathrm{~mL} \text { of } \\
\text { PBS. }\end{array}$ \\
\hline ABC Reagent & $\begin{array}{l}\text { Prepare reagent } 30 \text { minutes before use (see Step } 5) \text {. Add } 2 \text { drops }(90 \mu \mathrm{L}) \\
\text { of Reagent } A \text { to } 10 \mathrm{~mL} \text { of PBS followed by } 2 \text { drops }(90 \mu \mathrm{L}) \text { of Reagent } \mathrm{B} \text {. } \\
\text { Immediately mix the solution and allow } 30 \text { minutes for the complex to } \\
\text { form. }\end{array}$ \\
\hline Detection Substrate & $\begin{array}{l}\text { Thermo Scientific Metal Enhanced DAB Substrate Kit (Product No. } \\
\text { 34065) }\end{array}$ \\
\hline
\end{tabular}

Slides were washed 3 times for 10 minutes with PBS. The biotinylated secondary antibodies were applied and incubated for 30 minutes at RT. Slides were washed 3 times for 10 minutes with PBS. The tissue sections were incubated with the $A B C$ Reagent for 30 minutes. Slides were washed 3 times for 10 minutes with PBS (Table 7).

\subsection{Immunofluorescence staining}

ESCs were cultured on chamber slides (Nuc Lab-Tek) to reach the desire dconfluency. Cells were washed 3 times for 5 minutes with PBS, and rinsed with NP400.1 to $0.2 \%$ in PBS for 10 min for permeabilization. Washing steps were repeated by PBT (1x PBS $0.1 \%$ Tween 20). Chamber slide walls were removed and samples were surrounded by fat pen. Cells were covered with block solution for 60 minutes at RT (1\% BSA, $22.52 \mathrm{mg} / \mathrm{ml}$ glycine in PBT). First antibody was applied and incubated overnight at $4{ }^{\circ} \mathrm{C}$ (Table 9). Slides were washed 3 times for 10 minutes with PBT. Secondary antibody was applied and incubated for 60 minutes at RT. Slides were washed 3 times for 10 minutes with PBS. Samples were mounted with VECTASHIELD ${ }^{\circledR}$ Mounting Medium with DAPI (Vector Laboratories). The coverslips were sealed using nail polish. The sample was documented by confocal microscopy (Leica SP3).

To find the best antibody against Mad212 different antibodies were tested.(Table 10) Test procedure had two steps. First recognition of antigen in a native form and wild-type and knockout cells were subjected to immunofluorescence staining. Secondly, antibody capability in recognition of denatured protein was checked by western blot. Just one antibody* passed both 
tests. Results from this antibody were in contradiction with some previously published reports (Medendorp et al., 2009; Weterman et al., 2001).

Table 9. List of antibodies

\begin{tabular}{|c|c|c|c|}
\hline Name & Company & Catalog number & Concentration \\
\hline Anti pH3 & Cell Signaling & 9706 & $1: 200$ \\
\hline Anti Cyclin B1 & Santa Cruz & sc-245 & 1: 100 \\
\hline Anti Sox2 & Millipore & AB5603 & 1: 200 \\
\hline Anti Oct4 & Abcam & ab18976 & 1: 200 \\
\hline Anti Nanog & Abgent & AM1486b & 1: 200 \\
\hline Anti Erk & Cell Signaling & 9102 & 1: 100 \\
\hline Anti pERK & Cell Signaling & 9101 & 1: 100 \\
\hline Anti $Y H 2 A X$ & Millipore & $05-636$ & 1: 100 \\
\hline Anti TFAP2C & Santa Cruz & sc-53162 & 1: 100 \\
\hline Anti Dppa3 & Santa Cruz & sc-19878 & 1: 100 \\
\hline Anti pChk2 & Cell Signaling & $2661 S$ & 1: 100 \\
\hline Anti Ki67 & Abcam & ab15580 & 1: 200 \\
\hline Anti H3K9me2 & Abcam & $a b 6002$ & 1: 200 WB 1: 2000 \\
\hline Anti H3K27me3 & Abcam & ab8580 & 1: 200 WB 1: 2000 \\
\hline Anti-Rabbit (HRP) & Abcam & ab6721 & WB 1: 10000 \\
\hline Anti-mous (HRP) & Abcam & ab97046 & WB 1: 10000 \\
\hline Alexa Fluor $488 \alpha-m$ & Thermo Fisher & Z25002 & 1: 1000 \\
\hline Alexa Fluor 594 a-m & Thermo Fisher & Z25007 & 1: 1000 \\
\hline Alexa Fluor $647 \alpha-m$ & Thermo Fisher & Z25008 & 1: 1000 \\
\hline Alexa Fluor $488 \alpha-r$ & Thermo Fisher & Z25302 & 1: 1000 \\
\hline Alexa Fluor $594 \alpha-r$ & Thermo Fisher & Z25307 & 1: 1000 \\
\hline Alexa Fluor $647 \alpha-r$ & Thermo Fisher & Z25308 & 1: 1000 \\
\hline STAR $635 \alpha-r$ & Abberior & 2-0032-051-9* & 1: 100 \\
\hline STAR $580 \alpha-m$ & Abberior & 2-0032-051-9* & 1: 100 \\
\hline Protein A/G & Santa Cruz & sc-2003 & $50 \mathrm{ul}$ \\
\hline Anti AcH4 & Millipore & $06-946$ & WB 1: 10000 \\
\hline Anti RNF168 & Santa Cruz & sc-101125 & 1: 100 \\
\hline Anti 53BP1 & Santa Cruz & sc-22760 & 1: 100 \\
\hline Anti p53BP1 & Santa Cruz & sc-135748 & 1: 100 \\
\hline Anti SSEA1 & $R \& D$ & FAB2155P-025 & 1: 200 \\
\hline Anti integrin $\beta 3$ & $R \& D$ & FAB2266A & 1: 200 \\
\hline
\end{tabular}

* A STED microscopy dual secondary antibody kit

Table 10. List of Mad2/2 different antibodies

\begin{tabular}{llll}
\hline Name & Company & Catalog number & Concentration \\
\hline Anti Mad212* & Abcam & ab180579 & 1:200 WB 1: 1000 \\
Anti Mad212 & Abcam & ab3630 & WB 1: 1000 \\
Anti Sox2 & Abnova & H00010459-D01P & $1: 200$ \\
\hline
\end{tabular}




\subsection{TUNEL assay}

For the TUNEL assay, TdT in Situ Apoptosis Detection Kit - Fluorescein (R\&D system, ca.no:4812-30-K) was used. ESCs were cultured on chamber slides (Nuc LabTek) to reach the desire confluency. Samples were placed in 1X PBS for 10 minutes at RT. $100 \%$ ethanol was used for fixation after rinsing with PBS for rehydration. The slide wall was removed and the sample was surrounded by fat pen. Slide was covered with $50 \mu$ of Proteinase K Solution $30 \mathrm{~min}$ at RT. Slide was washed 2 times in deionized water 2 min and immersed in $1 X$ TdT Labeling Buffer 5 min. Samples were covered with $50 \mu \mathrm{l}$ of Labeling Reaction Mix and were incubated for $1 \mathrm{~h}$ at 37 ${ }^{\circ} \mathrm{C}$. Labeling was stopped by $1 \mathrm{X}$ TdT Stop Buffer 5 min at RT. Washing step was repeated 2 times by $1 \mathrm{X}$ PBS for 5 minutes each at room temperature. Slide was covered with $50 \mu \mathrm{l}$ of Strep-Fluor solution for $20 \mathrm{~min}$ at RT. After another washing step and documented by confocal microscopy (Leica SP3).

\subsection{Metaphase chromosome spreads}

Double thymidine Block: ESCs were culture in N2B27 medium supplemented with LIF/2i to approximately $40 \%$ confluency. $20 \mathrm{ul}$ of Thymidine $(1 \mathrm{mg}$ per $50 \mathrm{ml}$ medium) was added to each $1 \mathrm{ml}$ of culture media. Cells were incubated for exactly 19 hours at $37^{\circ} \mathrm{C}$. Medium was removed and cells were washed with 1X PBS 3 times. Fresh medium was used and cells were incubated for 9 hours. Again 20ul of Thymidine was added to each $1 \mathrm{ml}$ of culture media and cells were incubated for an additional 16 hours. Medium was removed and cells were washed with 1X PBS 3 times. Fresh medium was added and cells were cultured for 4-5 $h$, when most had entered metaphase.

Table 11. List of materials for chromosome spreads

\begin{tabular}{lll}
\hline Name & Company & Catalog Number \\
\hline Thymidine & Sigma & $15212-012$ \\
HBSS Buffer & Gibco & $24020-117$ \\
0.5\% Trypsin EDTA 10x & Gibco & $15400-054$ \\
Permount & Fisher Scientific & SP15-100 \\
Buffer Tablets "GURR" & Gibco & $10580-013$ \\
Methanol & Caledon Laboratory Chemicals & 6700130 \\
Glacial Acetic Acid & Krackeler Scientific Inc. & $11-9508-05$ \\
\hline
\end{tabular}


Preparation of slides: Cells gently were washed in $2 \mathrm{ml}$ of HBSS Buffer and dissociated by trypsin after 2 min incubation at $37{ }^{\circ} \mathrm{C}$. Cell suspension was transferred into $15 \mathrm{ml}$ conical tubes and trypsin was neutralized with MEF medium. Tubes were centrifuged at $200 \times \mathrm{g}$ for $10 \mathrm{~min}$ and supernatant was removed. Pellet was dissolved in $10 \mathrm{ml}$ of $0.075 \mathrm{M} \mathrm{KCl}$ which has been pre-warmed to $37{ }^{\circ} \mathrm{C}$ for 10 min. Tube was centrifuged at $200 \times \mathrm{g}$ for $5 \mathrm{~min}$ at $25^{\circ} \mathrm{C} .5 \mathrm{ml}$ of fresh Carnoy's Fixative (3:1 ratio of methanol:glacial acetic acid) was add to the cells while vortexing. Then $5 \mathrm{ml}$ of fixative was added for a total of $10 \mathrm{ml}$. Tube was centrifuged at $200 \times \mathrm{g}$ for $5 \mathrm{~min}$. Cells were resuspended in $5 \mathrm{ml}$ of fixative to each tube. Tube was centrifuged at $200 \times \mathrm{g}$ for $5 \mathrm{~min}$. Condensed cell suspension was dropped on slide and tilted at an angle of about $45^{\circ}$. A large drop of fresh Carnoy's Fixative was added to the slide. Slide was dried with a paper from one direction, and was covered with VECTASHIELD ${ }^{\circledR}$ Mounting Medium with DAPI (Vector Laboratories). The coverslips were sealed using nail polish. The samples were monitored and documented with the BX-60 fluorescence microscope (Olympus).

\subsection{Dot blot}

DNA was isolated by standard protocol (Sambrook and Russell, 2006) and was precipitated by $70 \%$ ethanol. Precipitated DNA was dissolved in deionized water and denatured at $99{ }^{\circ} \mathrm{C}$. Samples were cooled on ice, spinned down, and neutralized with 0.1 vol of $6.6 \mathrm{M}$ ammonium acetate. $50 \mathrm{ng}$ DNA was dropped on the membrane and air-dried, while the membrane was placed on a filter. DNA was cross-linked to the membrane by UV. The membrane was blocked by blocking solution $10 \%$ milk, $1 \%$ BSA, PBT (1xBPS + 0.1\% Tween-20), then washed by PBT 3 times at RT, and incubated with primary antibody against $5 \mathrm{mC}(1: 1000)$ overnight at $4{ }^{\circ} \mathrm{C}$. The membrane was washed by PBT 3 times at RT and incubated with HRP secondary antibody (1:10000 in blocking solution) for $60 \mathrm{~min}$ at RT. Washing step was repeated for one more time, and the membrane was developed by Pico chemiluminescent substrate (Thermo Scientific). 


\subsection{Western blotting}

Western blot procedure is described in details in Bio-rad website (www.biorad.com). Cells at the desired confluency were washed with PBS three times and harvested by RIPA (radio immune precipitation assay) buffer supplemented with protease inhibitor. Protein concentrations were measured by Bradford analysis. Samples were mixed with $4 \mathrm{X}$ protein loading buffer, and were incubated for $5 \mathrm{~min}$ at $99^{\circ} \mathrm{C}$. Equal amounts of proteins were loaded on a precast $12 \%$ SDS-Gel (bio-rad). Electrophoresis was started for $5 \mathrm{~min}$ at $50 \mathrm{v}$ and voltage was increased to $150 \mathrm{~V}$ for 1h. After this step, the gel was blotted to on the nitrocellulose membrane. The membrane was blocked by blocking solution 10\% milk, 1\% BSA, PBT (1xBPS $+0.1 \%$ Tween-20). PBT was used for washing step, 3 times at RT. Consequently, the membrane was incubated by primary antibody over night at $4{ }^{\circ} \mathrm{C}$. The washing step was repeated, and the membrane was incubated with HRP secondary antibody (1:10000 in blocking solution) for $60 \mathrm{~min}$ at RT. This procedure was followed by a final washing step (PBT, 3 times at RT). The membrane was developed by Pico chemiluminescent substrate (Thermo Scientific).

\subsection{Cryosectioning}

Aggregates were harvested after PGCLCs induction and they were washed three times with PBS at room temperature for $5 \mathrm{~min}$. Samples were fixed in $4 \%$ paraformaldehyde (PFA; $7.4 \mathrm{pH}$ ) for 2 hours at RT. PFA solution was removed and samples were rinsed with PBS. To prevent freezing damages, cells were dehydrated by sucrose solutions steps. First $10 \%$ sucrose solution was used, and the sample was floated in the solution for $15 \mathrm{~min}$. The same procedure was repeated for $20 \%$ and $30 \%$ Sucrose solutions, respectively. Finally, 30\% the solution was removed three times and replaced with fresh $30 \%$ sucrose. Samples were removed from sucrose solution and placed on the bottom of the bottom of the chamber. Remainins solution was removed by Whatman paper as much as possible. The Chamber was filled with tissue-tek, and the block was frozen down on dry ice. Blocks were sectioned by a cryo-microtome and sections were stored frozen in $-80^{\circ} \mathrm{C}$. 


\subsection{STED microscopy}

This procedure is a modified version of the previously published protocol (Revelo et al., 2014). p-toluenesulfonic acid monohydrate (Sigma-Aldrich) and 2,4,6Tris[bis(methoxymethyl)amino]-1,3,5-triazine (melamine) was solved in water, and shaken for $2 \mathrm{~h}$ at $\mathrm{RT}$. Immunostained cells were mixed with resin and a BEEM capsule (BEEM, Inc.). The mounted sample was put in a jar containing silica overnight at RT to allow penetration of melamine into the cells. The box was then heated to $40^{\circ} \mathrm{C}$ for $24 \mathrm{~h}$. The BEEM capsule was re-filled to the top by Epon resin (EpoFix kit; Struers). The samples was heated to $60^{\circ} \mathrm{C}$ for $48 \mathrm{~h}$. Melamine blocks were cut into thin sections with an ultramicrotome (EM UC6; Leica). Sections were documented by STED microscope (TCS SP5; Leica). STED microscopy was performed in collaboration with Dr. Dirk Kamin, Department of Nano Biophotonics, Max Planck Institute for Biophysical Chemistry, Goettingen. STED microscopy increases the resolution by minimizing the area of illumination at the focal point. Therefore by this technique close points can be distinct from each other beyond the confocal microscope ability.

\subsection{Immune precipitation}

The protocol is described in abcam company website in details (www.abcam.com). Cells were cultured to the desired confluency in appropriate medium. $100 \mu \mathrm{l}$ denaturing lysis buffer was used for 0.5 to $2 \times 10^{7}$ cells and was mixed by vortexing briskly for 2 to $3 \mathrm{sec}$ at maximum speed. For further homogenization, samples were sonicated by Diagenode sonicator for 20 cycle 30s pulse and 30 rests in high power. $50 \mu \mathrm{l}$ of normal serum was added to $1 \mathrm{ml}$ of lysated, and Incubated for $1 \mathrm{hr}$ on ice. $100 \mu \mathrm{l}$ of protein A/G bead was added to the lysate. This suspension was incubated for $30 \mathrm{~min}$ at $4^{\circ} \mathrm{C}$ with gentle agitation. Beads were collected by centrifugation at $14,000 \times \mathrm{g}$ at $4^{\circ} \mathrm{C} .10 \mu \mathrm{l}$ of primary antibody was added to lysis buffer and sample were incubated over night at $4^{\circ} \mathrm{C}$. Pre-cleaned protein $A / G$ beads were added to sample and were incubated for $1 \mathrm{~h}$ at $4^{\circ} \mathrm{C}$. Beads were collected by centrifuge at $1,000 \mathrm{~g}$ for $2 \mathrm{~min}$ at $4^{\circ} \mathrm{C}$ and supernatant was discarded. Beads washed by PBS or lysis buffer 3 times 5 min at $4^{\circ} \mathrm{C}$. 
Table 12. RIPA buffer

\begin{tabular}{ll}
\hline Name & Final concentration \\
\hline Tris $\mathrm{HCl} \mathrm{pH} 8$ & $50 \mathrm{mM}$ \\
$\mathrm{NaCl}$ & $150 \mathrm{mM}$ \\
$\mathrm{NP}-40$ & $1 \%$ \\
Sodium deoxycholate & $0.5 \%$ \\
$\mathrm{SDS}$ & $0.1 \%$ \\
\hline
\end{tabular}

Table 13. Washing buffer

\begin{tabular}{ll}
\hline Name & Final concentration \\
\hline Tris $\mathrm{HCl} \mathrm{pH} \mathrm{7.4}$ & $10 \mathrm{mM}$ \\
EDTA & $1 \mathrm{mM}$ \\
EGTA pH 8.0 & $1 \mathrm{mM}$ \\
$\mathrm{NaCl}$ & $150 \mathrm{mM}$ \\
Triton X-100 & $0.2 \mathrm{mM}$ \\
\hline
\end{tabular}

Beads were collected by centrifuge at $1,000 \mathrm{~g}$ for 2 min at $4^{\circ} \mathrm{C}$ and supernatant was discarded. $50 \mu \mathrm{l}$ of beads were eluted in $50 \mu \mathrm{l}$ of 2 X SDS buffer without DTT for 10 min at $50^{\circ} \mathrm{C} .100 \mathrm{mM}$ DDT was added to sample. Sample boiled for $5 \mathrm{~min}$ at $99^{\circ} \mathrm{C}$.

\subsection{Cell fractionation}

This protocol is modified version of a previously published protocol (Carey and Smale, 2007). $10^{8}$ cells were pelleted at $300 \mathrm{~g}$ at $4{ }^{\circ} \mathrm{C}$ for $10 \mathrm{~min}$ in a centrifuge at $4^{\circ} \mathrm{C}$. Supernatant was discarded. Cell pellets were washed with $10 \mathrm{ml}$ of ice-cold $1 \mathrm{X}$ PBS, and cells pelleted at $300 \mathrm{~g}$ at $4{ }^{\circ} \mathrm{C}$ for $10 \mathrm{~min}$ in a centrifuge. Cell pellets were suspended in $5 \mathrm{ml}$ of ice-cold NP-40 lysis buffer for $5 \mathrm{~min}$. Nuclei were pelleted at $120 \mathrm{~g}$ at $4{ }^{\circ} \mathrm{C}$ for $10 \mathrm{~min}$. The supernatant was collected as the cytoplasmic fraction. Nuclei were washed with $2.5 \mathrm{ml}$ of MNase digestion buffer. Nuclei were pelleted at $120 \mathrm{~g}$ at $4{ }^{\circ} \mathrm{C}$ for $10 \mathrm{~min}$. Supernatant was collected as the nucleoplasmic fraction. Samples were sonicated by Diagenode sonicator for 20 cycle 30 s pulse/30s rest in high power.

Table 14. NP-40 lysis buffer:

\begin{tabular}{ll}
\hline Name & Final concentration \\
\hline Tris $\mathrm{HCl} \mathrm{pH} \mathrm{7.4}$ & $10 \mathrm{mM}$ \\
Nonidet P-40 & $0.5 \%$ \\
$\mathrm{MgCl}_{2}$ & $1 \mathrm{mM}$ \\
\hline
\end{tabular}




\begin{tabular}{ll}
\hline $\mathrm{NaCl}$ & $10 \mathrm{mM}$ \\
Spermine & $0.15 \mathrm{mM}$ \\
Spermidine & $0.5 \mathrm{mM}$ \\
\hline
\end{tabular}

Table 15. MNase digestion buffer:

\begin{tabular}{ll}
\hline Name & Final concentration \\
\hline Tris $\mathrm{HCl} \mathrm{pH} \mathrm{7.4}$ & $10 \mathrm{mM}$ \\
$\mathrm{NaCl}$ & $15 \mathrm{mM}$ \\
$\mathrm{KCl}$ & $60 \mathrm{mM}$ \\
Spermine & $0.15 \mathrm{mM}$ \\
Spermidine & $0.5 \mathrm{mM}$ \\
\hline
\end{tabular}

\subsection{Flow cytometry}

Cells were trypsinized and pellets were washed in ice cold PBS 3 times. Cells were fixated with using pre cooled methanol $\left(-20^{\circ} \mathrm{C}\right)$ and incubated for $5 \mathrm{~min}$ at -20 ${ }^{\circ} \mathrm{C}$. Cells were washed 3 times for 5 minutes with PBT (1x PBS 0.1\% Tween 20.). The cell pellet was resuspended in block solution for 60 minutes at RT (1\% BSA, 22.52 $\mathrm{mg} / \mathrm{ml}$ glycine in PBST). First, antibodies were applied and incubated overnight at 4 ${ }^{\circ} \mathrm{C}$. Slides were washed 3 times for 10 minutes with PBS. Secondary antibody was applied and incubated for 60 minutes at RT. Slides were washed 3 times for 10 minutes with PBS. Sample was read by accuri-6000 machine from BD.

\subsubsection{Chromatin immunoprecipitation}

Chromatin immunoprecipitation was performed base on two published protocols (Adli and Bernstein, 2011; Dahl and Collas, 2008).

\subsection{Bioinformatic analysis}

\subsubsection{For RNA-seq data reanalysis workflow}

Fastq files were analyzed for quality (fastx_toolkit) and trimming (fastx_toolkit). Alignment and removing duplications: bowtie for illumine was used for fastq file alignment based on mm10 genome reference. SAM file was converted to BAM file and duplicated sequences and enriched sequences from PCR were removed by RmDup version 2.0.0. Deeptools analyzed correlation between BAM files. Genes with different expression was measured via two independent methods 
(Cuffdiff and deseq2). Data were visualized by Visualization-Bioconductor package for R (version 3.2.2) Gene expression profile were visualized base on their position on genome by cuff-diff.

\subsubsection{ChIP-seq}

Fastq files were analyzed for quality (fastx_toolkit) and trimming (fastx_toolkit). Alignment and removing duplications: bowtie for illumina was used for fastq file alignment based on mm10 genome reference. SAM file was converted to BAM file and duplicated sequences and enriched sequences from PCR were removed by RmDup version 2.0.0. Deeptools analyzed correlation between BAM files. Reference genome was made by merging of Gff3 8 columns annotated files and BAM files (mm10). Merged file in combination with INPUT file was used for peak calling by MACS (ver 2.2.2). Significant peak were annotated and searched for motif enticement. MeDIP-seq data was analyzed by MEDIPS. Gene expression profile was visualized base on their position on genome by MEDIPS. 


\section{Results}

\subsection{The in vitro differentiation of ESCs towards germ cells}

To evaluate the potential of Mad2/2-deficient ESCs to differentiate into PGCLCs, a well-established and characterized protocol was applied (Hayashi et al., 2011). As an endogenous transgenic marker Oct4 expression was assessed by using the GFP reporter knock in ESC line "OG2" (Wu et al., 2013). This line expresses Oct4 under control of the distal enhancer, which is active in ESCs, but not after differentiation into EpiLCs, where it would normally be driven from the proximal enhancer. One day after the induction of differentiation in EpiLCs medium, the morphology of ESCs had changed significantly. Colonies now grew as monolayers, and no longer in the typical dome-shape of ESCs (Figure 5). The nuclear-cytoplasmic ratio was higher, and boundaries between the cells were clear. GFP expression was heterogeneous and low, but still clearly visible (Figure 5, D1). After 48 hours wildtype cells had become confluent, and GFP expression was not detectable (Figure 5, D2). All cells were again GFP positive on the first day after aggregate formation (3 days after induction of differentiation), but during the next two days GFP expression became limited to distinct areas of the aggregates (Figure 5, D3-5). These signals were brighter than the GFP noise levels on the first day. The morphology Mad212deficient cells differed significantly from control cells five days after aggregate formation (Figure 5, D7). In differentiating wild-type cells the small areas with GFP positive cells expanded dramatically under the influence of BMP4. In contrast, Mad2I2-deficient aggregates lost their GFP expression gradually, and just a few Oct4GFP spots were detectable on D8 (Figure 5). To study the morphology of GFPpositive cells, D6 aggregates were fixed and analyzed by confocal microscopy. Wildtype Oct4-positive cells grew in close contact, and formed coherent colonies close to the aggregate surface. In contrast, Mad2/2-deficient cells grew separately, and were located closer to the inside of the aggregates (Figure 6). Taken together, the development of Mad212-deficient ESCs into PGCLCs appeared strongly compromised as evident by inspection of GFP-positive cells. 


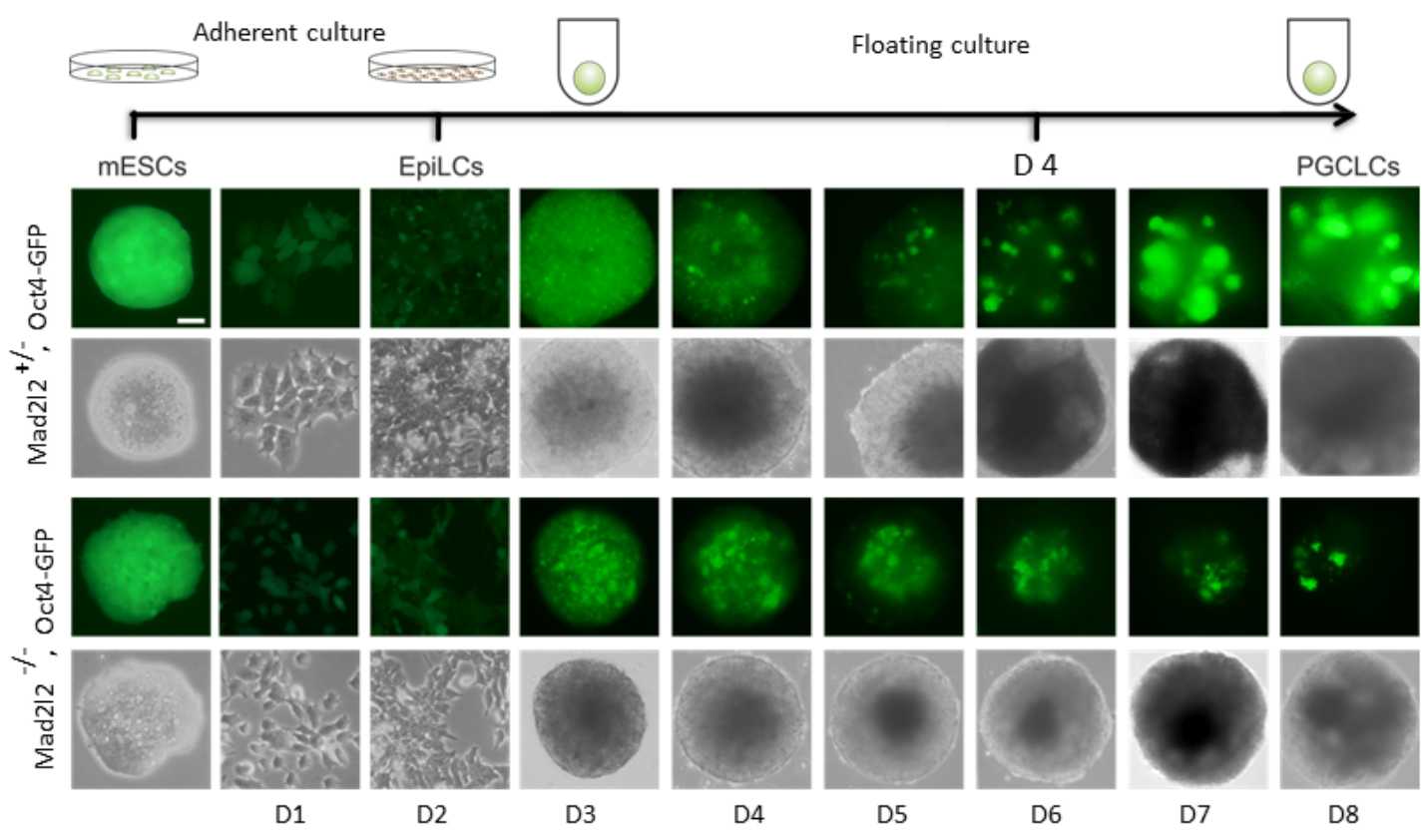

Figure 5: Differentiation of ESCs via EpiLCs into PGCLCs.

In D1 and D2 days, cells were cultured on a 2 dimensional surface, and from D3 to D8 cells were cultured in an aggregate form ( 3 dimensional cultures). Note that GFP is drastically downregulated in both wild-type and mutant EpiLCs (D2). It then returns in wild-type PGCLCs, while in mutant cells the reactivation is not as robust, and diminishes further.
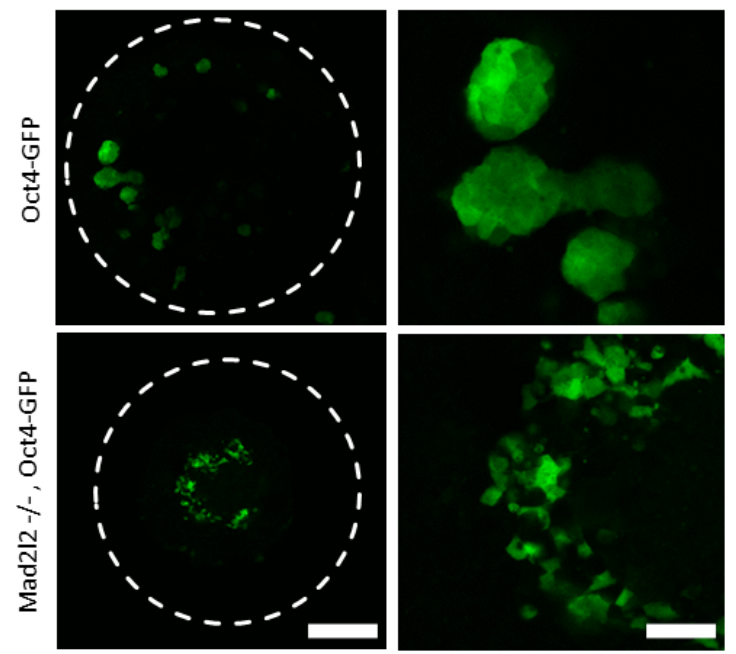

Figure 6: Colony morphology of differentiating cells growing in PGCLC inducing conditions. Localization of GFP-positive cells in wild type and Mad2/2-deficient cell aggregates. Dashed line indicates aggregate. Bar $=200 \mu \mathrm{m}$ (left) and $50 \mu \mathrm{m}$ (right). 


\subsubsection{Mad2/2-deficient EpiLCs resemble wild-type EpiLCs}

The doubling time and number of mitotic EpiLCs were measured in order to compare general growth parameters of wild-type and mutant cells. Equal number of ESCs ( $n=200.000$ ) were seeded onto tissue culture dishes in EpiLCs medium, and counted after $48 \mathrm{~h}$. In the control group, around $25.000 .000( \pm 200.000)$ cells were counted, indicating a doubling time of $13.76 \mathrm{~h}$. The number of Mad2/2-deficient cells was significantly lower (around 1.800.000), indicating a doubling time of around

\section{$15.14 \mathrm{~h}$ (Figure 7a).}

To confirm a lower proliferation rate of Mad2/2-deficient EpiLCs, they were stained with antibody against $\mathrm{pH} 3$, demarcating cells in mitosis, and samples were analyzed by flow cytometry. About 1.2 percent of wild-type cells were $\mathrm{pH} 3$ positive, as compared to 0.5 percent of mutant cells (Figure $7 \mathrm{~b}$ ). Altogether, these data show that Mad2/2 is important for cell cycle progression in EpiLCs.

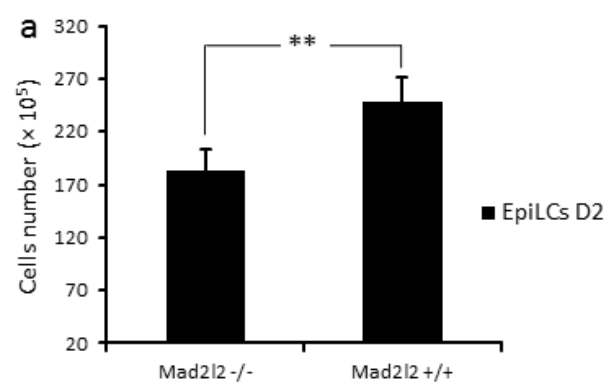

Cell Doubling time

\begin{tabular}{|l|l|}
\hline Mad2l2\%- & $13.76 \mathrm{~h}$ \\
\hline Mad2I2 ${ }^{+/+}$ & $15.14 \mathrm{~h}$ \\
\hline
\end{tabular}
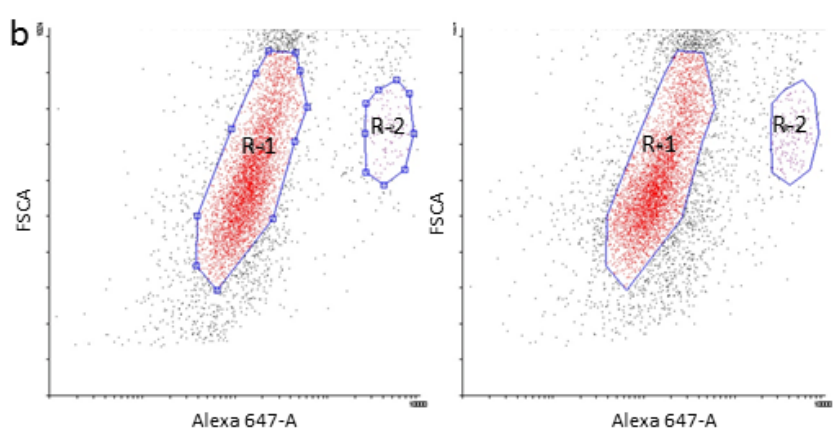

Percent of mitotic cells $(\mathrm{pH} 3)$

\begin{tabular}{|l|c|c|c|}
\hline Mad2I2\% & 0.5 & 0.4 & 0.6 \\
\hline Mad212+/+ & 1.1 & 1.2 & 1.2 \\
\hline
\end{tabular}

Figure 7: Proliferation of EpiLCs is decreased in the absence of Mad2/2

(a) Cell number determination indicates a slight decrease in the doubling time of Mad2/2 $2^{-1}$ cells. (b) Less mutant cells are in mitosis at a given time.

As a first indication for a successful transition from naive to primed pluripotency the downregulation of the OG2 construct was checked under the fluorescence microscope. Regardless of the genotype GFP expression vanished within 2 days of growth in EpiLC medium. EpiLCs normally do not express primitive endoderm (PE) markers, a prerequisite for induction of PCLCs. The expression of 
naive ESC markers (KIf4), EpiLCs markers (Dnmt3b, Wnt3) and PE markers (Gata4, Gata6 and Sox17) was evaluated by RT-PCR. The absence of KIf4 and the simultaneous increase of Dnm3b and Wnt3 RNA levels confirmed the transition from a naive to a primed state for both genotypes (Figure 8). In contrast, the PE markers were already considerably active in mutant ESCs before induction. This reflects the mutant cells (Pirouz et al., 2015), and may already indicate problems for the further differentiation towards PGCLCs.

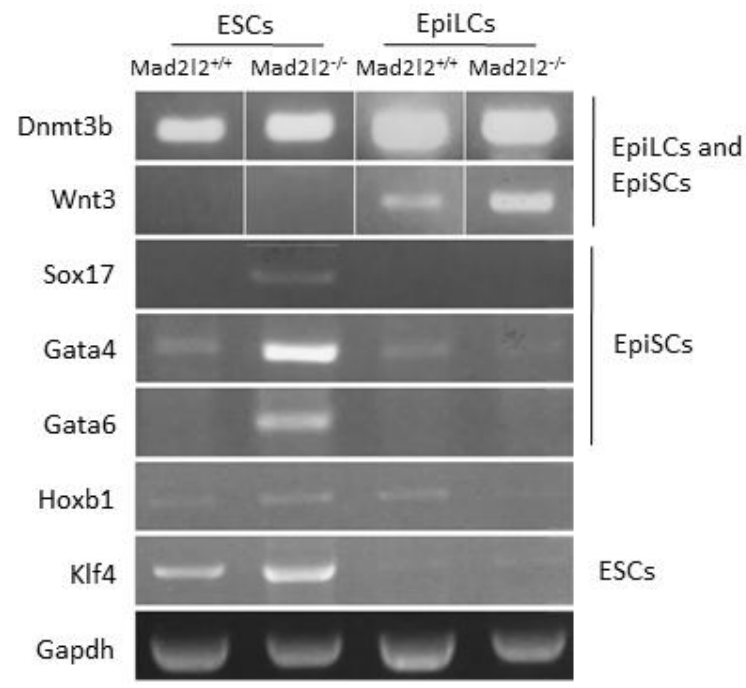

Figure 8: RNA expression analysis of ESCs and EpiLCs markers in both wild-type and Mad2/2-deficient groups.

Note the characteristic expression of KIf4 in ESCs, and Wnt3 in EpiLCs. The Gata4/6 RNAs in mutant ESCs indicate that differentiation into PE is not properly blocked predict problems for a later development into PGCLCs.

The expression of Sox2, Nanog, Oct4 (pluripotency related markers), FGF5, Dnmt3b, Wnt3 (EpiLCs markers), Gata4 and Gata6 (epiblast stem cell markers) was measured by quantitative RT-PCR before and after differentiation (D0-D2) (Figure 9). The linear expression of Oct4 mRNA and the simultaneous downregulation of Oct4GFP proved that the OG2 transgene was under control of the proximal Oct4 enhancer. The downregulation of Nanog and Sox 2 was in agreement with a previous report (Hayashi et al., 2011). Upregulation of EpiLC markers and downregulation of epiblast stem cell markers showed that Mad212 knockout ESCs differentiated into a primed state, which differed from epiblast stem cells by suppression of Gata4 and 
Gata6. Wnt3 expression was higher in knockout ESCs. However, the expected raise after differentiation to EpiLCs was not observed in both groups. In conclusion, Mad2I2-deficient EpiLCs resembled closely their wild-type counterparts, except for the slightly decreased proliferation rate.
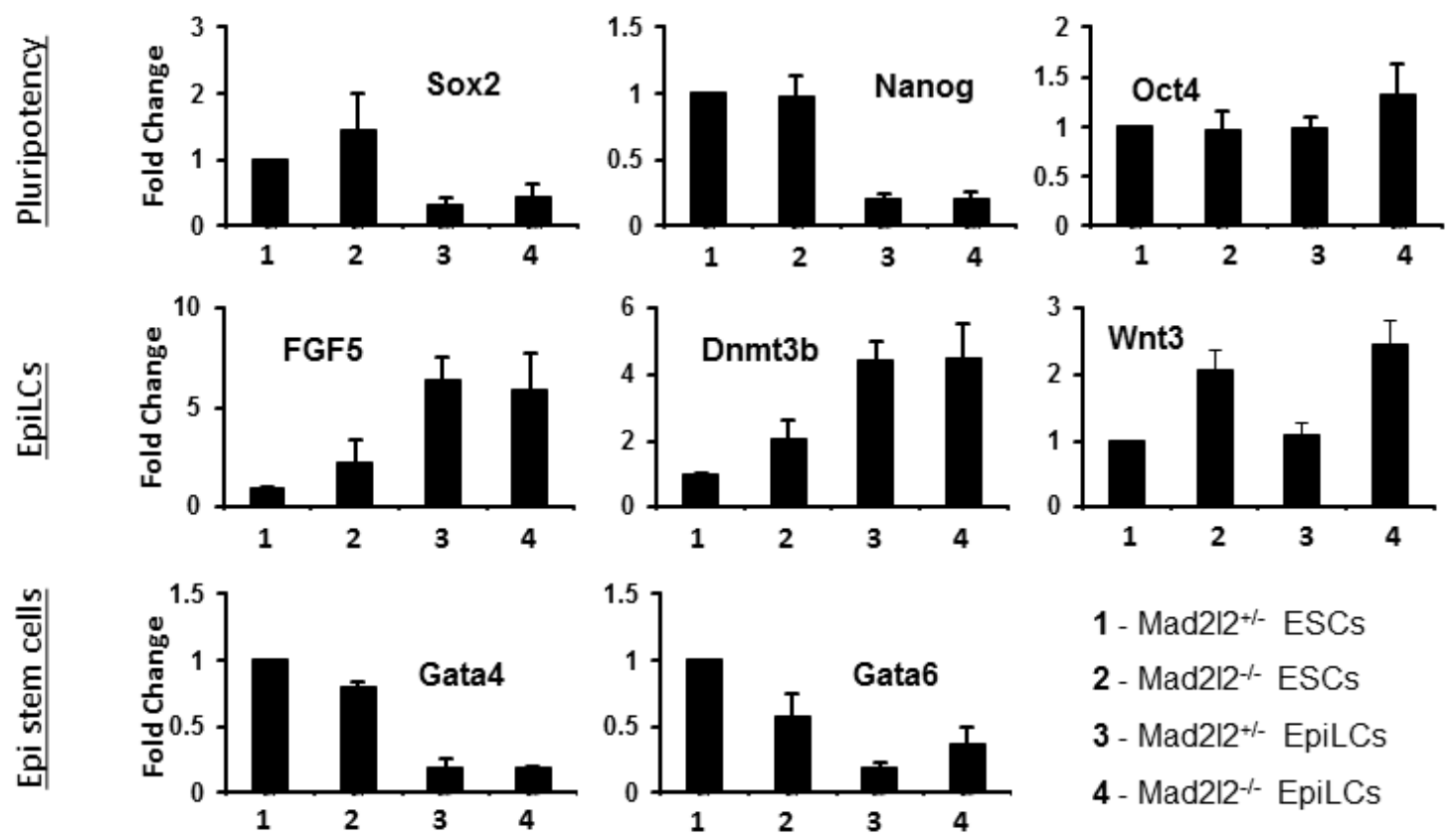

Figure 9: Expression of marker genes in wild-type and Mad212-deficient ESCs and EpiLCs. There was no significant difference between wild-type and knockout cells. Fold changes were calculated by the delta-delta Ct method (Schmittgen and Livak, 2008).

\subsubsection{The differentiation of ESCs under PGCLC-inducing conditions in the presence or absence of Mad212}

To quantify the differentiation Mad2/2-deficient ESCs into PGCLCs, Oct4-GFP positive cells were analyzed by flow cytometry. Three groups of cells with high, intermediate and low/absent levels of GFP were identified. After six days of differentiation approximately $70 \%$ cells expressed Oct4-GFP at the same level of ESCs, $10 \%$ had intermediate levels, and $15 \%$ cells were negative (Figure 10). In the Mad2/2-deficient group, the number of Oct4-GFP positive cells was lower (around $30 \%)$, and the number of intermediate cells significantly higher. These data indicated a lower efficiency of Mad2I2-deficient ESCs to differentiate into PGCLCs. 

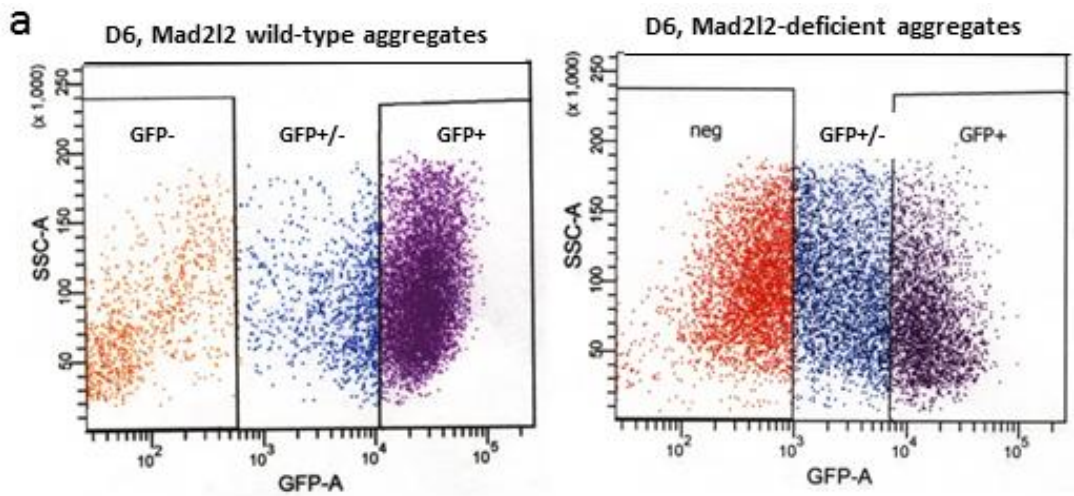

b

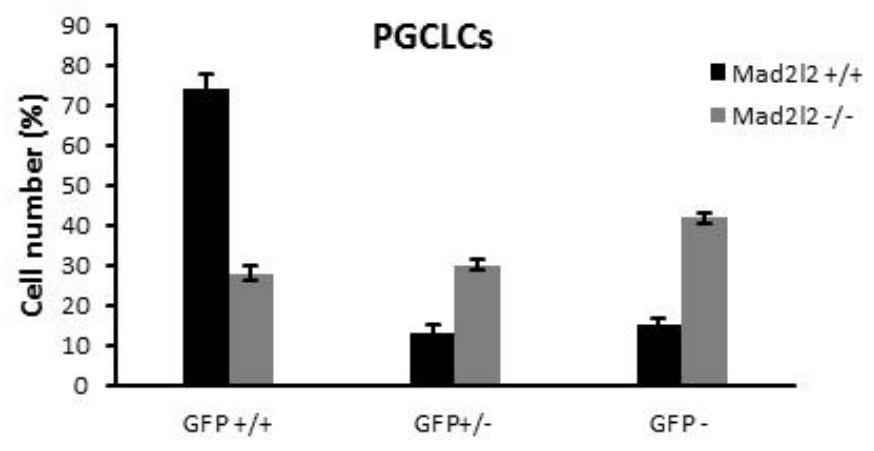

Figure 10: Flowcytometry analysis of differentiation into PGCLCs.

a) Orange: GFP negative cells, blue: cells with weak GFP expression, purple: GFP positive cells.

b) Bar diagram indicating the number (percent) of cells per gate.

In vivo developing PGCs arrest the cell cycle on E9 in the G2 phase, a pause apparently correlated or essential for their epigenetic reprogramming (Seki et al., 2007). It was previously shown that Mad2/2-deficient cells do not stop, and do not reprogram in the G2 phase of the cycle (Pirouz et al., 2013). In order to test the behavior of Mad2I2-deficient cells differentiating in vitro, they were analyzed by immunofluorescence for the subcellular localization of Cyclin B1, which is normally detected in the cytoplasm at the G2 phase, and moves into the nucleus upon the beginning of mitosis (Hochegger et al., 2008). On D8 around $58.5 \%$ of wild-type Oct4-GFP positive cells were in the G1 phase of the cell cycle, $4.5 \%$ in mitosis, and $37 \%$ in G2 (Figure 11). The percentages of both mitotic (0.9 \%) and G2 cells were decreased drastically in Mad2/2-deficient cells (Figure 11). This finding was in agreement with in vitro findings and shows that Mad212-deficient PGCLCs do not arrest in $\mathrm{G} 2$ phase of cell cycle. 


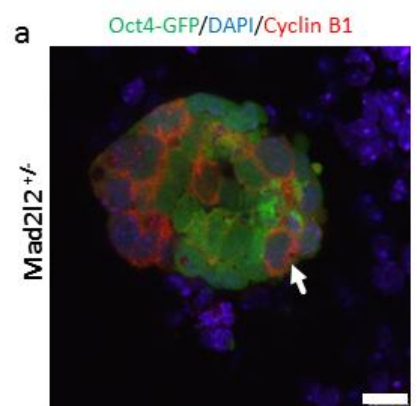

b
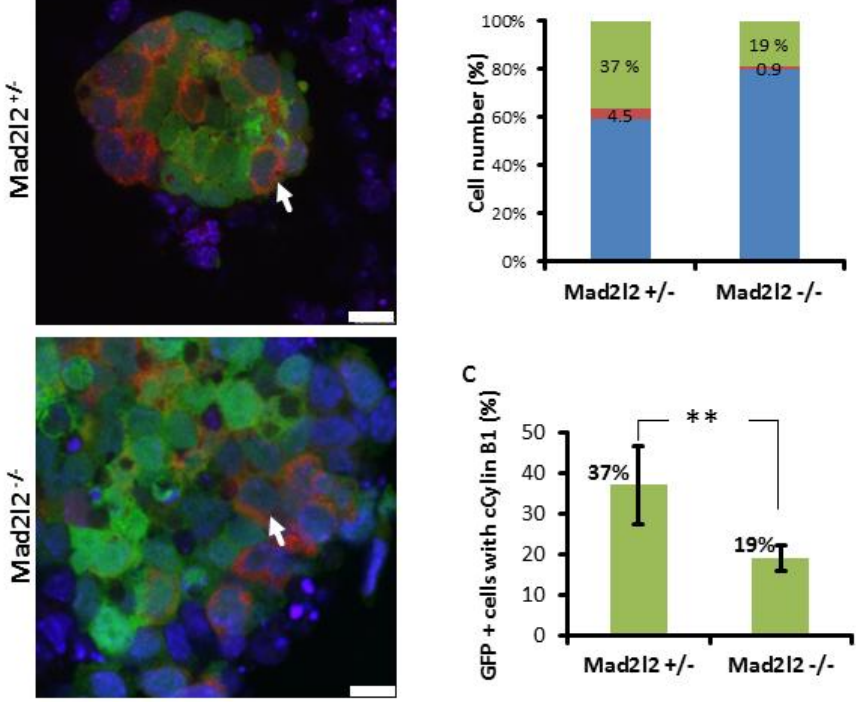

Figure 11: Mad2/2-deficient GFP positive cells do not arrest in the G2 phase.

a) Immunofluorescence staining with antibody against Cyclin B1 (red). Cells with cytoplasmic expression of cyclin B1 (arrow) are in G2, cells with nuclear expression in $M$, and negative cells are in other cell cycle phases. b) Quantification of immunofluorescence staining: Green, red and blue colors show number of cells in G2, M and other cell cycle phase, respectively. c) Significantly more wild-type cells are in the $\mathrm{G} 2$ phase. Bar $=10 \mu \mathrm{m}$.

The TUNEL assay was used to check for apoptosis in D8 aggregates. Apoptotic cells were limited to GFP negative cells in the wild-type cells aggregate. However, in differentiating mutant cells apoptosis was equally distributed between GFP-positive and -negative cells (Figure 12). This indicates an elimination of Mad2/2-deficient cells during their differentiation into PGCLCs. It confirms observations made on differentiating PGCs in vivo (Khalaj et al., 2014; Pirouz et al., 2013).

In vivo, PGCs reactivate many pluripotency related transcription factors, and at the same time suppress the Erk signaling pathway, which positively regulates somatic cell differentiation (Kimura et al., 2014). In principle reactivation of Oct4, Nanog and Sox2, and suppression of Erk occurred in the Oct4-GFP positive, even if the numbers of GFP-Oct4 positive cells are lower in Mad212-deficient aggregates (Figure 13). Immunofluorescence analysis revealed that the Erk protein was expressed equally, but that the phosphorylated Erk was considerably lower in the 
Oct4-GFP positive cells (Figure 13). Altogether, Mad2/2 protein appeared not to be essential for reactivation of core factors, and suppression of Erk.
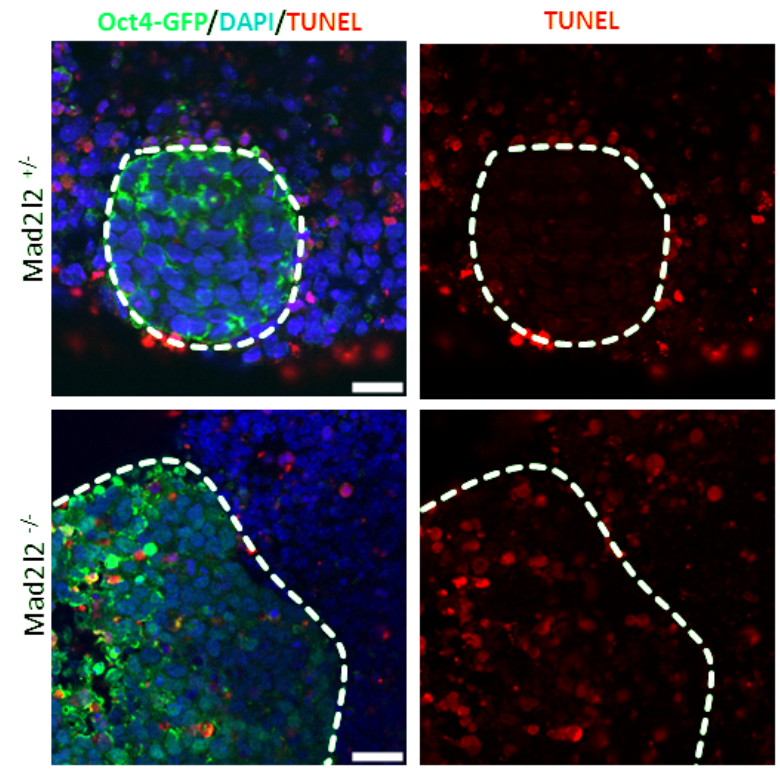

Figure 12: Increased apoptosis in Mad2/2-deficient, GFP positive cells.

TUNEL positive, GFP-positive areas within D8 aggregates are enriched (dash line). Note the high numbers of apoptotic cells in the absence of Mad2I2 in GFP positive cells. Bar $=25 \mu \mathrm{m}$.

In vivo, PGCs reactivate many pluripotency related transcription factors, and at the same time suppress the Erk signaling pathway, which positively regulates somatic cell differentiation (Kimura et al., 2014). In principle reactivation of Oct4, Nanog and Sox2, and suppression of Erk occurred in the Oct4-GFP positive, even if the numbers of GFP-Oct4 positive cells are lower in Mad2/2-dedicient aggregates (Figure 13). Immunofluorescence analysis revealed that the Erk protein was expressed equally, but that the activated, phosphorylated Erk was considerably lower in the Oct4-GFP positive cells (Figure 13). Altogether, Mad2/2 protein appeared not to be essential for reactivation of core factors and suppression of Erk. 

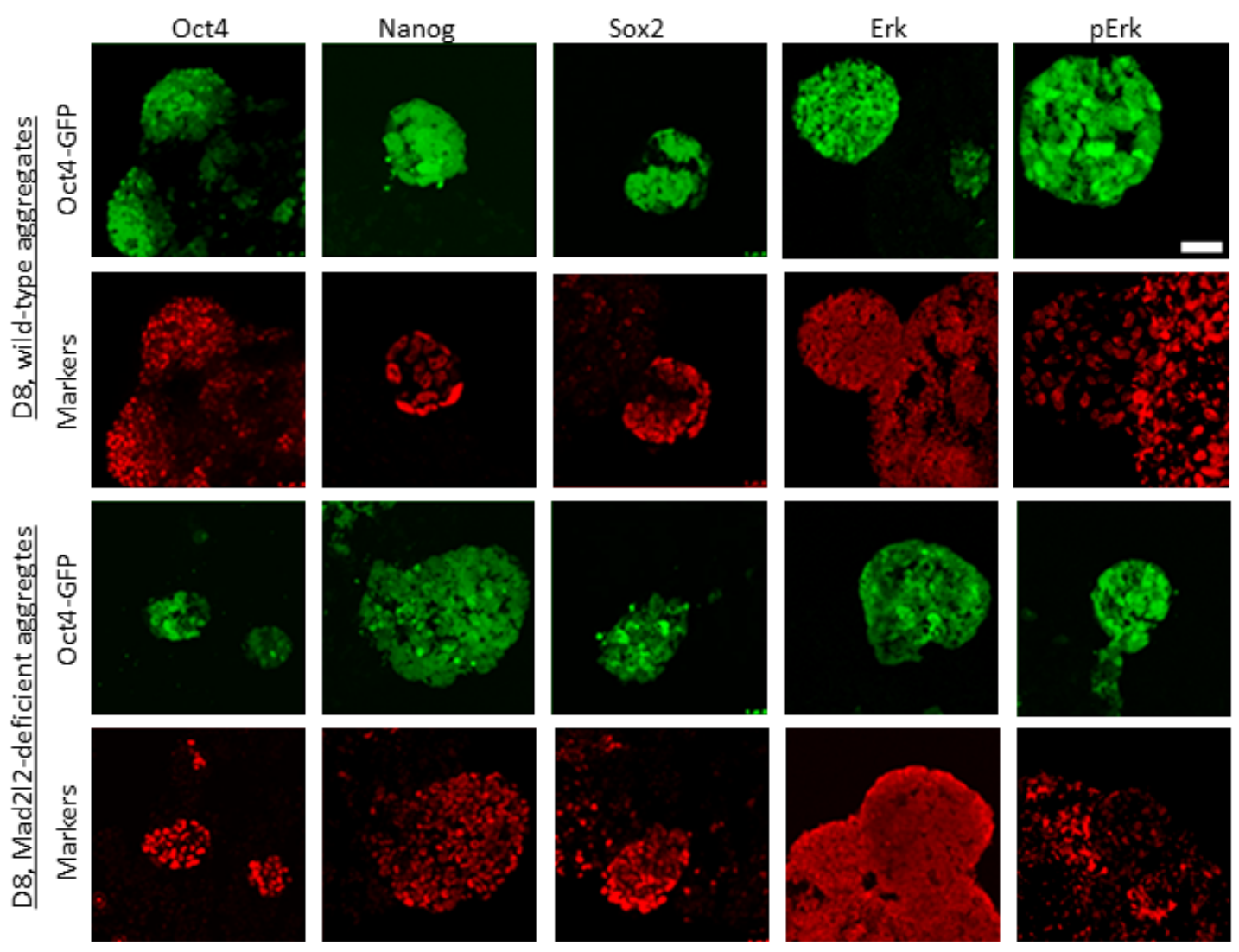

Figure 13: Similarities between PGCLCs and Mad2/2-deficient GFP positive cells.

Wild-type and Mad2/2 knockout cells express pluripotency related markers. Both somatic and germ cells express Erk protein but it is not actived by phosphorylation in germ cells. Bar $=25 \mu \mathrm{m}$.

Prdm1 (Blimp1) was previously described as a key PGC factor, necessary for in induction and differentiation, and detectable in both nascent and migratory PGCS (Ohinata et al., 2005). To check the efficiency of the differentiation protocol a ESCs line with a Blimp1-membrane-directed Venus reporter (Blimp1-mVenus) was used (Ohinata et al., 2008). Eight days after differentiation (six days after BMP4 treatment), mVenus positive cells were visible in cell aggregates, and thus identified as PGCLCs. They expressed higher amount of Mad2/2 in comparison with surrounding somatic Blimp-mVenus -negative cells (Figure 14). 

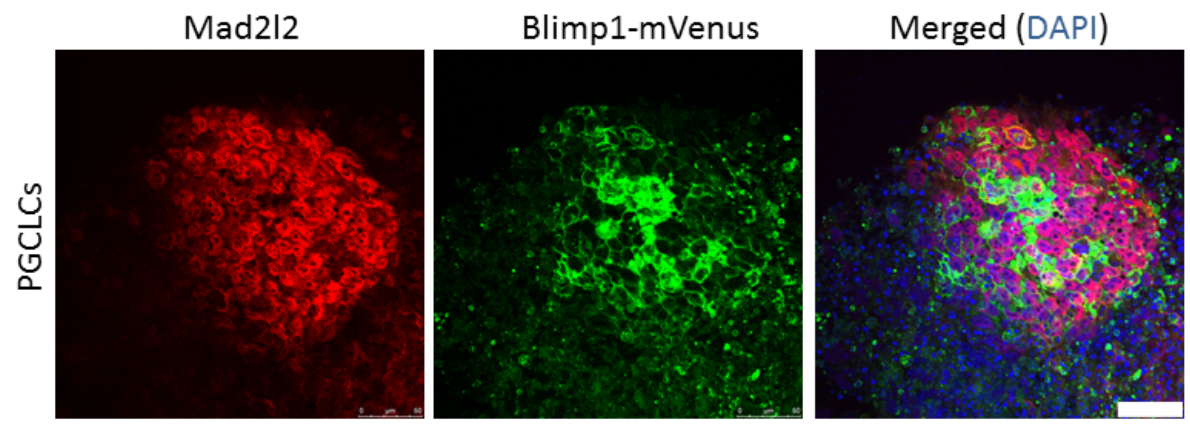

Figure 14: Detection of PGCLCs by expression the Blimp-mVenus transgene and Mad2/2. Immunofluorescence exhibited Mad2I2 expression in wild-type D8 aggregates. Note that this protein expression is higher in Blimp1-mVenus positive cells. Bar $=50 \mu \mathrm{m}$.

The epigenetic landscape of PGCs is significantly remodeled around E9, in particular by a global exchange of the stably repressive histone H3K9me2 by the more flexible H3K27me3 (Seki et al., 2007). This process is followed by a global demethylation of DNA (Kawasaki et al., 2014). In Mad2I2 knockout embryos PGCs die around E9, and the reprogramming is not completed (Pirouz et al., 2013). Immunostaining demonstrated that the epigenetic reprogramming failed also in the in vitro differentiation of Mad2/2-deficient EpiLCs, which remained strongly positive for H3K9me2, and did not switch to H3K27me3 (Figure 15).
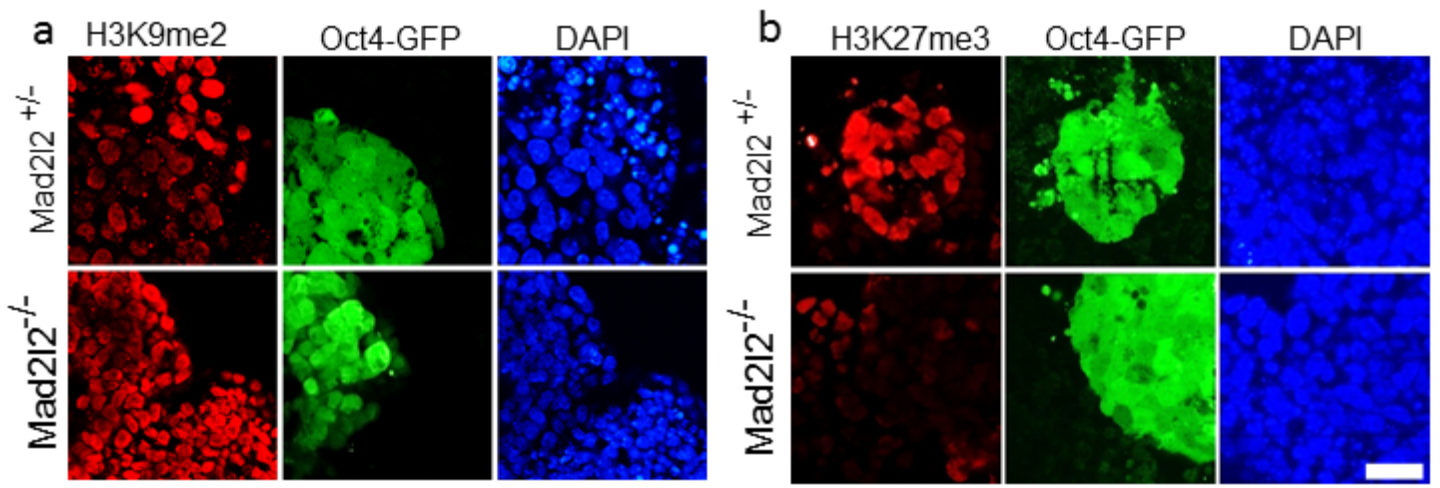

Figure 15: Failure of epigenetic reprogramming during the differentiation from EpiLCs to PGCLCs in the absence of Mad2/2.

a) Immunofluorescence staining of D8 aggregates with antibody against H3K9e2.

b) Immunofluorescence staining of D8 aggregates with antibody against H3K27me3.

Bar $=25 \mu \mathrm{m}$. 
$\mathrm{H} 2 \mathrm{AX}$ is a key modified histone in the DSB repair pathway, and it plays a critical role in chromatin relaxation, signal amplification and recruitment of downstream factors (Panier and Boulton, 2014). The level of $\gamma \mathrm{H} 2 \mathrm{AX}$ is naturally high in ESCs, and cannot be explained by the presence of DSBs (Turinetto et al., 2012). $\mathrm{YH} 2 \mathrm{AX}$ foci accumulated in the Oct4-GFP positive aggregates on D8, and there was no significant difference between Mad2/2 knockout and control cells (Figure 16).
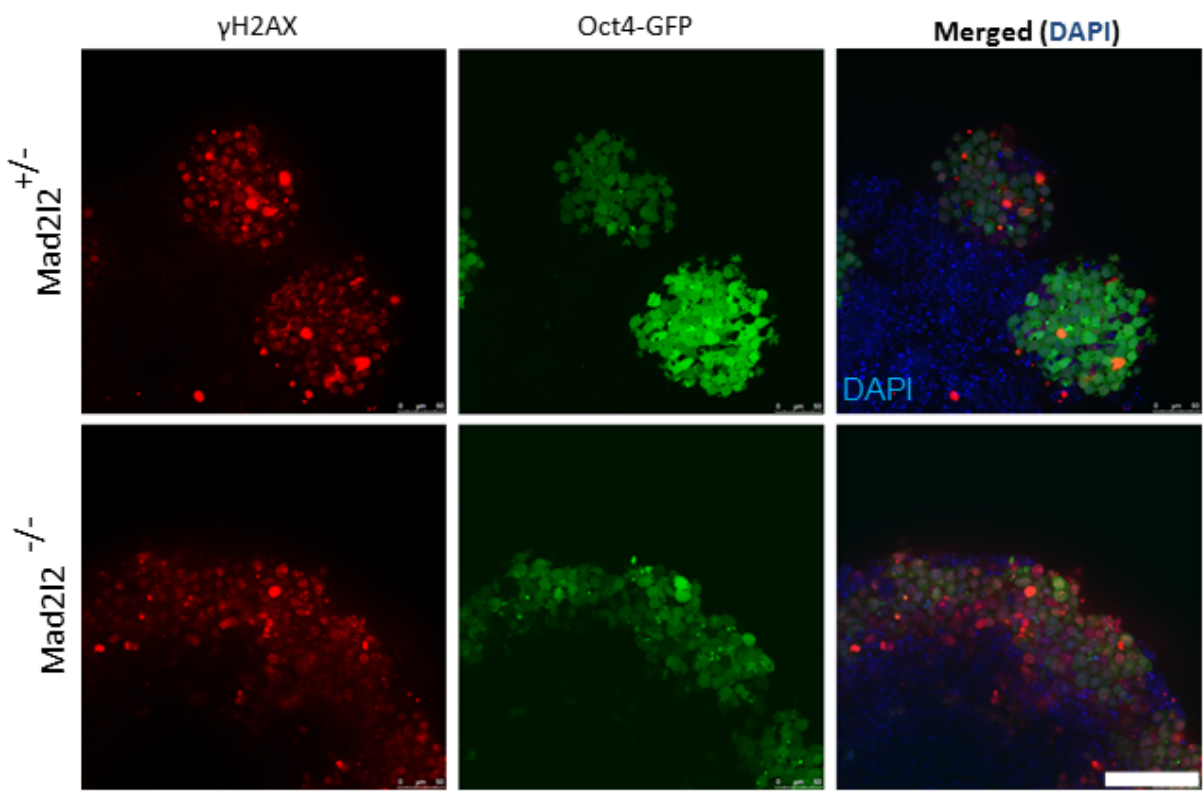

Figure 16: $\mathrm{\gamma H} 2 \mathrm{AX}$ is present in high levels in Oct4-GFP positive aggregates in both wild-type and mutant ESCs.

Immunofluorescence staining of D8 aggregates with antibody against $\mathrm{YH} 2 \mathrm{AX}$. Both wild-type and Mad2l2-deficient groups show an increase of $\mathrm{H} 2 \mathrm{AX}$ phosphorylation in Oct4-GFP positive cells. Bar $=100 \mu \mathrm{m}$.

TFAP2C is highly expressed in PGCs, is essential for PGC development, and is sufficient for the induction of PGCLCs in vitro in collaboration with PRDM14 (Magnusdottir et al., 2013; Nakaki et al., 2013). Its expression in Mad2l2-deficient cells differentiating in BMP4 medium was investigated by immunocytochemistry. After four, six and nine days in BMP medium a large population Oct4-GFP and TFAP2C double positive wild-type cells developed, thus identified as PGCLCs. In contrast, only a few TFAP2 positive cells were detected on D4 and D9, while none were found on D6. The absence of simultaneous GFP expression suggested, that 
these cell did not represent PGCLCs (Figure 17). In conclusion, the absence of TFAP2 suggested that no bona fide PGCLCs could be derived from Mad212-deficient EpiLCs.

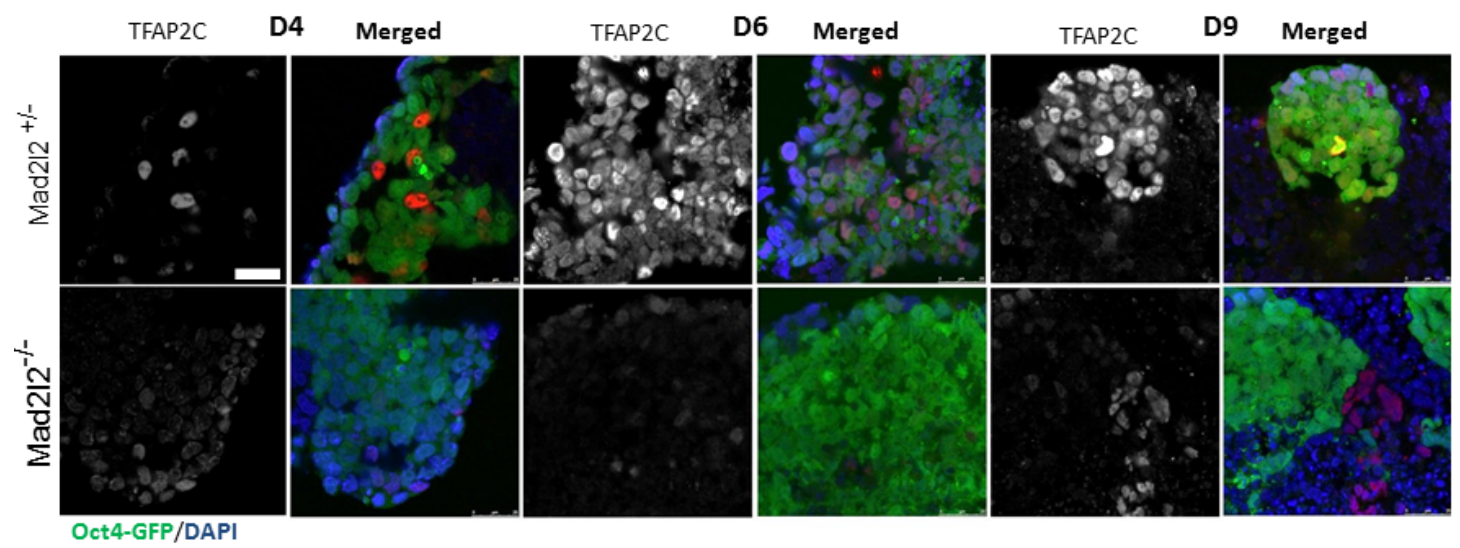

Figure 17: Failure to induce TFAP2C cells from Mad2/2-deficient ESCs.

Immunofluorescence staining of D6, D8, and D10 aggregates with antibody against TFAP2C (red). This important transcription factor for PGC development was not detected in Mad2/2deficient cells Blue: DAPI, Green: GFP. Bar $=25 \mu \mathrm{m}$.
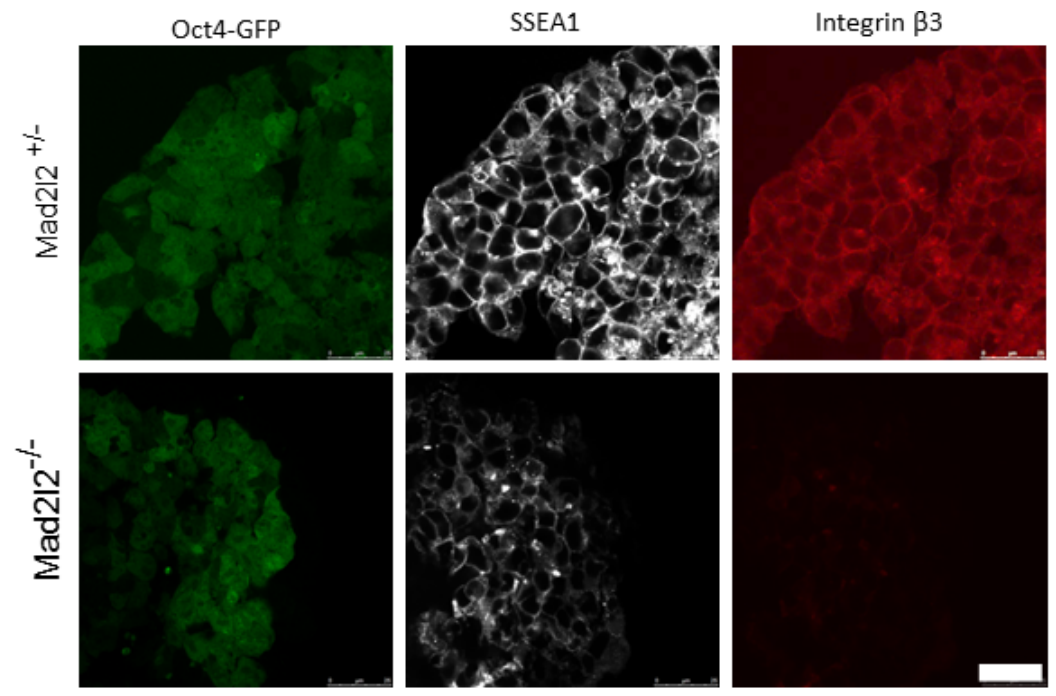

Figure 18: Mad212-deficient, GFP positive cells do not express integrin beta 3.

Immunofluorescence staining of D8 aggregates with antibodies against SSEA1 (white) and integrin beta 3 (red). Expression of integrin $\beta 3$ is specific for PGCs, in contrast to ESCs.

(Magnification bar is equal with $25 \mu \mathrm{m}$ )

PGCs and PGCLCs are normally double positive for cell surface markers SSEA1 and integrin beta 3 (Hayashi et al., 2011). Indeed, the majority of GFP-positive cells derived from wild-type ESCs expressed both of these markers, confirming their 
PGCLC identity. However, Mad2/2-deficient cells undergoing the same differentiation protocol expressed neither integrin beta 3 nor significant levels of SSEA1 (Figure 18). These observations confirmed that PGCLCs were not induced Mad2/2-deficient cells.

Dppa3 is a marker for ICM cells, PGCs, ESCs and PGCLCs (Hayashi et al., 2011; Ohinata et al., 2008). The typical, heterogeneous Dppa3 distribution was found in condensed cell populations of wild-type D6 aggregates, but much less in Mad2/2 knockout aggregates (Figure 19a). Expression of Dppa3 mRNA was measured by quantitative RT-PCR in the different differentiation stages, namely ESCs, EpiLCs and PGCLCs (Figure 19b). In the wild-type group, Dppa3 expression was high in ESCs, low in EpiLCs, but back to ESC levels in PGCLCs on D8. In the absence of Mad2I2, Dppa3 expression was low in ESCs and EpiLCs, and only slightly increased after differentiation for 8 days (D8), in agreement with protein levels.

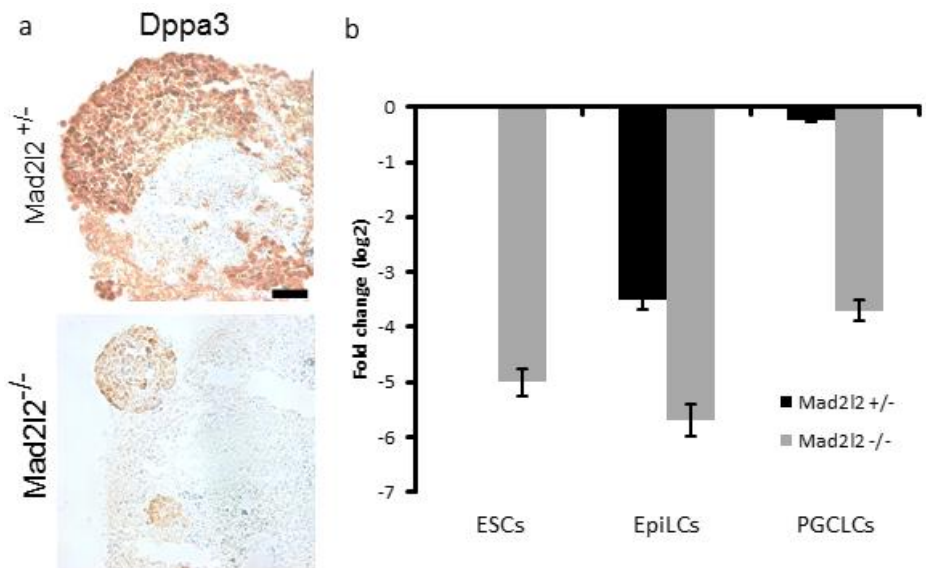

Figure 19: Dppa3 positive cells were not induced 8 days after differentiation of Mad2/2deficient aggregates.

a) Brown dots represent Dppa3 positive cells identified by $A B C$ staining in D8 aggregates. Bar $=100 \mu \mathrm{m}$.

b) Expression patterns of dppa3 genes in ESCs, EpiLCs and PGCLCs in both wild-type and Mad212-deficient groups. Note the general down regulation of dppa3 in both ESCs and PGCLCs in the absence of Mad2/2. 


\subsection{DDR in Mad2/2-deficient murine embryonic fibroblasts}

\subsubsection{Mad2/2-deficiency leads to activation of a DDR.}

Phosphorylation of the histone variant $\mathrm{H} 2 \mathrm{AX}$ by the ATM kinase, and the accumulation of $\mathrm{yH} 2 \mathrm{AX}$ on single or double strand breaks are immediate early responses to DNA damage. Wild-type MEFs did not contain detectable levels of $\mathrm{YH} 2 \mathrm{AX}$. Mad2/2-deficient MEFs, on the other hand, regularly contained varying levels of $\mathrm{yH} 2 \mathrm{AX}$, even without external damage induction (Figure 20a).

CHK1 and CHK2 are two kinases which are activated by ATR and ATM respectively in response to DNA damage (Cimprich and Cortez, 2008). CHK1 activation is restricted to the G1 phase of the cell cycle, and CHK2 to S and G2 (Cimprich and Cortez, 2008). All Mad2/2-deficient MEFs died 24 hours after treatment with the DNA cross-linker cisplatin. To study the DDR, exposure time was reduced to 8 hours, and pCHK2-positive cells were counted before and after the addition of cisplatin. In wild-type MEFs the percentage of pChk2 positive cells rose from 0 to $\sim 15 \%$ (Figure 20c). In Mad2/2-deficient cells the percentage of positive cells was on a high level ( $45 \%$ ) both before and after exposure (Figure 20b, c). A higher magnification revealed that PCHK2 accumulated in small dense nuclear foci in wild-type cells (Figure 20d). In Mad212-deficient MEFs, on the other hand, more CHK2 protein was detected around the nucleolus (Figure 20d). In summary, the DDR was already activated before exposure to a damaging agent in Mad2/2-deficient MEFs, and these cells were hypersensitive to cisplatin. 

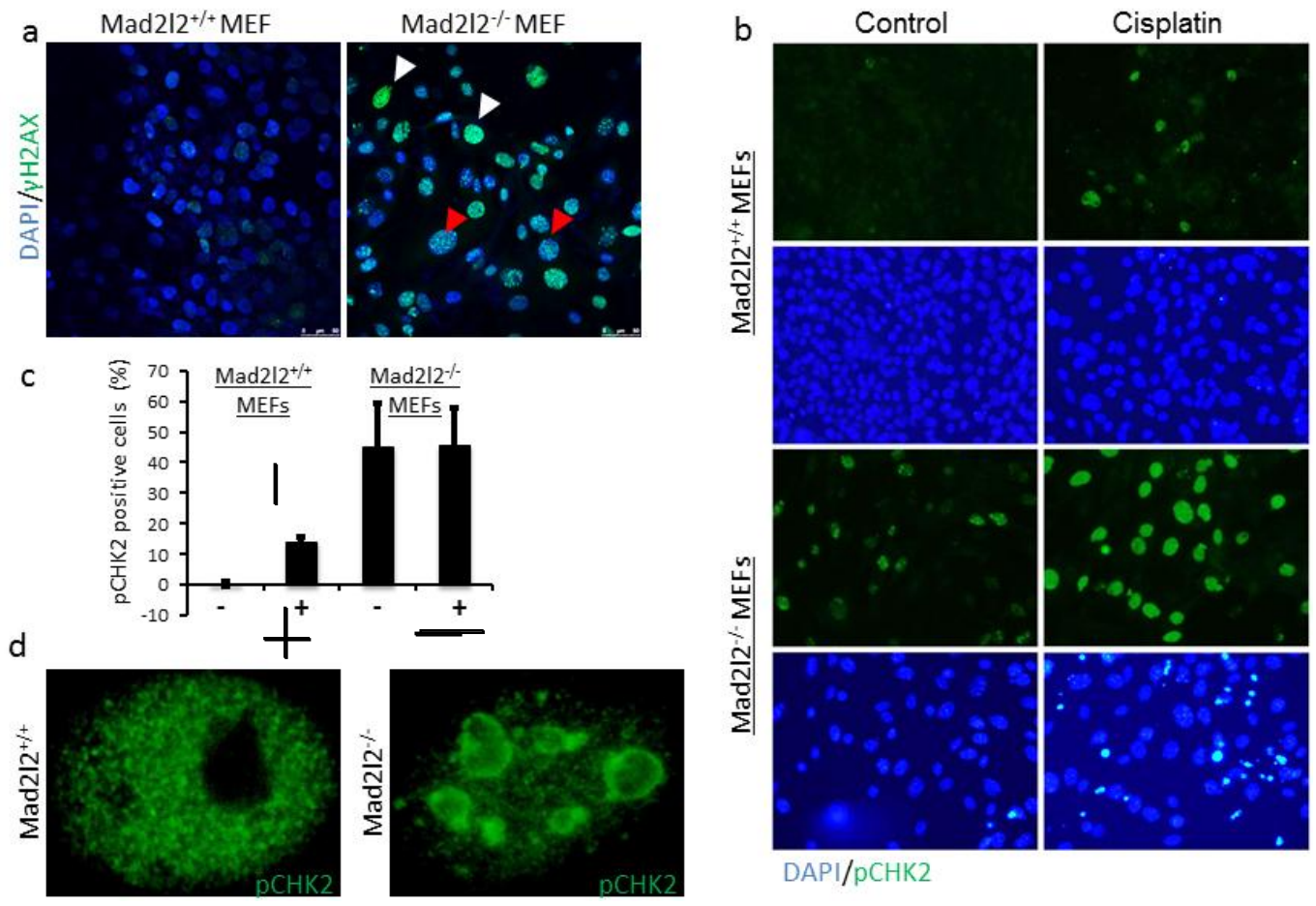

$\mathrm{DAPI} / \mathrm{pCHK} 2$

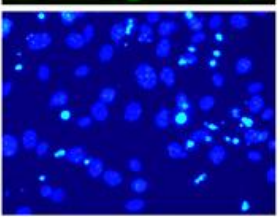

Figure 20: Activation of a DNA damage response in unexposed and exposed MEFs.

a) Without exposure to cisplatin MEFs accumulate $\mathrm{YH} 2 \mathrm{AX}$ only in the absence of Mad2I2. White arrowheads point to cells with a high, confluent amount of $\mathrm{yH} 2 \mathrm{AX}$. Red arrowheads point to nuclei with $\mathrm{\gamma H} 2 \mathrm{AX}$ foci. Bar $=50 \mu \mathrm{m}$. b) pChk2 levels in MEFs before and after an eight hour exposure to cisplatin. Bar $=100 \mu \mathrm{m}$. c) Quantitation of the experiment depicted in panel. d) Distribution of pChk2 in single nuclei of MEFs. Bar $=2 \mu \mathrm{m}$.

\subsubsection{Cell proliferation is decreased in Mad2/2-deficient MEFs}

Mad212-deficient ESCs and EpiLCs cells have a decreased proliferation rate (Pirouz et al 2015; 3.1.2.). MEFs were analyzed with an antibody against the proliferation-related antigen Ki-67 before and after cisplatin treatment. Around 60 percent were positive for Ki-67 before exposure to cisplatin, and only 20 percent after eight hours of treatment. For Mad2/2-deficient MEFs the percentage dropped from 40 to 25 percent (Figure 21). Taken together, the number of proliferative cells was lower in Mad212-deficient MEFs. 


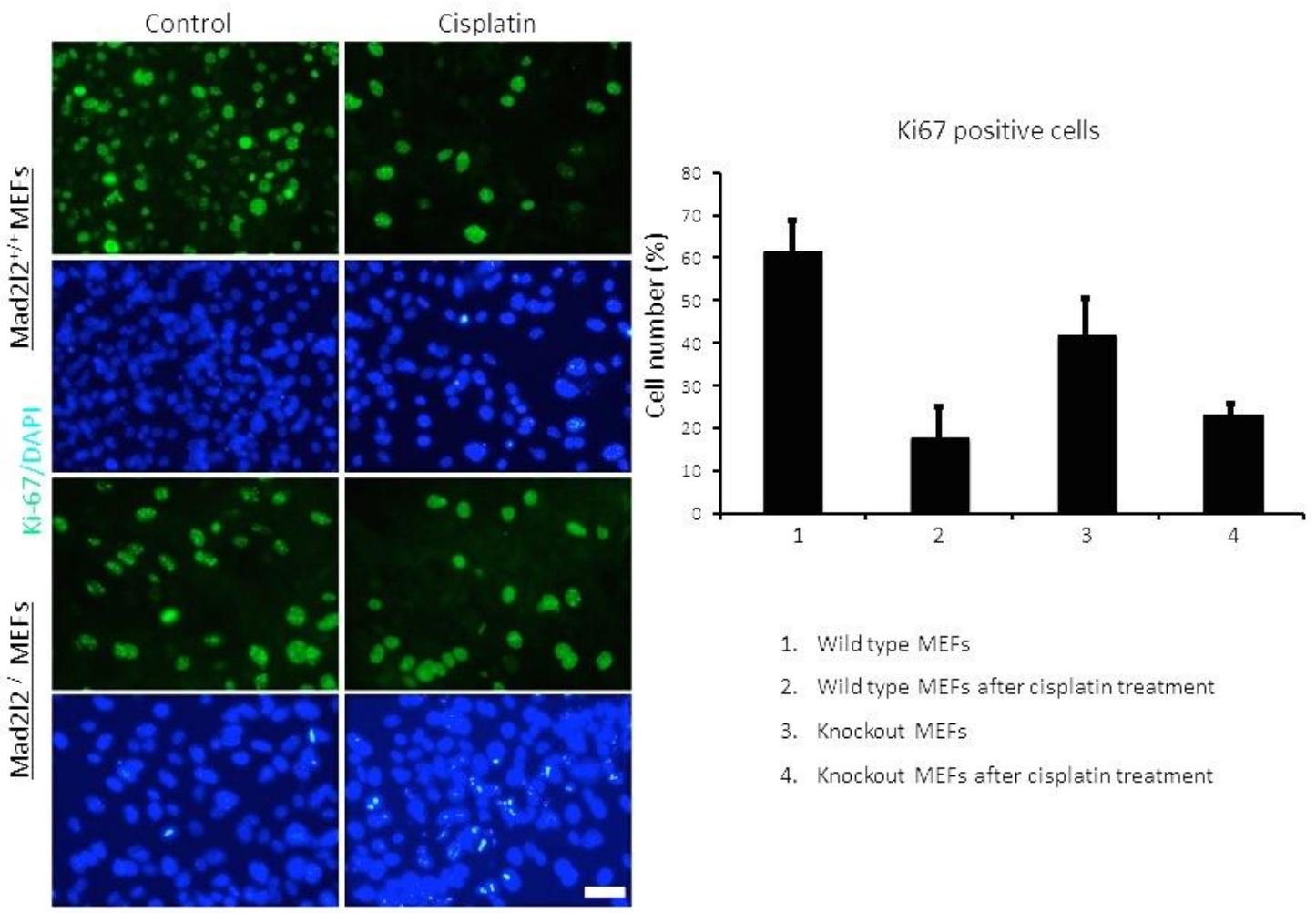

Figure 21: Proliferation in exposed and unexposed MEFs.

Marked cells with immunofluorescence staining represent Ki67 positive cells in Mad2/2deficient MEFs and wild-type MEFs before and cisplatin treatment. The immunofluorescence data were quantified by cell counting. Bar $=100 \mu \mathrm{m}$.

\subsubsection{Histone modifications were misregulated in Mad2/2-deficient MEFs}

\section{after DNA damage.}

A DDR is accompanied by drastic epigenetic changes (Sulli et al., 2012). Histone modifications were studied in Mad2/2-deficient MEFs exposed to cisplatin for eight hours. In wild-type MEFs, cisplatin exposure induced $\mathrm{yH} 2 \mathrm{AX}$, which then correlated to a loss of $\mathrm{H} 3 \mathrm{~K} 9 \mathrm{me} 2$ expression. In mutant cells $\mathrm{\gamma H} 2 \mathrm{AX}$ was already present without exposure to cisplatin, and H3K9me2 remained (Figure 22). This unique correlation was not observed for $\mathrm{H} 3 \mathrm{~K} 9 \mathrm{me} 3$ and $\mathrm{H} 3 \mathrm{~K} 4 \mathrm{me} 3$ (data is not shown). The loss of H3K9me2 represents the loss of repressive chromatin and formation of relaxed chromatin which is necessary for DDR (Rossetto et al., 2010). Remarkable is that no loss of repressive chromatin occurred in the absence of Mad212. 


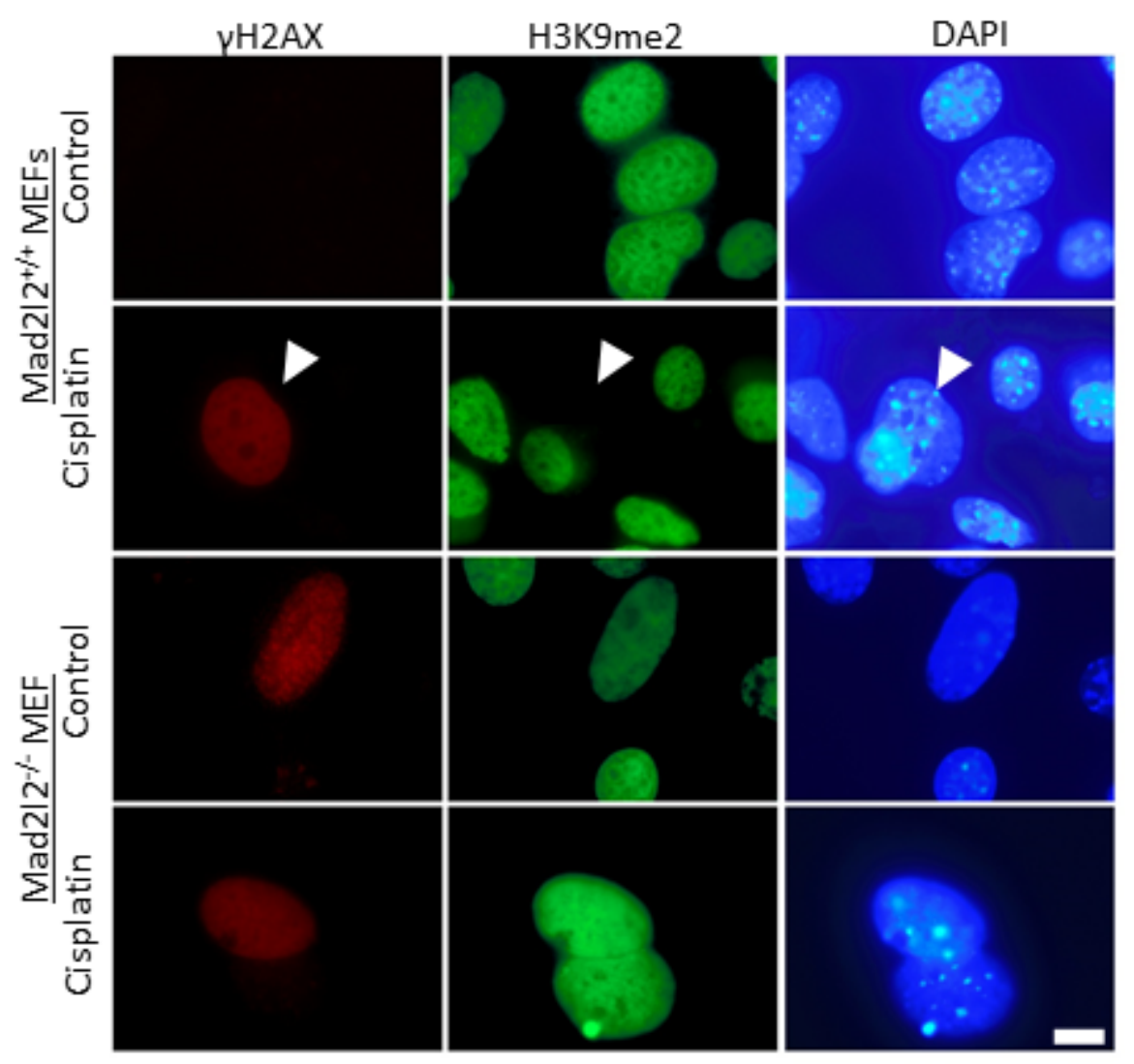

Figure 22: H3K9me2 histone modification is decreased after DNA damage induction. In cisplatin exposed wild-type cells the expression of $\mathrm{\gamma H} 2 \mathrm{AX}$ corresponds with the absence of H3K9me2 (arrow). In Mad2/2-deficient MEFs YH2AX is expressed both with or without exposure to cisplatin, and the expression of $\mathrm{H} 3 \mathrm{~K} 9 \mathrm{me} 2$ is maintained.

\subsection{Characterization of Wild-type and Mad2/2-deficient ESCs}

\subsubsection{Mad2/2 is highly expressed in the euchromatin of ESCs}

Mad2I2 RNA as well as Mad212 protein levels is extraordinarily high in naive ESCs (Figure 23a, c). The level of protein is strongly reduced after differentiation to the primed state, and the RNA level is drastically lower in MEFs as compared to ESCS (Figure $23 \mathrm{~b}, \mathrm{c}$ ). The protein is located in small foci all over the nucleus, excluding nucleolus and nuclear lamina (Figure 23e), and associates significantly with the chromatin fraction (Figure 23d). Optical sections with the confocal microscope revealed that Mad2I2 levels varied from high to barely detectable levels in cells of an ESC colony, with a global or a focal nuclear distribution (data not shown). Such a 
distribution would be expected to result from fluctuating protein levels in a given cell (Singer et al., 2014).

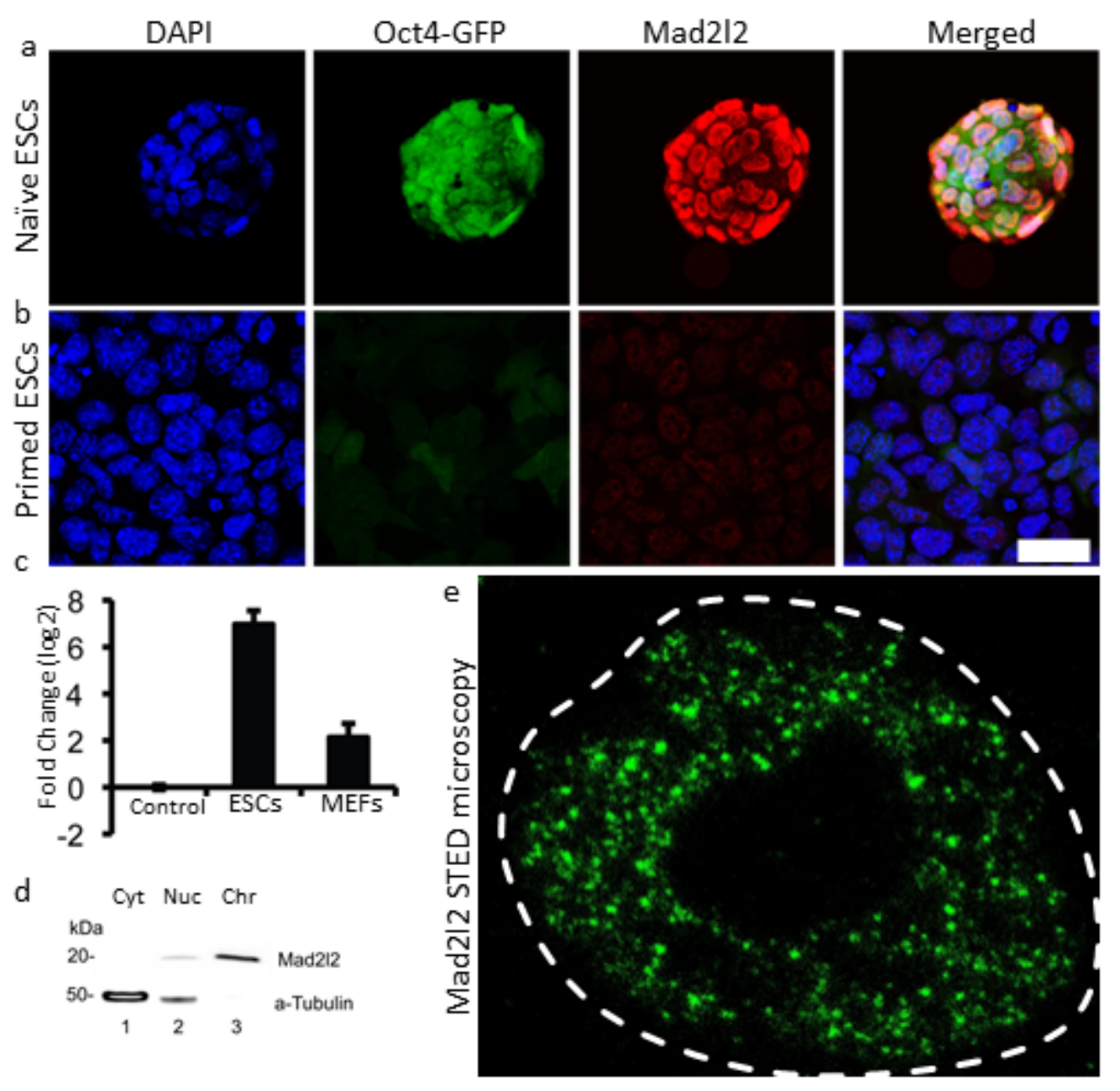

Figure 23: ESCs express high levels Mad2/2.

a) Mad2I2 protein expression in a colony of naive ESCs, and b) in EpiLCs. Bar $=25 \mu \mathrm{m}$. c) Mad2I2 RNA was detected by qRT-PCR in ESCs and MEFs. d) In ESCs, Mad2I2 protein is predominantly localized in the chromatin fraction. e) Nuclear distribution of Mad2/2 protein identified by STED microscopy.

The correlation between Mad2/2 and heterochromatin was investigated by double staining for DNA (DAPI) and Mad2I2. DAPI fluorescence was high in the nuclear periphery and around the nucleolus, where the level of Mad2l2 protein was low or undetectable. Analysis of color intensity by ImageJ software confirmed a negative correlation between areas with high DNA contents and Mad2l2 (Figure 24a, 
b). Mad2/2 did not localize to mitotic chromosomes (Figure 24c). Mad2/2 localization was compared with the two heterochromatin markers H3K9me2 and H3K27me3. H3K9me2 was present in the nuclear periphery and around the nucleolus, while H3K27me3 was detected in the nucleoplasm between nuclear lamina and nucleolus (Figure 24d, e). This distribution of heterochromatin and Mad2I2 was mutually exclusive, since also in high resolution no overlaps of the staining were detectable. In conclusion, Mad2I2 localized to euchromatin, and was specifically excluded from heterochromatin and from mitotic chromosomes.
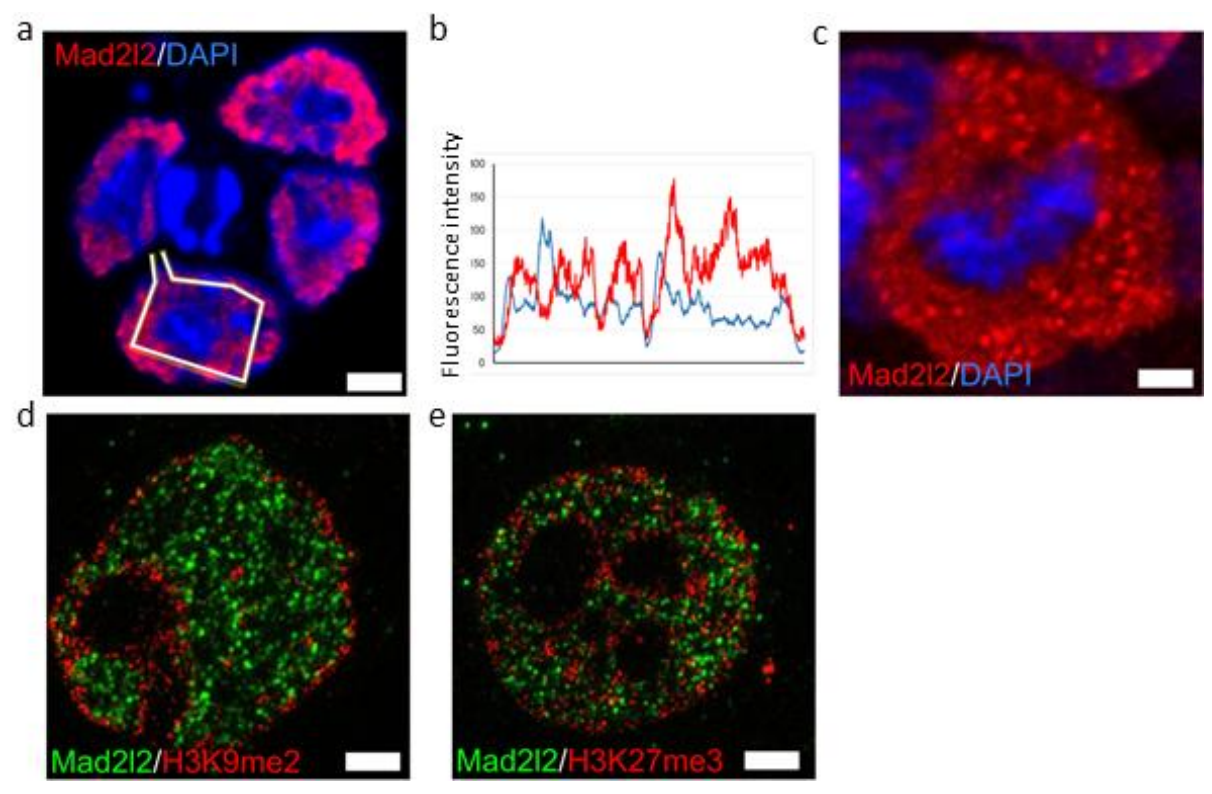

Figure 24: Mutually exclusive localization of heterochromatin and Mad2/2.

$\mathrm{a}, \mathrm{b})$ Exclusion of Mad212 from areas of high DNA content. Bar $=10 \mu \mathrm{m}$. c) Exclusion of Mad2/2 from condensed chromosomes d) Mutually exclusive localization of H3K9me2 and Mad2I2 as detected by STED microscopy. e) Mutually exclusive localization of H3K27me3 and Mad2/2 as detected by STED microscopy. Bar $=2 \mu \mathrm{m}$.

\subsubsection{Comparison histone 3 modifications in wild-type and mutant ESCs}

The level of H3K9me2 was low in the majority of naive, wild-type ESCs, however, it increased in Mad2l2 knockout cells (Pirouz et al., 2015). To check this increase on a single cell level, cells were counted by flow cytometry. Significant differences were revealed between wild-type and mutant cells, when they were plotted against each other based on $\mathrm{H} 3 \mathrm{~K} 9 \mathrm{me} 2$ levels. To quantify cells with low and high levels of H3K9me2, the graph was gated to two separate parts based on curve 
intersection point. This analysis showed that $27 \%$ of wild-type cells contained high levels of H3K9me2 protein, whereas the percentage increased to $64 \%$ for mutant cells (Figure $25 \mathrm{~b}$ ).
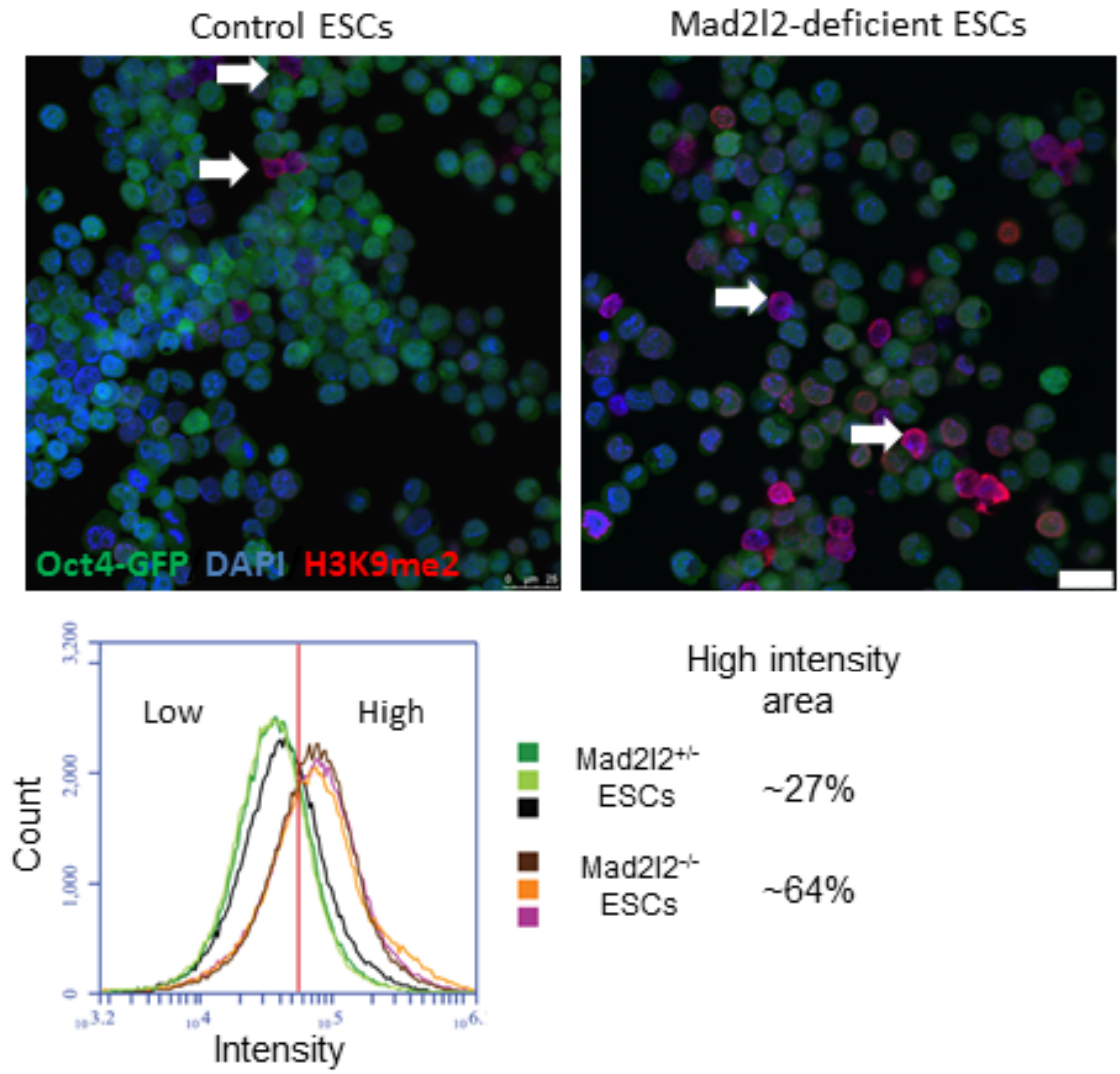

High intensity area Mad212+iESCs $\quad \sim 27 \%$ Mad2/2 ESCs $\quad \sim 64 \%$

Figure 25: H3K9me2 in wild-type and mutant ESCs

a) White arrows show wild-type and knockout cells with high levels of H3K9me2. b) Three replicates of mutant (red) or wild-type (green) populations were analyzed by flow cytometry and gave highly similar results. The majority of wild-type cells had low levels of Mad212, whereas the majority of mutant cells had high levels. Within the high level expressers the percentage of mutant cells was larger by a factor of 2, $3(64 \%: 27 \%)$. Bar $=25 \mu \mathrm{m}$.

The natural fluctuation of Mad2/2 levels in a naive ESC population was investigated in correlation with the formation of heterochromatin (H3K27me3). High resolution microscopy revealed that cells with a high level of Mad2/2 protein always had very low levels of H3K27me3 and vice versa (Figure 26a). This negative correlation is in agreement with the global increase of heterochromatin markers H3K27me3 and H3K9me2 in the Mad2I2-deficient ESCs (Figure 26b). 

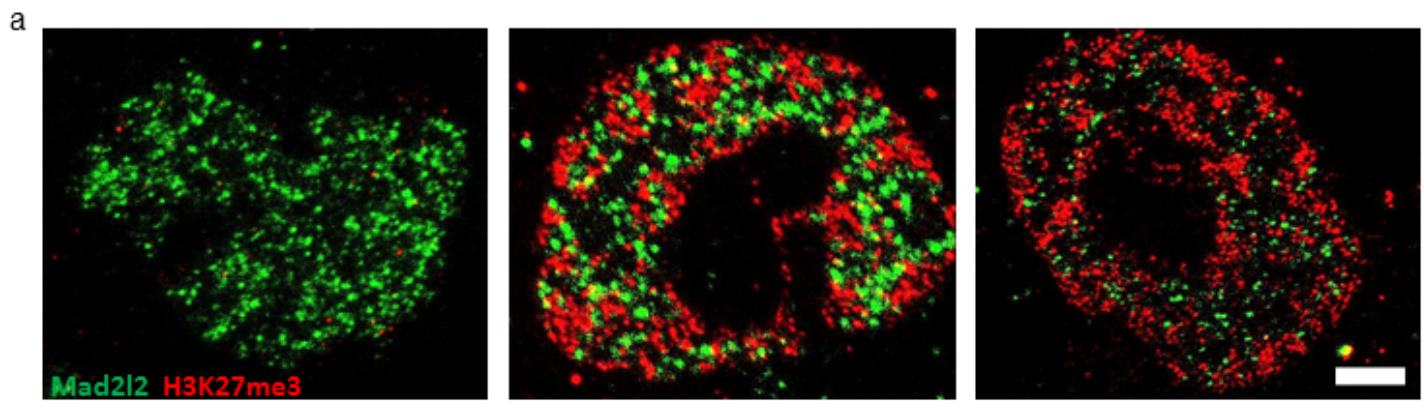

Mad212

H3K27me3

b
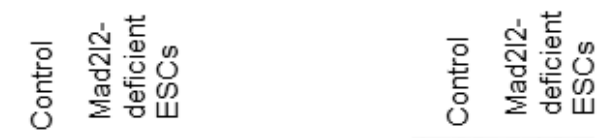

H3K9me2

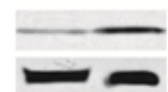

H3K27me3

a-Tubulin

Figure 26: Negative correlation between Mad2/2 and H3K27me3 levels.

a) The localization of Mad2I2 and H3K27me3 proteins in the nucleoplasm was determined by high resolution STED microscopy. Note, that proteins never overlapped, regardless of the absolute levels. b) The two heterochromatin markers, H2Aub119 and H3K27me3 are increased in Mad2/2-deficient cells. Bar $=2 \mu \mathrm{m}$.

\subsubsection{No evidence for DNA damage in Mad2/2-deficient ESCs}

Signs for a DDR were observed in Mad2/2-deficient MEFs without a prior exposure to genotoxic agents (Figure 20, 3.2.1). Therefore, DDR parameters were also studied in ESCs. Here, the pCHK2 level was not raised (Figure 27a). To be sure that this was not due to a cell cycle arrest in G1, cells were analyzed by flowcytometry after PI staining, revealing a non-significant increase of cells in $\mathrm{S}$ phase (3\%; Figure 27b). There was no arrest of the cell cycle, as confirmed by the presence of $S$ and $G 2$ cells in the CHK2-negative population. The transcription of genes involved in base excision repair normally increases in response to point mutations (Saha et al., 2010). Relevant mRNAs were checked in the transcriptome of Mad2/2-deficient ESCs. The levels of Tdg, Xrcc1, Parp1, Apex1, Ercc1, Xpa and Gadd45a mRNAs were not increased, and the only significant change was a decrease of Gadd45b, a factor responsible for the removal of modified nucleotides (Figure 
27c). This enzyme contributes to active DNA demethylation by removal of the 5hydroxymethylcytosine (Zhang et al., 2011). Chromosome spreads derived from synchronized ESCs were checked for abnormalities, but neither joined chromosomes nor abnormal formations of centromeres were observed (Figure $27 \mathrm{~d}$ ). In conclusion, there was no evidence for an increase of DNA damage in the Mad212 ${ }^{-/-}$ESCs.

a

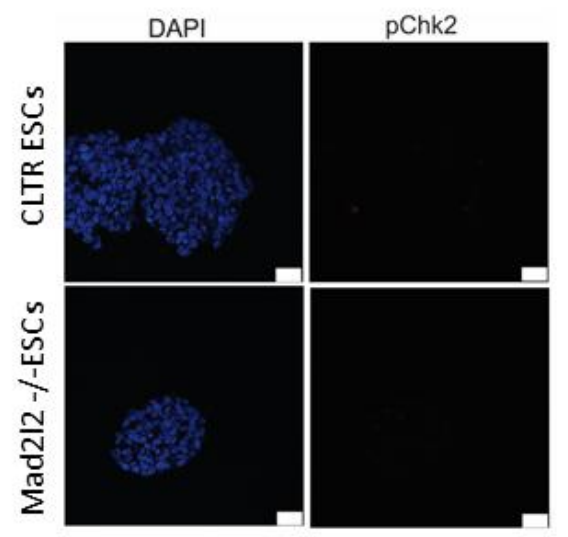

C

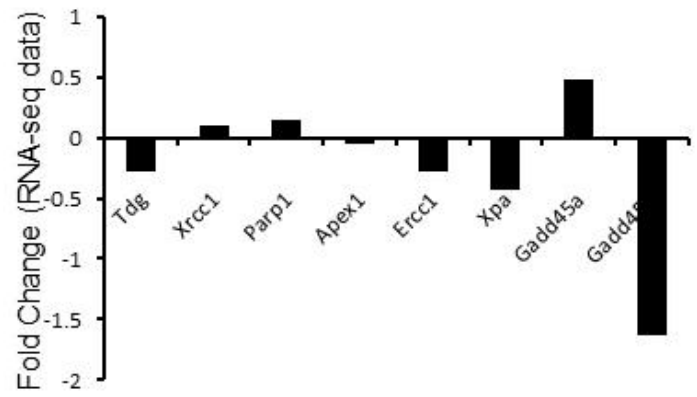

b
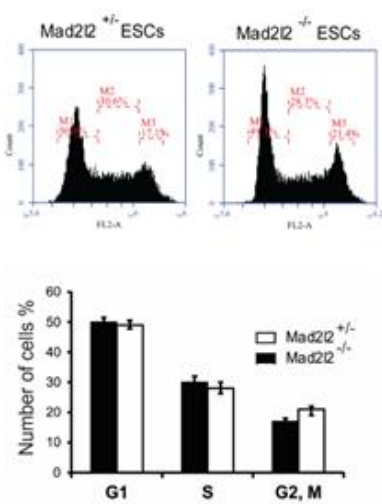

d

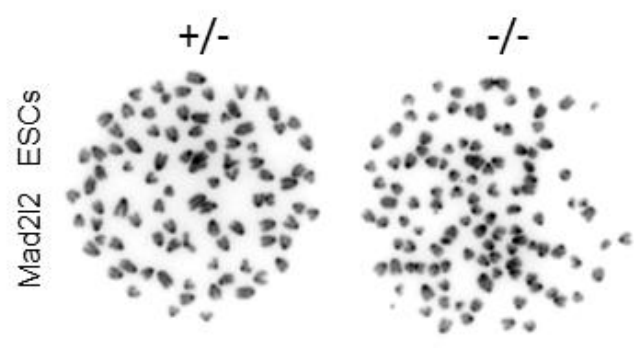

Figure 27: No evidence for the activation of a DDR.

a) No activation of the Chk2 protein by phosphorylation occurred in Mad2/2-deficient ESCs.

b) No significant distortions of the cell cycle were detected in Mad2/2-deficient ESCs. c) The only significantly changed DDR mRNA in the transcriptome of Mad2/2-deficient ESCs is Gadd45b. Its level would be expected to rise, rather than fall after DNA damage. d) No chromosomal aberrations were detected in spreads from synchronized Mad212 ${ }^{-1}$-ESCs. Bar $=$ $25 \mu \mathrm{m}$.

\subsubsection{Comparison of transcriptomes from wild-type and Mad2/2-deficient}

\section{ESCs}

A first analysis of the raw RNA-sequencing data comparing naive wild-type and mutant ESCs was published in 2015 (Pirouz et al., 2015). These data were 
reanalyzed by new methods to find a correlation between Mad2/2 deficiency and developmental instability (see Materials and Methods 2.19). For the alignment of sequencing data now the new genomic reference sequence "mm10" was used, while previously only mm9 from 2007 could be applied. This increased the aligned sequences from approximately $60 \%$ to $95 \%$, so that new targets were available for comparison. A new statistical tool (Diseq2) increased the sensitivity of the analysis (data not shown), which were displayed by volcano plots.

A striking finding of the new analysis was the dramatic decrease in the expression of Dppa3, identifying it as one of the ten most significantly downregulated genes (Figure 28a). Among the top ten upregulated genes was Smarcd3 (BAF60C), encoding a subunit of the SWI/SNF chromatin remodeling complex, which regulates post-mitotic events in mature cardiomyocytes and neurons (Kaji et al., 2006). ESCAPE (http://www.maayanlab.net/ESCAPE/), a new database was used for gene ontology analysis. It revealed a significant increase in the expression of axonal guidance related genes, which may correspond to the significant rise of Smarcd3 (BAF60c) expression. Smarcd3 is a member of BAF complex protein, which regulates Dppa3 expression in competition with NurD complex (Kaji et al., 2006). Further annotation was performed by ESC applying the atlas of pluripotency (ESCAPE) database. This database is able to compare genes list with other high throughput studies ESCs (ChIP-sequencing and RNA-sequencing). The results showed that a significant number of miss-regulated genes respond similarly to a decrease or increase of $\mathrm{H} 3 \mathrm{~K} 27 \mathrm{me} 3$ and $\mathrm{H} 3 \mathrm{~K} 4 \mathrm{me} 3$ in the ESCs. This finding is in agreement with change in global level of these histone modifications (Figure 28b, data not shown). 

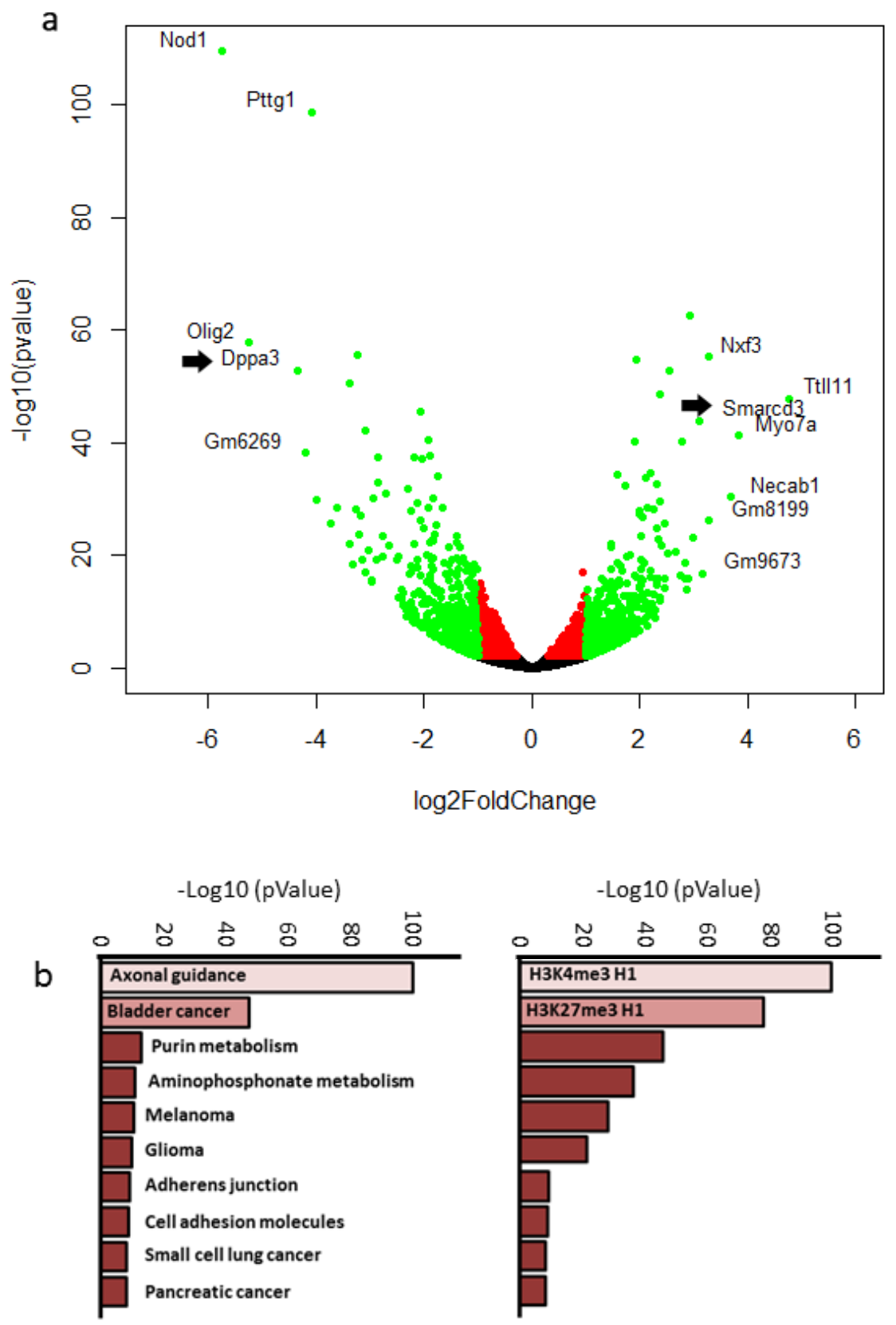

Figure 28: Comparison of transcriptomes from wild-type and Mad2/2-deficient ESCs

a) Volcano plot with downregulated genes to the left, and upregulated genes to the right. Black dots refer to insignificant changes. Arrows point to dppa3 and smarcd3. Red and green dots refer to statistically significant up or downregulated genes, respectively. Green dots show log 2 fold change cutoff. b) Molecular function based ontology showed enrichment of genes involved in axonal guidance (upper panel). Epigenetic regulation based Ontology showed enrichment of genes that are also regulated by H3K27me3 and H3K4me3 (lower panel).

Normalized read numbers were calculated with the "Cuff diff" software, and the output was arranged relative to the gene position on a chromosome (Figure 29). 
This analysis revealed three genomic regions on chromosome 13 hosting three major histone gene clusters, which exhibited significant increases of transcriptional activity in knockout cells (Figure 29). A raw dataset from the public GSE database describing transcriptional activities in wild-type and Prdm14 $14^{-/}$ESCs was applied for an independent comparison. These data were chosen because of the related phenotype between Mad2I2 and Prdm14-deficient ESCs (Grabole et al., 2013). This comparison demonstrated that the hyper-activity of the histone gene clusters was unique for the Mad2I 2 knockout ESCs, and not related to their instability and cell differentiation problems.

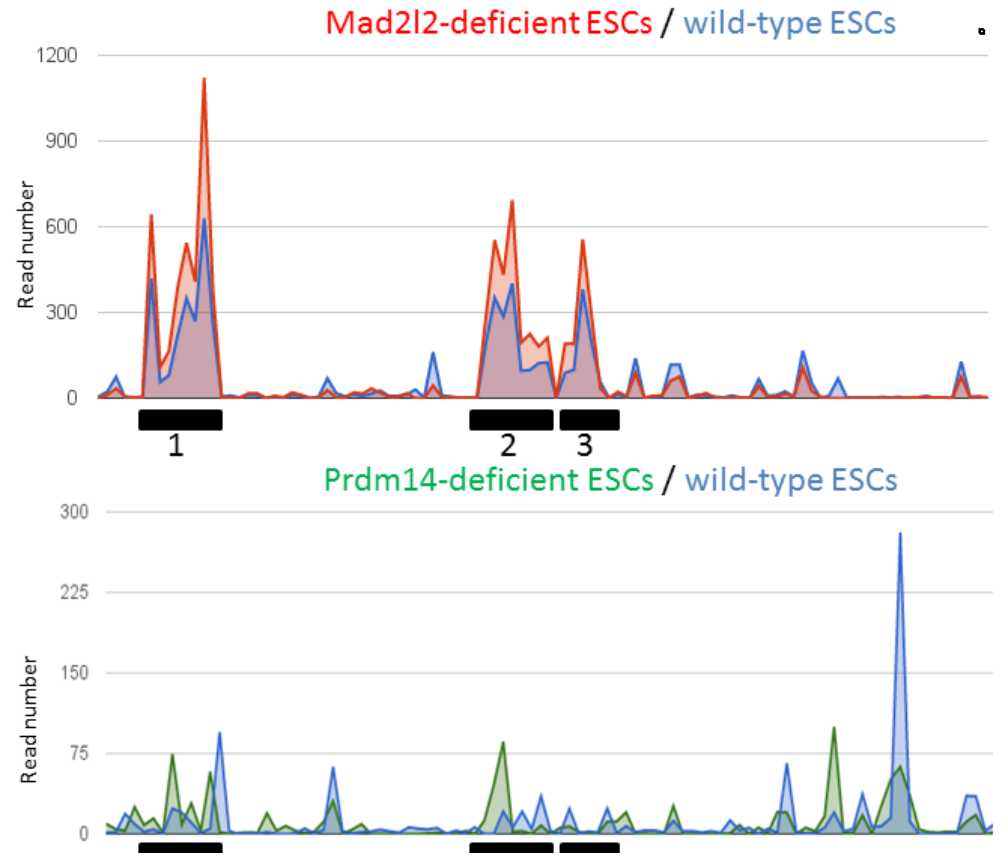

Figure 29: Transcriptional activities of histone gene clusters on chromosome 13.

Raw data of Mad212 ${ }^{-/}$and Prdm14 ${ }^{-/}$ESC gene expression profile were taken from (Pirouz et al., 2015) and (Yamaji et al., 2013), respectively. Data were evaluated by the Cuff Diff software and read numbers were arranged against gene position on chromosome. 1, 2 and 3 point to three gene clusters. Note the principal difference between the two plots, and the specific activation of three histone gene clusters in the Mad2I 2 mutant cells.

\subsubsection{Dppa3 is downregulated in Mad2/2-deficient ESCs}

The downregulation of Dppa3 observed in the RNA-seq analysis was confirmed by immunofluorescence and qRT-PCR (Figure 30). To check for a causal relation between Mad2/2 and Dppa3 expression, Mad2/2-deficient cells were 
transfected with a GFP-Mad2I2 expression vector (Figure 31a). qRT-PCR analysis demonstrated that the down regulation of Dppa3 mRNA expression was largely rescued by Mad2I2 overexpression (Figure 31b). To study the correlation between Dppa3 and Mad2/2 heterogeneity, GFP-Mad2/2 was overexpressed in ESCs carrying a Dppa3-eCFP reporter. All GFP positive cells co-expressed eCFP, indicating the activation of the Dppa3 promoter by Mad2I2 (Figure 31c). ChIP-Seq analysis revealed significant increases of H3K9me2 marks on Dppa3 promoter in Mad2/2-deficient cells (Figure 32a). Global decrease of both H3K9me2 and H3K27me3 by inhibition of Ehmt2 and Ezh2 respectively did not rescue dppa3 expression in ESCs. Altogether, Dppa3 expression was not observed in Mad2/2-deficient cells. Both Dppa3 heterogeneity and absence of expression in Mad2/2-deficient cells was rescued by Mad2/2-GFP expression. A global reduction of silencing chromatin marks was not enough for the rescue of Dppa3 in the mutant cells.

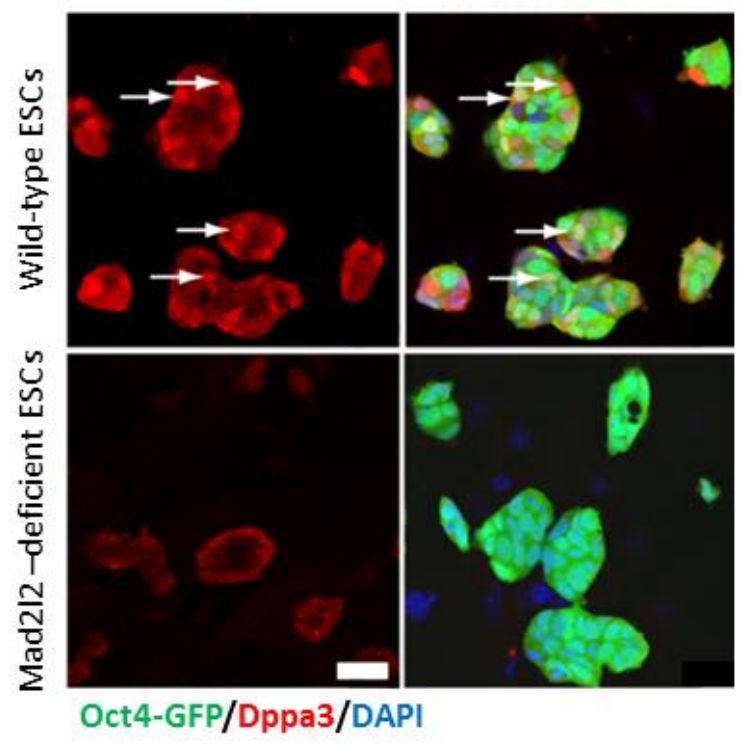

Figure 30: Heterogeneous expression of Dppa3 (white arrows) is not observed in Mad2/2 knockout colonies. Bar $=200 \mu \mathrm{m}$. 
a
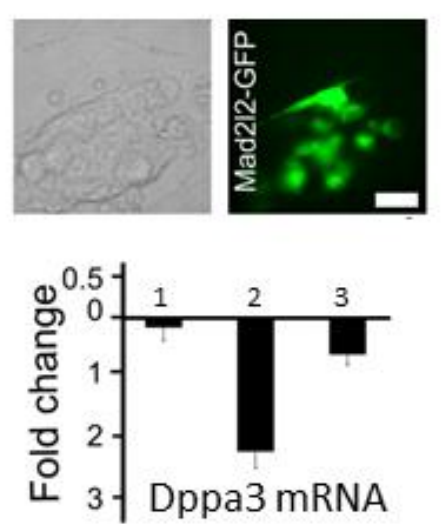

b
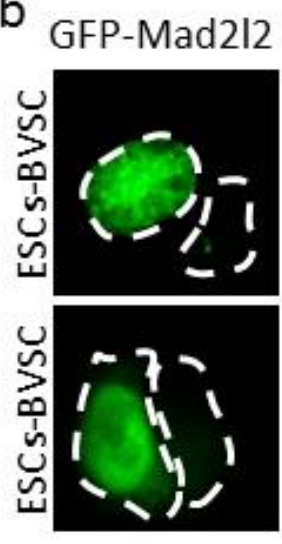

Merged (PI)
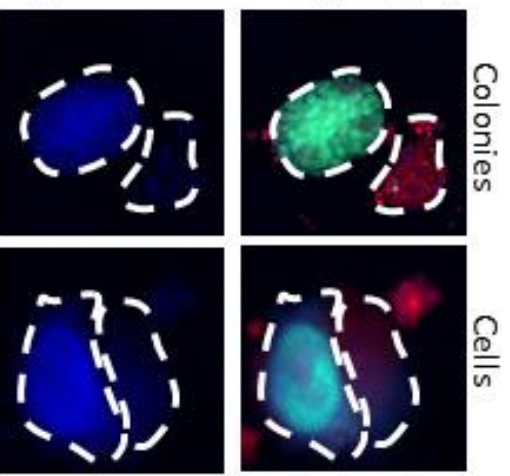

Figure 31: Requirement of Mad2/2 for the expression of Dppa3.

a) Expression of Dppa3 mRNA before and after Mad2/2-deficient ESCs transfection by Mad2I2-GFP. Green cells show transfected cells in a ESCs colony. 1 wild-type ESCs, 2 Mad2/2deficient ESCs, 3 transfected Mad2/2-deficient ESCs. Note that Mad2I2-GFP overexpression in knockout ESCs returned Dppa3 expression to a normal level. b) Mad2/2-GFP overexpression in ESCs with Dppa3-eCFP. Green cells show transfected cells and blue color represents Dppa3 expression. Bar $=25 \mu \mathrm{m}$ in $\mathrm{a}, \mathrm{Bar}=50 \mu \mathrm{m}$ in $\mathrm{b}$ and $\mathrm{Bar}=5 \mu \mathrm{m}$ in $\mathrm{d}$.

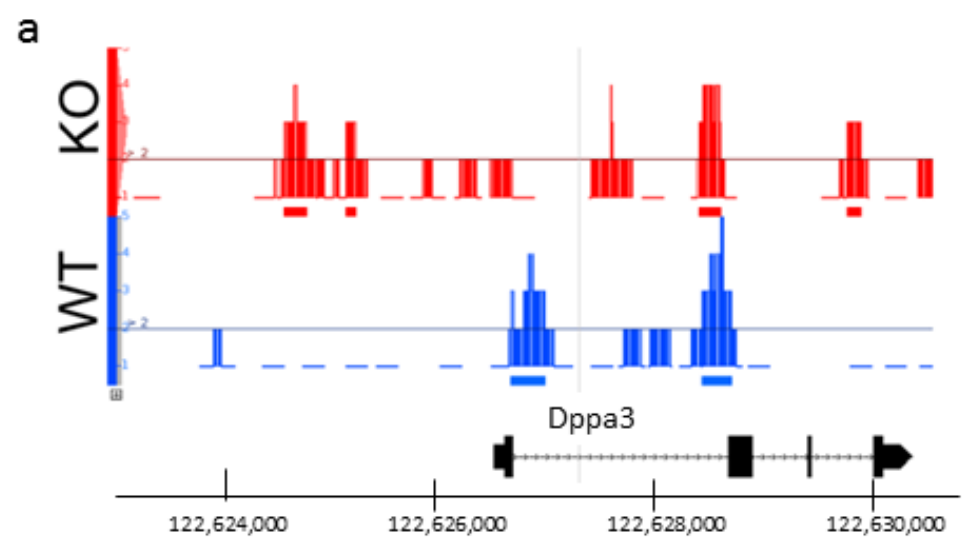

b

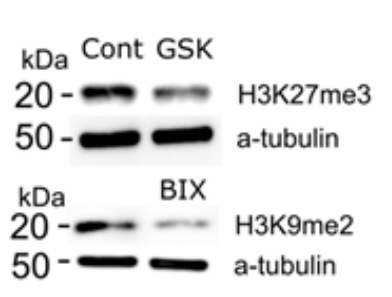

C

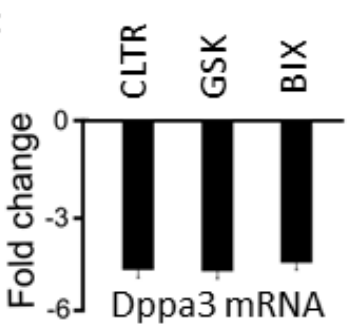

Figure 32: Increase of silencing chromatin marker on the promoter of dppa3. 
a) Significant increase of H3K9me2 on Dppa3 gene promoter. b) Ezh2 inhibitor (GSK) and Ehmt2 inhibitor (BIX) reduced H3K27me3 or H3K9me2, respectively, in Mad2I2-deficient ESCs. c) Global reduction of H3K27me3 and H3K9me2 did not rescue Dppa3 expression.

\subsubsection{Increase of DNA methylation in Mad2/2-deficient ESCs}

A low level of DNA methylation is a key feature of naive pluripotency (Singer et al., 2014). The global levels of 5-methylcytosine were measured by dot blot in DNAs from LIF2i/serum grown ESCs. DNA methylation was considerably more abundant in Mad212\% ESCs, although it did not reach the level of EpiLCs (Figure 33a). Cytosine methyl groups are known to be oxidized by Tet1, 2 and 3 enzymes. In LIF/2i and LIF/Serum, Tet1 was significantly downregulated in Mad2/2-deficient cells while Tet2 and Tet3 downregulation was limited to cells from LIF/Serum medium (Figure 33b).

To investigate DNA methylation at a single nucleotide resolution MeDIPsequencing was used. BAM correlation analysis confirmed a significant difference between wild-type and knockout ESCs, and biological replicates separated clearly based on the genetic backgrounds (Figure 34). DNA methylation mostly occurs in CpG islands, which can be very small or very large. Analysis of the MeDIP data revealed that the differences between DNAs from wild-type and mutant cells were mostly insignificant, with the possible exception of single methylation events per CPG Island, which were slightly higher in Mad2/2-- cells. GC\% analysis showed that a higher percentage of single CG sequences as methylated in Mad2/2-deficient cells (data not shown). To study the impact of DNA methylation on gene expression, the RNA-seq dataset was compared with the MeDIP-seq data. 221 genes, including Zfp42, were methylated in wild-type ESCs, and were unmethylated and upregulated in the Mad2/2-deficient ESCs. On the other hand 194 genes, including the pluripotency related markers KLF4 and Dppa2, were methylated and significantly downregulated in knockout ESCs. Noteworthy, these data also show that the overwhelming majority of DNA methylations in Mad2/2-deficient ESCs were not reflected in changes of gene expression. 
a

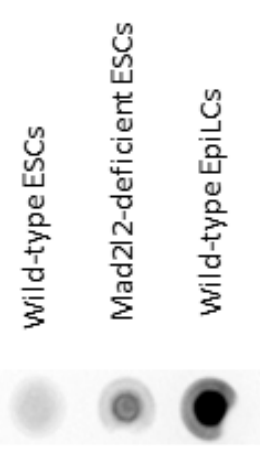

b

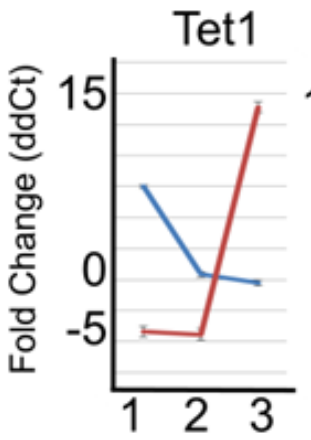

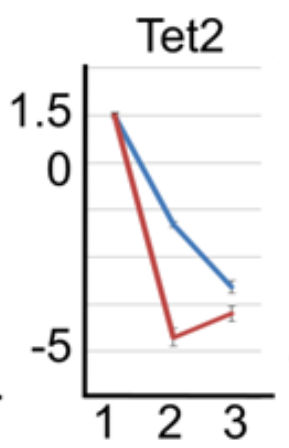

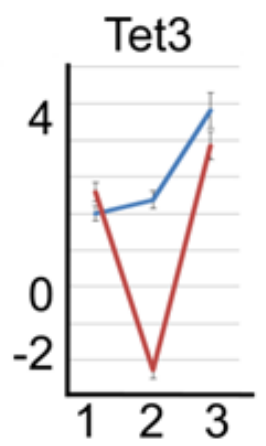

Figure 33: Increase of global DNA methylation in the absence of Mad2/2 in the ESCs.

a) $5 \mathrm{mC}$ increased in the absence of Mad2/2. 5-methylcytosine levels in wild-type ESCs, mutant ESCs, and wild-type EpiLCs were detected by southern blot. b) Expression of TET enzymes in LIF/2i ESCS (1), LIF/Serum ESCs (2) and activin/bFGF grown ESCs (3). Red line: Maad212 ${ }^{-/}$, Blue line: Mad212 ${ }^{+/+}$.

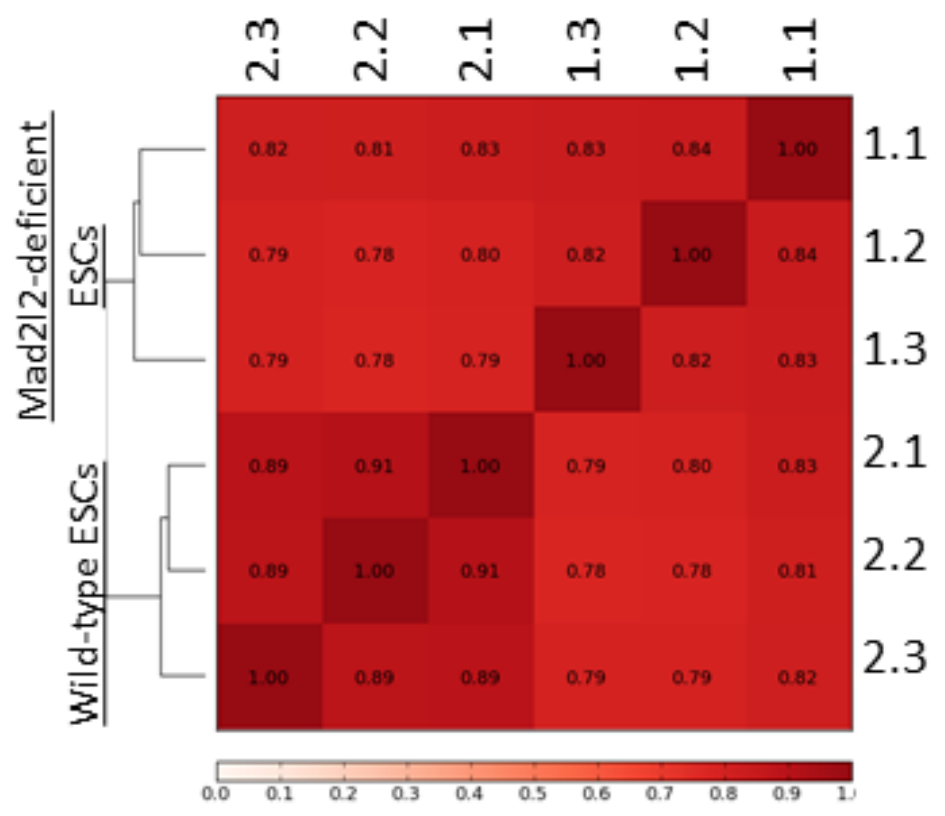

Figure 34: BAM correlation analysis by Bed tools.

Note that wild-type and mutant ESCs from three experimental repeats constitute separate groups.

Cytosine methylation is an important mechanism for the regulation of imprinted genes. A comparison between the expression of imprinted genes in knockout cells and methylated regions revealed that the top five upregulated imprinted genes (Peg3, Trp73, Ampd3, Mest, Nnan) were methylated in normal cells, and lost their 
methyl group in the absence of Mad2I2 (Figure 35). Such a strong correlation was not found between downregulated genes and an increase of DNA methylation in the knockout ESCs. Taken together, DNA methylation was increased globally in Mad2/2deficient ESCs, with a prominent effect on the upregulation of imprinted genes.

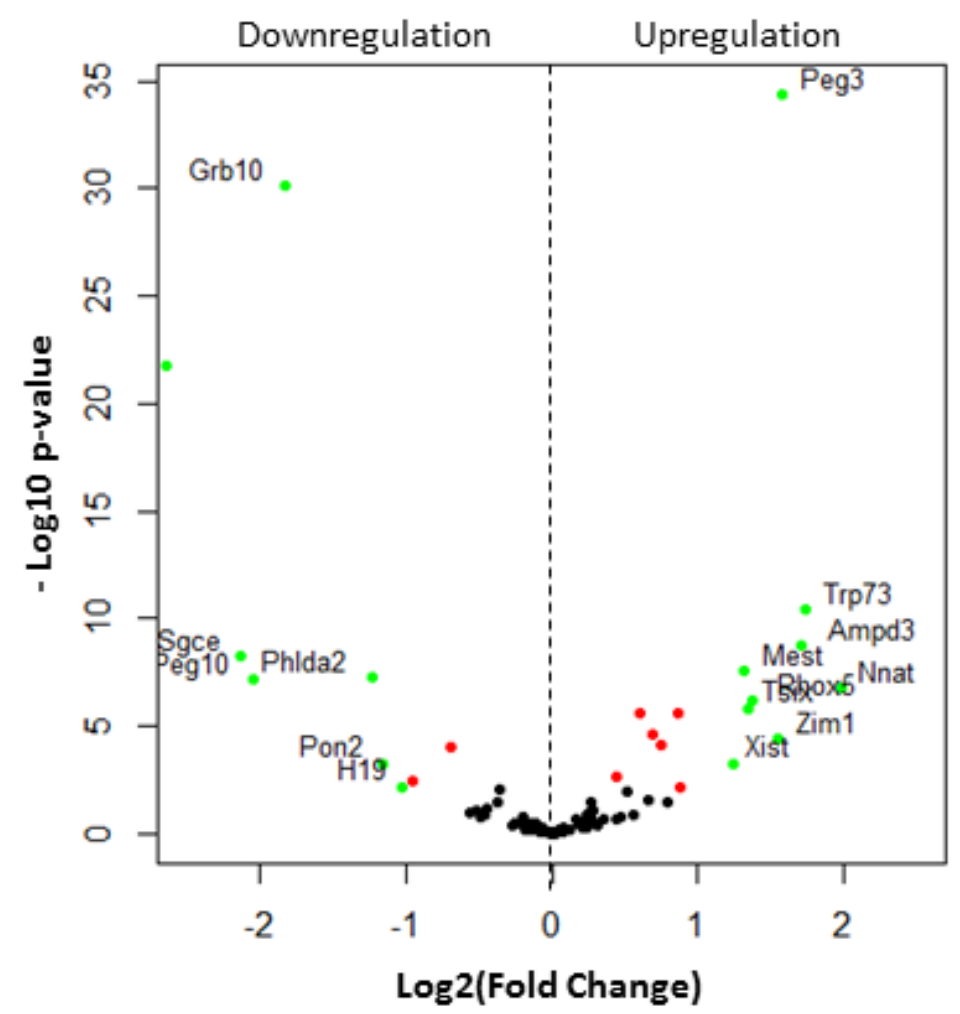

Figure 35: Expression of imprinted genes was affected by loss of DNA methylation in Mad2/2-deficient ESCs.

Volcano plot showed expression of imprinted genes in Mad2/2-deficient ESCs in comparison with ESCs. Red and green dots refer to statistically significant up- and downregulated genes, respectively. Green dots show 2 fold change cutoff.

Sequencing data were annotated by GREAT database, and the result exhibited a significant increase of regions occupied by DNA methylation. In wild-type ESCs 179 regions, which are not associated with any genes, were methylated and this number was increased to 358 in Mad2/2-deficient cells. Increase of methylated regions was also observed in genomic region associated with at least on gene region from 7163 to 8862 . However the distance between methylated areas and TSS did not change (Figure 36). 


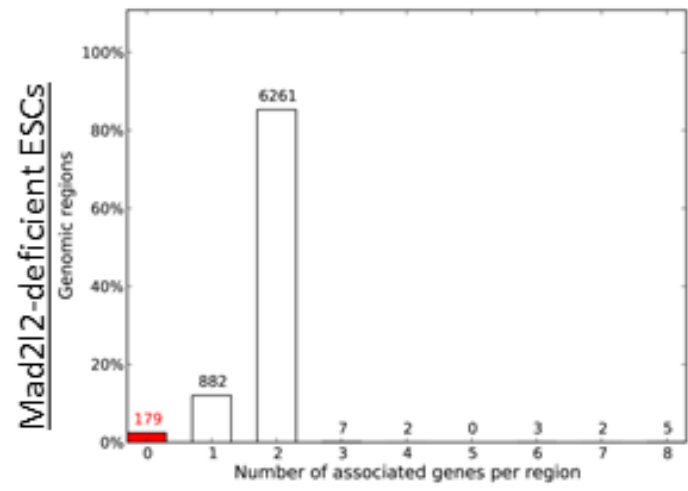

$\square$ Genomic regions associated with one or more genes Cenomic regions not assoxiated with any genes

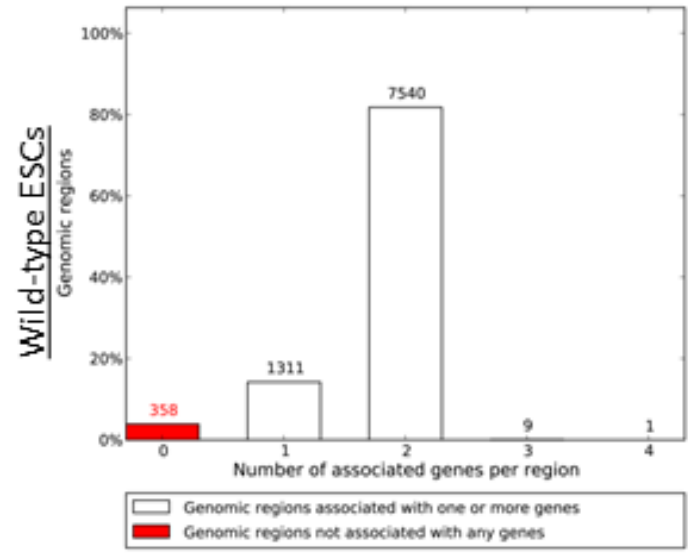

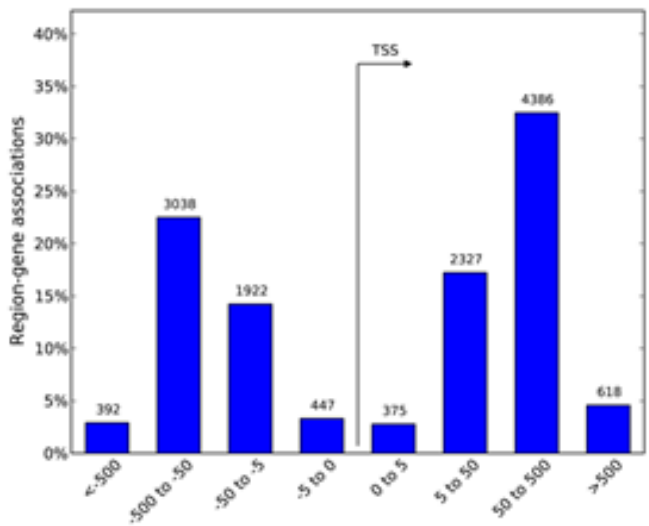

Distance to TSS $(\mathrm{kb})$

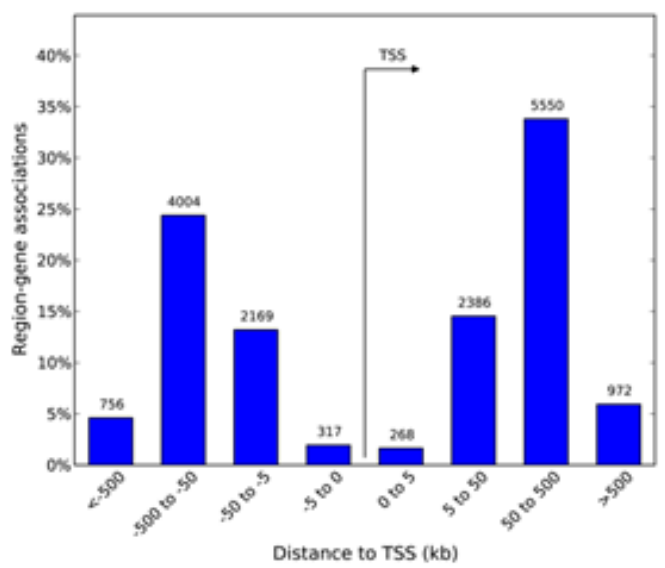

Figure 36: DNA methylation was increased in both gene-associated and non-associated genomic area in Mad2/2-deficient cells.

a) Column chart shows correlation between methyl occupied regions. b) Column chart shows average of DNA methylation distance to transcription start site (TSS).

\subsection{Mechanistic aspects of Mad2/2 function}

\subsubsection{Absence of Mad2/2 from meiotic testicular cells}

Like ESCs, also testes cells express very high levels of Mad2I2 RNA (Pirouz et al., 2013). Cryosections of seminiferous tubes cells were analyzed for the localization of Mad2/2 protein in the various cell types generated during spermatogenesis, which were identified by morphology and localization (Russell et al. 1990). High levels of Mad212 protein were detected in the triangular spermatogonial stem cells (cell number \#1) in the periphery of seminiferous tubules and in spermatids (cell numbers $\# 4, \# 5, \# 6 ;$ Figure 37a). Levels of Mad212 were strongly reduced in primary and secondary spermatocytes, which undergo the first and the second meiotic division (cell numbers \#2,\#3; Figure 37a). Spermatocytes expressed high levels of $\mathrm{\gamma H} 2 \mathrm{Ax}$ foci 
(Figure 37c, d), which is an indication for ongoing homologous recombination (Pacheco et al., 2015; Xu et al., 2015a). This observation is in agreement with published findings suggesting an interference of Mad2l2 with homologous recombination (Pacheco et al., 2015; Xu et al., 2015a).

a

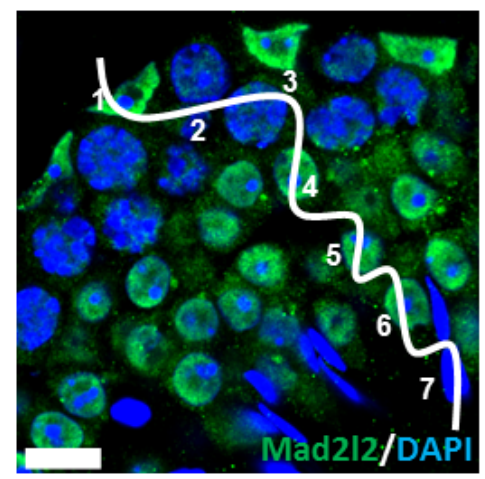

C

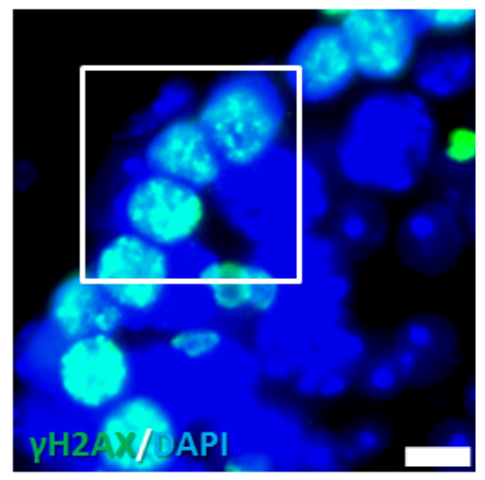

b

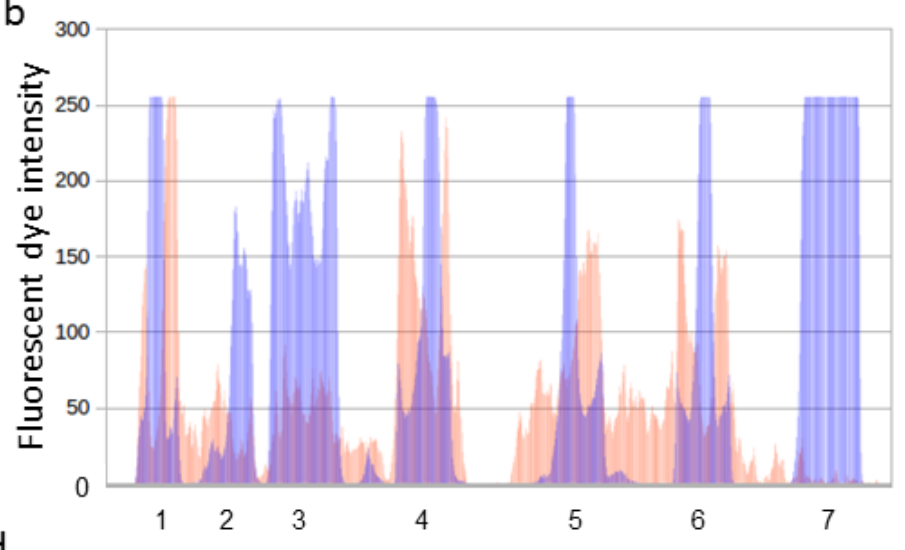

d

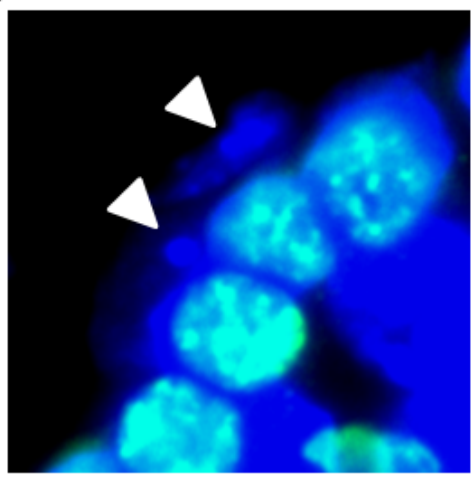

Figure 37: Mad2/2 protein during spermatogenesis.

a) A section of a seminiferous tubule shows high levels of Mad2/2 protein in spermatogonial stem cells (1) and spermatids $(4,5,6)$, but not in spermatocytes (2, 3), and sperm (7). b) Histogram of Mad2/2 and DAPI channels. Note the decrease of Mad2/2 expression in primary and secondary spermatocytes. c) and d) $\mathrm{pH} 2 \mathrm{AX}$ foci in nuclei of spermatocytes, but not of spermatogonial stem cells (arrowheads). Bar $=10 \mu \mathrm{m}$.

\subsubsection{Mad2/2 interacts with DDR factors directly}

To study Mad2/2 interaction partners, the chromatin fraction was isolated from both wild-type and Mad2/2 knockout ESCs. Mad2/2 binding proteins were immuneprecipitated and analyzed by mass spectrometry. Proteins also found in extracts from mutant cells were considered as false positives. Thus, 19 proteins were identified by label-free quantification as genuine Mad2/2 interaction partners. These 
included four factors related to the DDR (MDC1, Histone H1, DNL3 and RuvB), one replication factor (MCM5), one chromatin remodeling factor (WD40) and DNA methyltransferase (Dnmt1; Figure 38). The strong association between Mad2/2 and ATM cascade factors supported the hypothesis that Mad2/2 functions in normal ESCs in correlation with this cascade.

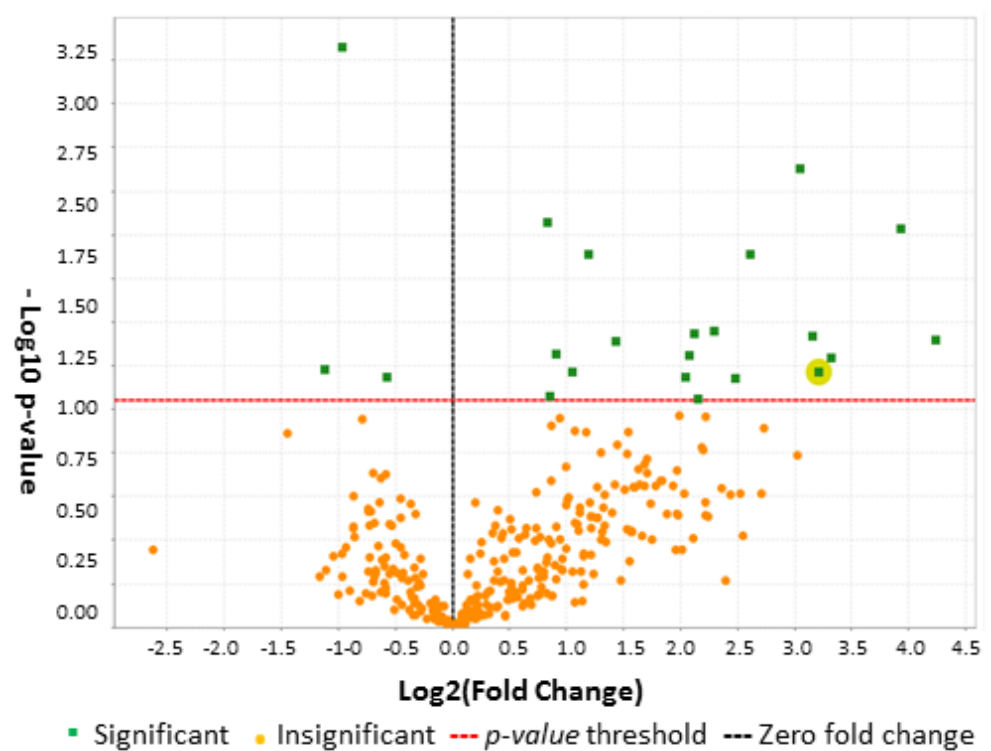

Figure 38: Mad2/2 interaction partners.

Green squares represent significantly enriched proteins, orange spheres show insignificant interactions. Minimum change cut off is $0.5(\log 2)$.

\subsubsection{Inhibition of histone or DNA modifications by small inhibitors in}

\section{Mad212-deficient ESCs}

Among the most significant responses to Mad212-deficiency in ESCs were the upregulation of Zfp42 and the downregulation of Dppa3 expression (3.3.4). In order to understand these effects better, rescue attempts were performed by applying small molecule inhibitors to Mad2/2-deficient ESCs. Specifically, the histone acetylase inhibitors TSA and SAHA, the histone 3 methylation inhibitors GSE and BIX, and the DNA methylation inhibitor 5-azacitidine were studied, with the pluripotency markers Oct4, Nanog and Sox2 as control read outs. Preliminary experiments demonstrated that protein levels of $\mathrm{\gamma H} 2 \mathrm{AX}$ and $\mathrm{AcH} 4$ were increased as expected after $8 \mathrm{~h}$ exposures to TSA or SAHA (Figure 39a, b), and histone 3 methylations were 
reduced as expected after inhibition of the catalyzing enzymes Ehmt2/Ehmt1 or Ezh2 (Figure 39c).

Expression of pluripotency markers was not affected significantly by any of the five inhibitors, with the exception of Sox 2 expression, which was reduced by TSA, but not in SAHA group (Figure 40). The expression of Dppa3, which is normally downregulated in Mad212-deficient ESCs was not rescued or affected by any inhibitor. However, significant was a decrease of the normally high Zfp42 level caused by TSA or SAHA treatment of $\mathrm{Mad}_{2} \mathrm{I}^{-/-}$cells (Figure 40). Together, the experiments indicated that the striking downregulation of Dppa3 in the absence of Mad2l2 is not a simple consequence of histone acetylation, histone methylation or DNA methylation. However, the significant effect of the deacetylation inhibitors on the $\mathrm{Zfp} 42$ gene may point to a histone deacetylation activity relevant for the $\mathrm{Zfp} 42$ locus in the presence of Mad212.

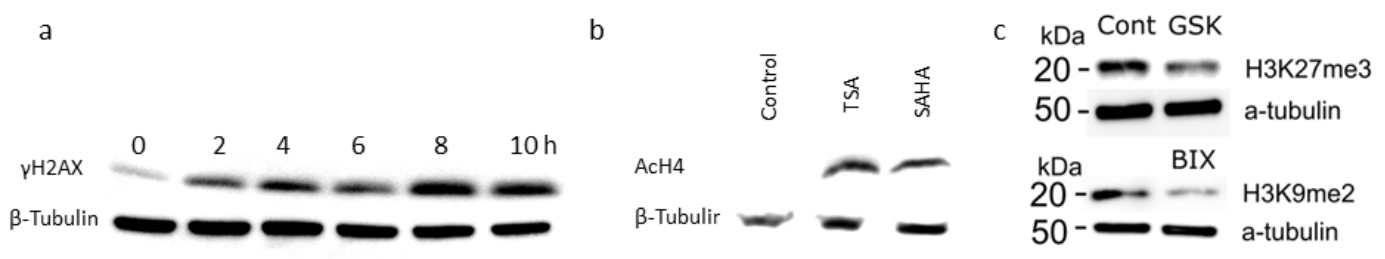

Figure 39: Control experiments in Mad212-deficient ESCs.

a) $\mathrm{YH} 2 \mathrm{~A}$ was increased after SAHA treatment and maximum level was observed after 8 hours treatment. b) $\mathrm{AcH} 4$ was increased eight hours after SAHA and TSA treatment of Mad2/2 knockout ESCs. c) Decrease of H3K9me2 and H3K27me3 confirmed inhibition of Ehmt2 and Ezh2, 24 hours after BIX or GSE treatment, respectively. 


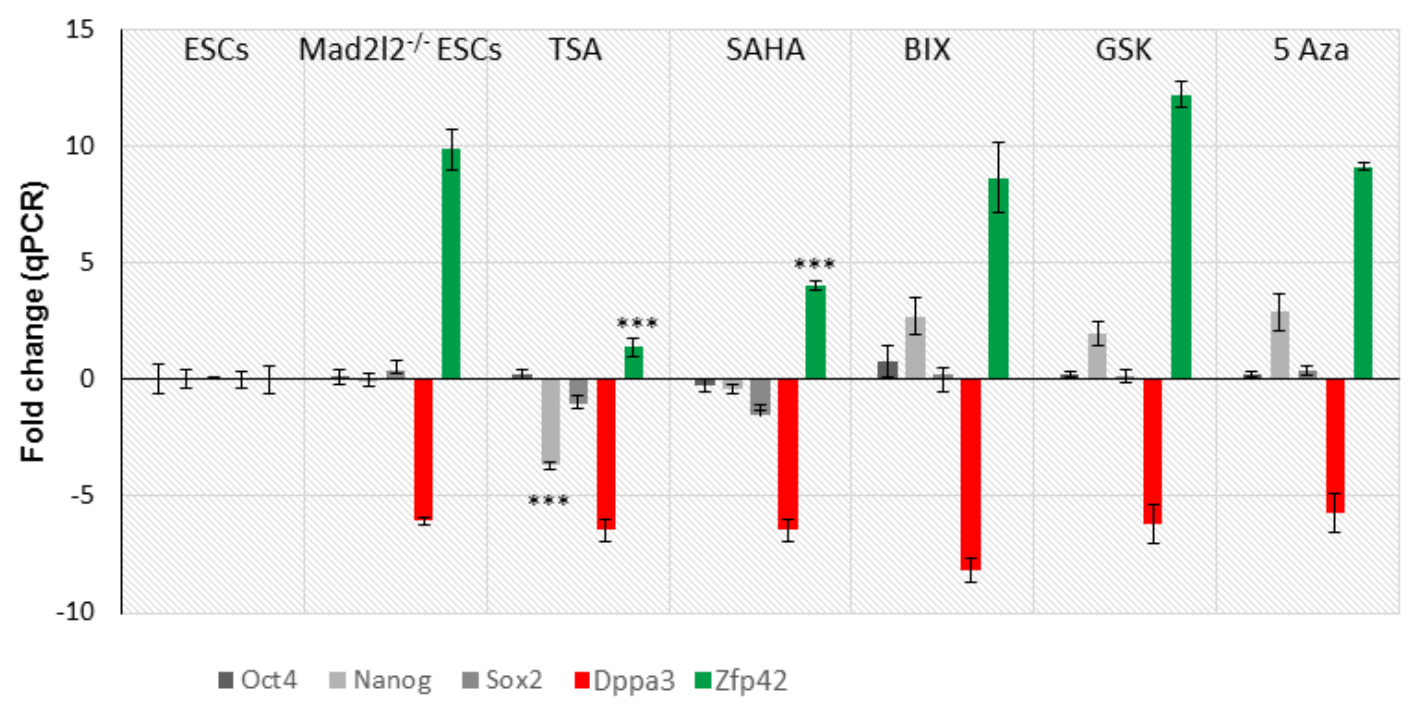

Figure 40: Significant response of $\mathrm{Zfp} 42$ expression to inhibition of histone deacetylation.

Change of Oct4, Nanog, Sox2, Dppa3 and Zfp42 expression in wild-type and Mad212deficient ESCs exposed to epigenetic inhibitors. TSA = trichostatin A, SAHA, BIX 0129, GSK126, 5-azacytidine. Note that TSA and SAHA treated cells expressed significantly lower amounts of Zfp42 (pvalue $\leq 0.001$ ).

\subsubsection{ATM cascade in the maintenance of pluripotency}

DNA damage normally triggers a complex cascade of factors, which finally allows the repair of DNA, and the continuation of the cell division cycle (Goldstein and Kastan, 2015). In the following this pathway is designated the "ATM cascade", even if ATM can often be replaced by ATR or DNA-PK (Ozeri-Galai et al., 2008). ESCs which clearly have no indication for DNA damage contain significant levels of ATM cascade proteins, in particular $\mathrm{yH} 2 \mathrm{AX}, \mathrm{RNF168}, 53 \mathrm{BP} 1$ and Mad2I2 (Figure 41a,b,c,d). $\mathrm{HH} 2 \mathrm{AX}$ foci were observed in both hetero- and euchromatin (Figure 41e), whereas the other three proteins were restricted to euchromatin (Figure 41f-h). 

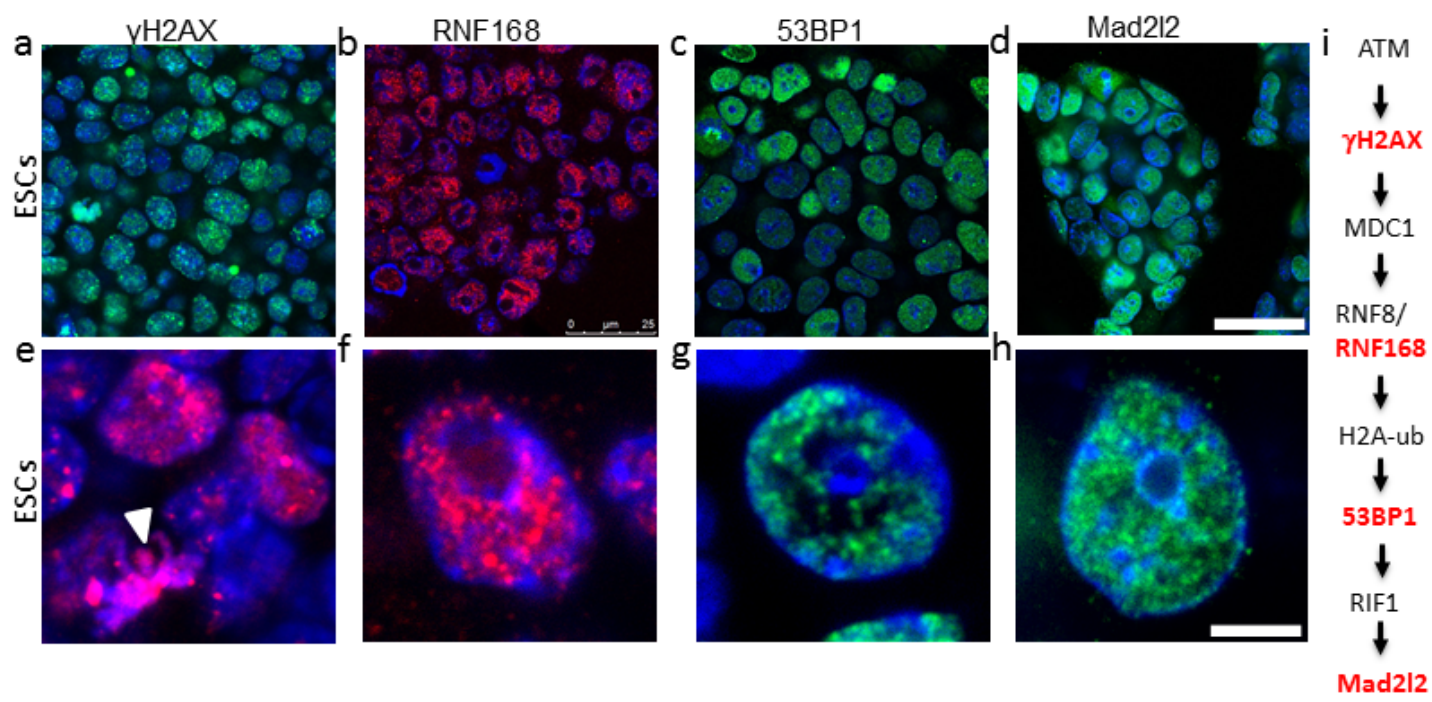

Figure 41: High expression levels of ATM cascade factors.

a-d) High levels of $\mathrm{yH} 2 \mathrm{AX}, \mathrm{RNF168}, 53 \mathrm{BP} 1$ and Mad2I2 in ESCs in the absence of DNA damage. e) $\mathrm{\gamma H} 2 \mathrm{AX}$ is localized in both eu- and heterochromatin. Arrow head shows mitotic

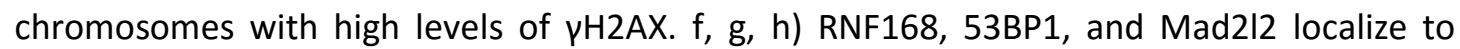
euchromatin in ESCs. Bar=25 $\mu \mathrm{m}$ in a,b,c,d. Bar=5 $\mu \mathrm{m}$ in e, f, g, h. i) ATM cascade, factors identified in ESCs are in red.

Western blot analysis confirmed the presence of active, i.e. phosphorylated, 53BP1 in ESCs (Figure 42). Levels of 53BP1 and Nanog were decreased if any of the three upstream kinases (ATM, ATR, DNA-PK) was inhibited by specific, small molecule inhibitors (Figure 42a), indicating their downstream position in the cascade. On the other hand, applying the kinase inhibitors to Mad2/2-deficient ESCs did not change the results for $\mathrm{YH} 2 \mathrm{AX}, 53 \mathrm{BP} 1$, or Nanog strongly, confirming the downstream position of Mad2/2 in the cascade.
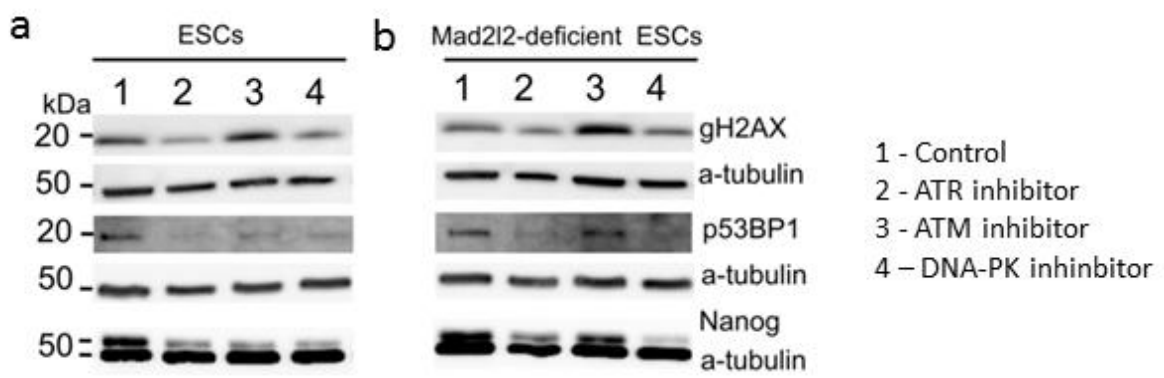

Figure 42: Probing the ATM cascade in ESCs with kinase inhibitors

Analysis of a) wild-type ESCs and b) Mad2/2-deficient ESCs exposed to kinase inhibitors. 
Since downregulation of Dppa3 was one of the key phenotypes of Mad2/2deficient ESCs (3.3.4), its expression was measured by qRT-PCR in ATM-deficient, DNA-PK-deficient and H2AX-deficient ESCs. All of these cell lines had decreased levels of Dppa3, most significantly the DNA-PK- and the H2AX-deficient cells (Figure 43a). Mad2/2 expression was reduced only in H2AX-deficient ESCs (Figure 43a), suggesting its position downstream in the ATM cascade (Figure 43b). In conclusion, the analysis confirms the activity of the ATM cascade in normal ESCs, and its importance for maintenance of pluripotency.

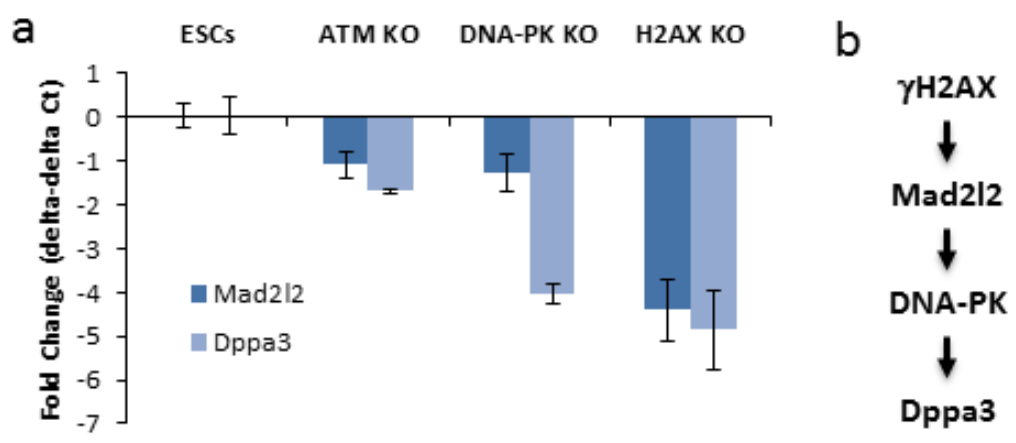

Figure 43: Downregulation of Dppa3 in DNA-PK and H2AX deficient ESCs.

a) Clustered column chart shows change of mRNA levels for Mad2I2 and Dppa3 in wild-type and mutant ESCs. b) Deletion of h2AX reduced expression of both mad2/2 and dppa3. Mad2/2-deletion reduced dppa3 expression and DNA-PK deletion just reduced dppa3 expression, without any significant effect on mad2/2 expression.

\subsubsection{Colocalization of 53BP1 and H3K27me3 in the ESCs nucleus}

53BP1 promotes open chromatin formation by several mechanisms in response to DSB (Zimmermann and de Lange, 2014). High amounts of activated 53BP1 were detected in ESCs both in absence and presence of Mad2I2 (Figure 44a). The correlation between 53BP1 and the open chromatin status was investigated by double immunofluorescence staining for 53BP1 and H3K27me3. Both markers were expressed heterogeneously in wild-type ESCs with mutually exclusive expression patterns (Figure 44 a). Cells highly positive for 53BP1, for H3K27me3, and for both markers were counted separately applying imageJ software. This analysis revealed 
that the majority of cells were highly positive for just one marker, while only around 7 percent were double positives (Figure 44c). It suggests a downstream position of Mad2I 2 in the ATM cascade and confirms a role for Mad2I 2 in open chromatin formation (Figure 44d).

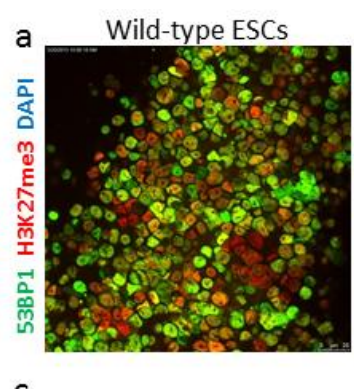

C

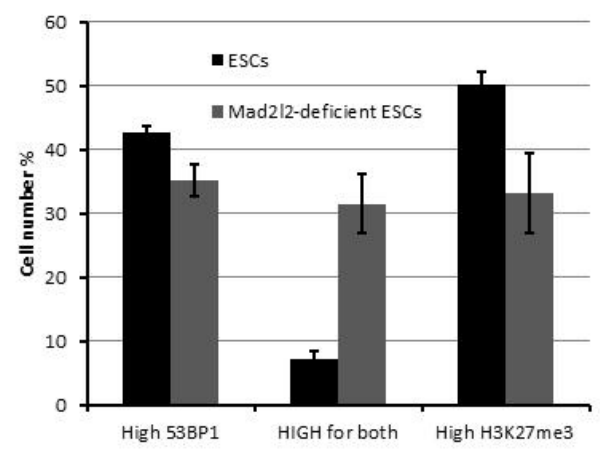

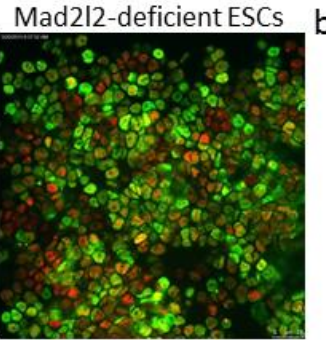

d

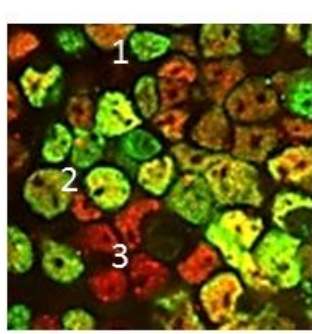

Mad2/2-deficient

ESCs

53BP1

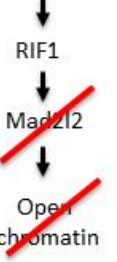

Figure 44: The number of double 53BP1 and H3K27me3 positive cells increases in the absence of Mad2/2. a) Immunofluorescence staining against 53BP1 (green) and H3K27me3 (red). Bar $=50 \mu \mathrm{m}$.

b) Three types of cells were identified: only 53BP1 positive green (1), double positive yellow (2), only H3K27 positive red (3). c) Quantification of immunofluorescen data in panel a. d) ATM cascade in the absence of mad2I2

To identify if the negative correlation is Mad2/2 dependent, the same experiment was repeated for Mad212-deficient ESCs. The number of double positive Mad212deficient ESCs was considerably increased to approximately 32 percent (Figure 45c). Taken together, these data suggest that Mad212 functions in the separation of open (53BP1) and closed (H3K27me3) chromatin in ESCs (Figure 45d). 


\section{Discussion}

\subsection{Failure of germ cell differentiation in the absence of Mad2/2}

Hayashi et al. developed and characterized precisely a protocol for the differentiation of ESCs into PGCLCs, which mimics closely the in vivo development of PGCs, as evident in transcription profiles, epigenetic reprogramming and cell cycle dynamics (Hayashi et al., 2011). This protocol was used to induce the differentiation of previously established Mad2/2-deficient ESCs (Pirouz et al., 2015). In the first step, highly similar EpiLCs were obtained from mutant and wild-type ESCs (Figure 9). This finding is in agreement with the formation of functional epiblast and viable animals from Mad2/2 null zygotes (Pirouz et al., 2013). Next, the potential of PGCLC induction by BMP4 from Mad212-deficient EpiLCs was examined. The initial phase of induction occurred similarly, as confirmed by the expression of Oct4, Nanog, Sox2 and SSEA1. However, the number of GFP-positive cell islands within the aggregates of mutant cells gradually decreased, and the typical late germ cell markers TFAP2C and Dppa3 were not activated (Hayashi et al., 2011; Seki et al., 2007). Finally, the presence of cells was limited to small, incoherent areas close to the center of aggregates. Noteworthy, TFAP2C overexpression in combination with Prdm14 promotes PGCLC differentiation, and TFAP2C knockout mice are infertile due to loss of PGCs shortly after their specification at E8.5, similar to Mad212-deficient mice (Magnusdottir et al., 2013; Nakaki et al., 2013; Pirouz et al., 2013; Weber et al., 2010). TFAP2C regulates Dppa3 expression directly, and therefore, the absence of TFAP2C might explain the downregulation of Dppa3 in Mad212-deficient cells [5]. Dppa3 regulates the demethylation of retrotransposons in primordial germ cells which occupy $39 \%$ of the mice genome (Estecio et al., 2010). Therefore, the role of Dppa3 as an epigenetic regulator may have a significant impact on the global level of DNA demethylation which is a key event during PGC development (Seki et al., 2007). Mad2/2-deficient GFP-positive cells failed to switch from a stably repressive H3K9me2 dominated chromatin to a more flexible, still repressive chromatin dominated by H3K27me3 (Figure 15). These epigenetic abnormalities may finally promote apoptosis, as was observed for Mad2/2-deficient cells in Hayashi cultures (Figure 12). However, a small population survived even eight days after BMP4 
treatment. Also in vivo there is evidence for a possible survival of a small number of mutant PGCs, as suggested by the rare observation of female gonadal tissues in mutant embryos (Pirouz et al., 2013). Altogether, this suggests that Mad2l2-deficient cells initiate PGCLC differentiation, but do not complete their development. This conclusion would closely fit to the in vivo observations.

\subsection{Prolongation of the cell cycle and spontaneous differentiation of Mad2/2-deficient ESCs}

Mad2/2 deficient cells show a prolonged cell cycle time that is not in the favor of a particular cell cycle phase, and therefore could not be explained by previously described interactions of Mad2I2 with APC, Cdc20 or Cdk1 (Pfleger et al., 2001; Pirouz et al., 2013). There was no distortion of the phases relative to each other (Figure 27b). Cell cycle length might correlate with the maintenance of pluripotency by at least by two possible mechanisms. First, the fate of ESCs becomes restricted into different lineages in preferred phases of the cell cycle (Calder et al., 2013). Thus, if in absolute terms cells spend a longer time in this phase, the likelihood for differentiation is increased. Secondly, ESCs have an ATM activity peak during the G2 phase, which enhances Nanog expression (Gonzales et al., 2015). If the doubling time is increased, the ATM induced Nanog expression would occur not as often as in wild-type ESCs. Less Nanog expression would generate less stable pluripotency, which is the observed phenotype of Mad2/2-deficient ESCS grown in LIF/Serum (Pirouz et al., 2013).

\subsection{A function of Mad2/2 role in heterochromatin replication}

CHK2 activation normally occurs in the S/G2 phase in response to DNA damage, when phosphorylated Chk2 becomes recruited to the damage site next to PCNA. The pattern of nuclear pCHK2 accumulation differed significantly between wild-type and knockout MEFs. Only in the mutant MEFs pChk2 localized around the nucleolus and nuclear lamina, mimicking the accumulation of PCNA and heterochromatic DNA in the mid to late S-phase of the cell cycle (Essers et al., 2005). It is conceivable that in the absence of Mad2l2 cells is not able to pass through DNA lesions and thus 
unreplicated DNA remains until the end of $S$ phase, accompanied by pCHK2 accumulation. However, since DNA damage induced by cisplatin occurs randomly in both hetero- and euchromatin, a random distribution including the nucleolus would be expected. A second interpretation would suggest a DNA damage-independent role of Mad2I2 in the replication of heterochromatin. The time of heterochromatin replication is regulated by the Rif1 protein, which is an upstream regulator of Mad2I2 (Boersma et al., 2015; Yamazaki et al., 2012). Rif1-recruited Mad2I2 might function to open heterochromatin not only during double strand break repair, but also during late replication. Thus, Mad2/2 would exert its function as an epigenetic regulator, providing access for the replication machinery in heterochromatin.

\subsection{Accumulation of damaged DNA in Mad2/2-deficient MEFs, but not ESCs}

In MEFs Mad2/2-deficiency promotes an accumulation of spontaneous or induced DNA damages, consequently the activation of $\mathrm{CHK} 2$, and an arrest of the cell cycle, followed by DNA repair (Figure 20,21). Depending on the type and frequency of damage events the repair can be more or less error prone. In ESCs the situation is different. These cells have a wide spectrum of developmental possibilities, including participation in the germ line. Here, a non-perfect repair of DNA damages could have dramatic consequences, and therefore the normal outcome is elimination via apoptosis. Neither wild-type nor Mad212-deficient ESCs accumulate damaged DNA and consequently no recruitment of activated CHK2 was observed. Although the level of Mad2/2 is high, no evidence for an active translesion or DSB repair by DNA Pol zeta subunits Rev3 and Rev7 (=Mad2/2) was observed, in particular no cell cycle arrest and no increase of $\mathrm{\gamma H} 2 \mathrm{AX}$ foci (Figure 28b).

\subsection{No naive pluripotency in the absence of Mad2/2}

Metastable ESCs fluctuate between the naive and the primed state, as evident by variable levels of methylated DNA, pluripotency related factors and early lineage commitment markers (Tajbakhsh et al., 2015). Independent from culture conditions (LIF/2i or LIF/serum) Mad2I2-deficient ESCs are never bona fide naive 
ESCs. They do not express the naive ESC marker Dppa3, which is essential for generating high quality induced pluripotent stem cells, and also relevant for the quality of ESCs. This phenotype cannot be rescued by an inhibition of histone deacetylase, and is independent of DNA methylation (Figure 33a) and histone modifications (H3K9me2 and H3K27me3). The fluctuation of Dppa3 expression corresponds to the observed heterogeneity of Mad2/2 expression. Loss of Dppa3 expression could be rescued by Mad2/2 (3.3.5). zfp42 (Rex1) is another misregulated gene in Mad2/2-deficient ESCs. This protein is important for triggering visceral endoderm differentiation of ESCs (Masui et al., 2008). In Mad2/2-deficient ESCs the level of Zfp42 is significantly elevated as compared to wild-type cells, in LIF/serum medium even higher than in LIF/2i medium. This finding corresponds to the spontaneous differentiation into visceral endoderm observed for Mad212-deficient ESCs (Pirouz et al., 2013). The Zfp42 expression level could be reduced to wild-type levels by inhibition of histone deacetylase, suggesting that the increase of Zfp42 is an indirect effect of the Mad2/2 knockout (Figure 40).

The epigenetics of Mad212-deficient ESCs are not typical for pluripotency. Global reduction of DNA methylation is one of the major characteristics of a naive ESC epigenome (Figure 33). Mad2/2-deficient ESCs, however, do not reduce DNA methylation to the level of wild-type cells, an effect possibly related to the loss of Dppa3 expression. Dppa3 protein is an H3K9me2 binder and has dual effects on DNA methylation (Nakamura et al., 2012). It promotes general demethylation by competing with Uhrf1, and protects maternally imprinted genes by interaction with H3K9me2 and inhibition of Tet3 (Bian and Yu, 2014). In addition there are several reports about a direct interaction of Mad2/2 with Dnmt1 (Hein et al., 2015; Vermeulen et al., 2010), which was confirmed by co-precipitation and mass spectrometry (Figure 39).

\subsection{Promotion of open chromatin versus suppression of heterochromatin by Mad2/2}

Both LIF/2i and LIF/Serum ESCs have a generally open chromatin (Meshorer and Misteli, 2006). Mad2/2 is typically localized in nuclei in association with eu-, but 
not heterochromatin. Within an ESC colony levels of the Mad2I 2 protein fluctuate, similar to the described stochastic expression of some early lineage specification markers (Gata4, Gata6 and Sox17) or some pluripotency related factors (Nanog, Dppa3; 3.3.1). Since the highly negatively charged Mad2/2 protein does not contain a DNA binding domain it is not associated with specific genomic loci. However, all HORMA domain proteins including apparently Mad2/2 are able to sense chromatin states (Fattah et al., 2014; Rosenberg and Corbett, 2015). The euchromatic localization of Mad2/2, the increase of heterochromatin upon deletion and its interaction with heterochromatin factors like POGZ, CBX3, Dnmt1, and Ehmt1 suggests that Mad2l2 actively promotes euchromatin and suppresses heterochromatin.

Mad2I 2 could be recruited to euchromatin via PCNA, which provides a platform for the recruitment of factors involved in replication, epigenetic regulation and DNA repair. Such factors include DNA pol zeta (Rev3/Rev7), but noteworthy also Rev7 (= yeast homolog of Mad2I2) alone (Fattah et al., 2014). A major constituent of heterochromatin is the methylated histone H3K9me2. Levels are globally low in both E3.5 ICM and in LIF/2i-cultured ESCs (Zylicz et al., 2015). With implantation heterochromatin markers increase significantly in the epiblast, and a similar increase occurs during the transition from naive to primed ESCs (Zylicz et al., 2015). Crucial methyltransferases for the formation of H3K9me2 are Ehmt2/Ehmt1, which would be a target for the suppression of heterochromatin. It was previously described that Ehmt2/Ehmt1 co-precipitate with Mad212, suggesting an anti-heterochromatin activity of Mad2/2 via direct, inhibitory interaction (Pirouz et al., 2013).

\subsection{Mad212: an epigenetic regulator in pluripotency and DNA damage}

The activation of ATM, ATR and/or DNA-PK kinases is typically observed immediately after the induction of DNA damage (Ciccia and Elledge, 2010). A major target of these kinases is the histone variant $\mathrm{H} 2 \mathrm{AX}$, which becomes phosphorylated into $\mathrm{yH} 2 \mathrm{AX}$. Both wild-type and Mad2/2-deficient ESCs have a high number of nuclear $\mathrm{yH} 2 \mathrm{AX}$ foci, which is necessary for the maintenance of pluripotency, as previously shown (Ahuja et al., 2016; Turinetto et al., 2012), and also exemplified in 
this study by the downregulated Nanog expression after kinase inhibition (Figure 42). $\mathrm{ATM} / \mathrm{\gamma H} 2 \mathrm{AX}$ triggers the recruitment of many important factors for DSB repair, such as the ATM, H2AX, MDC, RNF8, RNF168, 53BP1, and Rif1 (Zimmermann and de Lange, 2014). These proteins are also expressed at a high, constitutive level in the euchromatin ESCs, noteworthy in the absence of any evidence for DNA damage (Turinetto et al., 2012).

Thus, an ATM cascade is constitutively activated in ESCs, which among others induces various histone modifications, in particular the phosphorylation by ATR, ATM, or DNA-PK, or the ubiquitylation by E3 ligases RNF8 or RNF168. An important consequence of the cascade is the relaxation of chromatin, which occurs locally at damage sites, and globally in ESCs. The recruitment of 53BP1 promotes the formation of open chromatin. In the absence of 53BP1, accumulation of heterochromatin writers (Dnmt1, Suv39h1) and readers (CBX1, 3) next to the $\mathrm{yH} 2 \mathrm{AX}$ foci was reported (Ayrapetov et al., 2014; Broering et al., 2014; Ha et al., 2011). However, 53BP1 alone is not enough for the maintenance of an open chromatin status of ESCs, and Mad2/2 was described to function as a downstream effector (Boersma et al., 2015; Xu et al., 2015a). Suggested molecular mechanisms include the inhibition of histone methyltransferase Ehmt2, the blocking the cell cycle regulator Cdk1, which would otherwise block 53BP1 recruitment, or the binding of Dnmt1 (Figure 45; (Pirouz et al., 2013).

The expressions of both Mad2I2 and of its target gene Dppa3 are affected by the absence of $\mathrm{H} 2 \mathrm{AX}$ in ESCs, suggesting a function of $\mathrm{\gamma H} 2 \mathrm{AX}$ upstream of Mad2/2 and Dppa3 (Figure 43). However, DNA-PK deletion in ESCs reduced Dppa3 expression, without a significant effect on Mad2/2 expression. This finding is in agreement with the known hierarchy in NHEJ repair, and promotes the idea that Mad2I2 regulates Dppa3 expression via DNA-PK (Figure 43b). These molecular connections indicate, that the linear representation of the ATM cascade does not cover the whole complexity of the events in DNA damage and ESC chromatin regulation. Newly recruited factors regulate the processes by negative and positive feedback loops, so that the process cannot be represented adequately as a one directional pathway. The model in Figure 45 represents a more static view on the described molecular situation both for open and for compact chromatin. 
In conclusion, it occurs that in ESCs the major importance of DNA repair factors including Mad2I2, here discussed as the ATM cascade, lies in their epigenetic functions, namely to keep the ESC chromatin in a constitutively and globally open configuration. The described evidence supports a function of Mad2/2 as an epigenetic regulator in the context of other regulatory proteins, many of them known from the response to DNA damage. The function of Mad212 in DNA repair and in the maintenance of ESCs and PGCs may indeed represent different aspects of the same basic, epigenetic function.

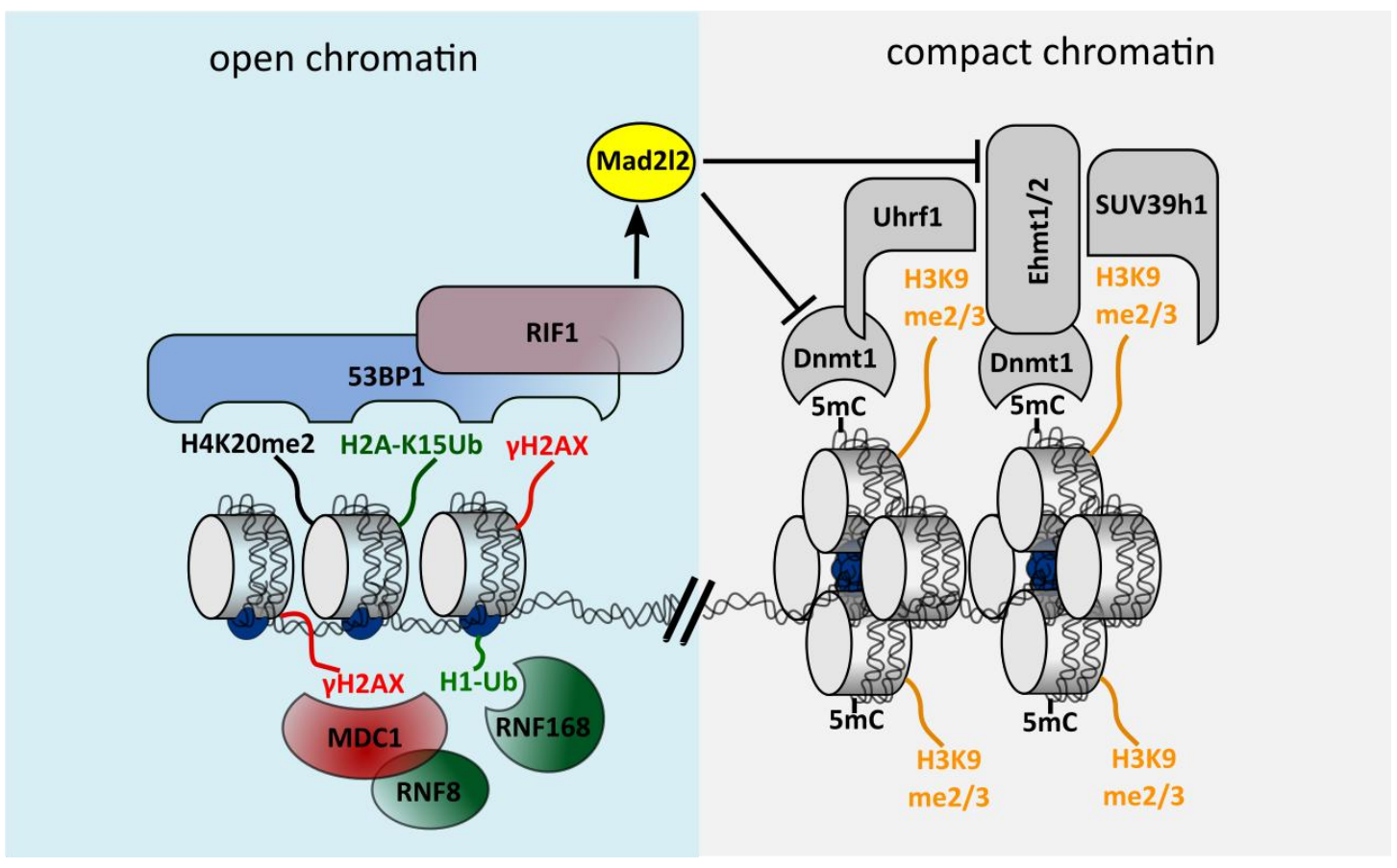

Figure 45: Mad2/2 as an epigenetic regulator promoting open chromatin in ESCs and after DNA damage.

For discussion see text in 4.6. and 4.7. The figure is extended and modified from a previously published representation (see Figure 4; (Zimmermann and de Lange, 2014). 


\section{References}

Adli, M., and Bernstein, B.E. (2011). Whole-genome chromatin profiling from limited numbers of cells using nano-ChIP-seq. Nat Protoc 6, 1656-1668.

Ahuja, A.K., Jodkowska, K., Teloni, F., Bizard, A.H., Zellweger, R., Herrador, R., Ortega, S., Hickson, I.D., Altmeyer, M., Mendez, J., et al. (2016). A short G1 phase imposes constitutive replication stress and fork remodelling in mouse embryonic stem cells. Nat Commun 7, 10660.

Alvarez-Quilon, A., Serrano-Benitez, A., Lieberman, J.A., Quintero, C., SanchezGutierrez, D., Escudero, L.M., and Cortes-Ledesma, F. (2014). ATM specifically mediates repair of double-strand breaks with blocked DNA ends. Nat Commun 5, 3347.

Ausubel, F.M. (2002). Short protocols in molecular biology : a compendium of methods from Current protocols in molecular biology, 5th edn (New York: Wiley).

Ayrapetov, M.K., Gursoy-Yuzugullu, O., Xu, C., Xu, Y., and Price, B.D. (2014). DNA double-strand breaks promote methylation of histone H3 on lysine 9 and transient formation of repressive chromatin. Proc Natl Acad Sci U S A 111, 9169-9174.

Baldock, R.A., Day, M., Wilkinson, O.J., Cloney, R., Jeggo, P.A., Oliver, A.W., Watts, F.Z., and Pearl, L.H. (2015). ATM Localization and Heterochromatin Repair Depend on Direct Interaction of the 53BP1-BRCT2 Domain with gammaH2AX. Cell Rep 13, 2081-2089.

Bao, S., Tang, F., Li, X., Hayashi, K., Gillich, A., Lao, K., and Surani, M.A. (2009). Epigenetic reversion of post-implantation epiblast to pluripotent embryonic stem cells. Nature 461, 1292-1295.

Bassing, C.H., Suh, H., Ferguson, D.O., Chua, K.F., Manis, J., Eckersdorff, M., Gleason, M., Bronson, R., Lee, C., and Alt, F.W. (2003). Histone H2AX: a dosage-dependent suppressor of oncogenic translocations and tumors. Cell 114, 359-370.

Bian, C., and Yu, X. (2014). PGC7 suppresses TET3 for protecting DNA methylation. Nucleic Acids Res 42, 2893-2905.

Boersma, V., Moatti, N., Segura-Bayona, S., Peuscher, M.H., van der Torre, J., Wevers, B.A., Orthwein, A., Durocher, D., and Jacobs, J.J. (2015). MAD2L2 controls DNA repair at telomeres and DNA breaks by inhibiting 5 ' end resection. Nature 521, 537-540.

Bortvin, A., Goodheart, M., Liao, M., and Page, D.C. (2004). Dppa3 / Pgc7 / stella is a maternal factor and is not required for germ cell specification in mice. BMC Dev Biol $4,2$.

Broering, T.J., Alavattam, K.G., Sadreyev, R.I., Ichijima, Y., Kato, Y., Hasegawa, K., Camerini-Otero, R.D., Lee, J.T., Andreassen, P.R., and Namekawa, S.H. (2014). BRCA1 
establishes DNA damage signaling and pericentric heterochromatin of the $X$ chromosome in male meiosis. J Cell Biol 205, 663-675.

Calder, A., Roth-Albin, I., Bhatia, S., Pilquil, C., Lee, J.H., Bhatia, M., Levadoux-Martin, M., McNicol, J., Russell, J., Collins, T., et al. (2013). Lengthened G1 phase indicates differentiation status in human embryonic stem cells. Stem Cells Dev 22, 279-295.

Carey, M., and Smale, S.T. (2007). Micrococcal Nuclease-Southern Blot Assay: I. MNase and Restriction Digestions. CSH Protoc 2007, pdb prot4890.

Chen, J., and Fang, G. (2001). MAD2B is an inhibitor of the anaphase-promoting complex. Genes Dev 15, 1765-1770.

Cheung, H.W., Chun, A.C., Wang, Q., Deng, W., Hu, L., Guan, X.Y., Nicholls, J.M., Ling, M.T., Chuan Wong, Y., Tsao, S.W., et al. (2006). Inactivation of human MAD2B in nasopharyngeal carcinoma cells leads to chemosensitization to DNA-damaging agents. Cancer Res 66, 4357-4367.

Chun, A.C., Kok, K.H., and Jin, D.Y. (2013). REV7 is required for anaphase-promoting complex-dependent ubiquitination and degradation of translesion DNA polymerase REV1. Cell Cycle 12, 365-378.

Ciccia, A., and Elledge, S.J. (2010). The DNA damage response: making it safe to play with knives. Mol Cell 40, 179-204.

Cimprich, K.A., and Cortez, D. (2008). ATR: an essential regulator of genome integrity. Nat Rev Mol Cell Biol 9, 616-627.

Collis, S.J., DeWeese, T.L., Jeggo, P.A., and Parker, A.R. (2005). The life and death of DNA-PK. Oncogene 24, 949-961.

Dahl, J.A., and Collas, P. (2008). A rapid micro chromatin immunoprecipitation assay (microChIP). Nat Protoc 3, 1032-1045.

De Los Angeles, A., Ferrari, F., Xi, R., Fujiwara, Y., Benvenisty, N., Deng, H., Hochedlinger, K., Jaenisch, R., Lee, S., Leitch, H.G., et al. Hallmarks of pluripotency. Nature 525, 469-478.

De Los Angeles, A., Ferrari, F., Xi, R., Fujiwara, Y., Benvenisty, N., Deng, H., Hochedlinger, K., Jaenisch, R., Lee, S., Leitch, H.G., et al. (2015). Hallmarks of pluripotency. Nature 525, 469-478.

Deriano, L., and Roth, D.B. (2013). Modernizing the nonhomologous end-joining repertoire: alternative and classical NHEJ share the stage. Annu Rev Genet 47, 433455.

Escribano-Diaz, C., Orthwein, A., Fradet-Turcotte, A., Xing, M., Young, J.T., Tkac, J., Cook, M.A., Rosebrock, A.P., Munro, M., Canny, M.D., et al. (2013). A cell cycledependent regulatory circuit composed of 53BP1-RIF1 and BRCA1-CtIP controls DNA repair pathway choice. Mol Cell 49, 872-883. 
Essers, J., Theil, A.F., Baldeyron, C., van Cappellen, W.A., Houtsmuller, A.B., Kanaar, R., and Vermeulen, W. (2005). Nuclear dynamics of PCNA in DNA replication and repair. Mol Cell Biol 25, 9350-9359.

Estecio, M.R., Gallegos, J., Vallot, C., Castoro, R.J., Chung, W., Maegawa, S., Oki, Y., Kondo, Y., Jelinek, J., Shen, L., et al. (2010). Genome architecture marked by retrotransposons modulates predisposition to DNA methylation in cancer. Genome Res 20, 1369-1382.

Fattah, F.J., Hara, K., Fattah, K.R., Yang, C., Wu, N., Warrington, R., Chen, D.J., Zhou, P., Boothman, D.A., and Yu, H. (2014). The transcription factor TFII-I promotes DNA translesion synthesis and genomic stability. PLoS Genet 10, e1004419.

Frum, T., and Ralston, A. (2015). Cell signaling and transcription factors regulating cell fate during formation of the mouse blastocyst. Trends Genet 31, 402-410.

Funaki, S., Nakamura, T., Nakatani, T., Umehara, H., Nakashima, H., and Nakano, T. (2014). Inhibition of maintenance DNA methylation by Stella. Biochem Biophys Res Commun 453, 455-460.

Gao, Y., Chaudhuri, J., Zhu, C., Davidson, L., Weaver, D.T., and Alt, F.W. (1998). A targeted DNA-PKcs-null mutation reveals DNA-PK-independent functions for KU in $\mathrm{V}(\mathrm{D}) \mathrm{J}$ recombination. Immunity 9, 367-376.

Goldstein, M., and Kastan, M.B. (2015). The DNA damage response: implications for tumor responses to radiation and chemotherapy. Annu Rev Med 66, 129-143.

Gonzales, K.A., Liang, H., Lim, Y.S., Chan, Y.S., Yeo, J.C., Tan, C.P., Gao, B., Le, B., Tan, Z.Y., Low, K.Y., et al. (2015). Deterministic Restriction on Pluripotent State Dissolution by Cell-Cycle Pathways. Cell 162, 564-579.

Grabole, N., Tischler, J., Hackett, J.A., Kim, S., Tang, F., Leitch, H.G., Magnusdottir, E., and Surani, M.A. (2013). Prdm14 promotes germline fate and naive pluripotency by repressing FGF signalling and DNA methylation. EMBO Rep 14, 629-637.

Guyochin, A., Maenner, S., Chu, E.T., Hentati, A., Attia, M., Avner, P., and Clerc, P. (2014). Live cell imaging of the nascent inactive $X$ chromosome during the early differentiation process of naive ES cells towards epiblast stem cells. PLoS One 9, e116109.

Ha, K., Lee, G.E., Palii, S.S., Brown, K.D., Takeda, Y., Liu, K., Bhalla, K.N., and Robertson, K.D. (2011). Rapid and transient recruitment of DNMT1 to DNA doublestrand breaks is mediated by its interaction with multiple components of the DNA damage response machinery. Hum Mol Genet 20, 126-140.

Hayashi, K., Ohta, H., Kurimoto, K., Aramaki, S., and Saitou, M. (2011). Reconstitution of the mouse germ cell specification pathway in culture by pluripotent stem cells. Cell 146, 519-532. 
Hein, M.Y., Hubner, N.C., Poser, I., Cox, J., Nagaraj, N., Toyoda, Y., Gak, I.A., Weisswange, I., Mansfeld, J., Buchholz, F., et al. (2015). A human interactome in three quantitative dimensions organized by stoichiometries and abundances. Cell $163,712-723$.

Hochegger, H., Takeda, S., and Hunt, T. (2008). Cyclin-dependent kinases and cellcycle transitions: does one fit all? Nat Rev Mol Cell Biol 9, 910-916.

Hong, C.F., Chou, Y.T., Lin, Y.S., and Wu, C.W. (2009). MAD2B, a novel TCF4-binding protein, modulates TCF4-mediated epithelial-mesenchymal transdifferentiation. J Biol Chem 284, 19613-19622.

Iwafuchi-Doi, M., Matsuda, K., Murakami, K., Niwa, H., Tesar, P.J., Aruga, J., Matsuo, I., and Kondoh, H. (2012). Transcriptional regulatory networks in epiblast cells and during anterior neural plate development as modeled in epiblast stem cells. Development 139, 3926-3937.

Iwai, H., Kim, M., Yoshikawa, Y., Ashida, H., Ogawa, M., Fujita, Y., Muller, D., Kirikae, T., Jackson, P.K., Kotani, S., et al. (2007). A bacterial effector targets Mad2L2, an APC inhibitor, to modulate host cell cycling. Cell 130, 611-623.

Joo, J.Y., Choi, H.W., Kim, M.J., Zaehres, H., Tapia, N., Stehling, M., Jung, K.S., Do, J.T., and Scholer, H.R. (2014). Establishment of a primed pluripotent epiblast stem cell in FGF4-based conditions. Sci Rep 4, 7477.

Kaji, K., Caballero, I.M., MacLeod, R., Nichols, J., Wilson, V.A., and Hendrich, B. (2006). The NuRD component Mbd3 is required for pluripotency of embryonic stem cells. Nat Cell Biol 8, 285-292.

Kawasaki, Y., Lee, J., Matsuzawa, A., Kohda, T., Kaneko-Ishino, T., and Ishino, F. (2014). Active DNA demethylation is required for complete imprint erasure in primordial germ cells. Sci Rep 4, 3658.

Khalaj, M., Abbasi, A., Yamanishi, H., Akiyama, K., Wakitani, S., Kikuchi, S., Hirose, M., Yuzuriha, M., Magari, M., Degheidy, H.A., et al. (2014). A missense mutation in Rev7 disrupts formation of Polzeta, impairing mouse development and repair of genotoxic agent-induced DNA lesions. J Biol Chem 289, 3811-3824.

Kimura, T., Kaga, Y., Ohta, H., Odamoto, M., Sekita, Y., Li, K., Yamano, N., Fujikawa, K., Isotani, A., Sasaki, N., et al. (2014). Induction of primordial germ cell-like cells from mouse embryonic stem cells by ERK signal inhibition. Stem Cells 32, 2668-2678.

Kojima, Y., Kaufman-Francis, K., Studdert, J.B., Steiner, K.A., Power, M.D., Loebel, D.A., Jones, V., Hor, A., de Alencastro, G., Logan, G.J., et al. (2014). The transcriptional and functional properties of mouse epiblast stem cells resemble the anterior primitive streak. Cell Stem Cell 14, 107-120.

Kolodziejczyk, A.A., Kim, J.K., Tsang, J.C., Ilicic, T., Henriksson, J., Natarajan, K.N., Tuck, A.C., Gao, X., Buhler, M., Liu, P., et al. (2015). Single Cell RNA-Sequencing of 
Pluripotent States Unlocks Modular Transcriptional Variation. Cell Stem Cell 17, 471485.

Kurimoto, K., Yabuta, Y., Hayashi, K., Ohta, H., Kiyonari, H., Mitani, T., Moritoki, Y., Kohri, K., Kimura, H., Yamamoto, T., et al. (2015). Quantitative Dynamics of Chromatin Remodeling during Germ Cell Specification from Mouse Embryonic Stem Cells. Cell Stem Cell 16, 517-532.

Lamarche, B.J., Orazio, N.I., and Weitzman, M.D. (2010). The MRN complex in double-strand break repair and telomere maintenance. FEBS Lett 584, 3682-3695.

Lawson, K.A., Dunn, N.R., Roelen, B.A., Zeinstra, L.M., Davis, A.M., Wright, C.V., Korving, J.P., and Hogan, B.L. (1999). Bmp4 is required for the generation of primordial germ cells in the mouse embryo. Genes Dev 13, 424-436.

Li, M., Liu, G.H., and Izpisua Belmonte, J.C. (2012). Navigating the epigenetic landscape of pluripotent stem cells. Nat Rev Mol Cell Biol 13, 524-535.

Magnusdottir, E., Dietmann, S., Murakami, K., Gunesdogan, U., Tang, F., Bao, S., Diamanti, E., Lao, K., Gottgens, B., and Azim Surani, M. (2013). A tripartite transcription factor network regulates primordial germ cell specification in mice. Nat Cell Biol 15, 905-915.

Mao, Z., Bozzella, M., Seluanov, A., and Gorbunova, V. (2008). DNA repair by nonhomologous end joining and homologous recombination during cell cycle in human cells. Cell Cycle 7, 2902-2906.

Marks, H., Kalkan, T., Menafra, R., Denissov, S., Jones, K., Hofemeister, H., Nichols, J., Kranz, A., Stewart, A.F., Smith, A., et al. (2012). The transcriptional and epigenomic foundations of ground state pluripotency. Cell 149, 590-604.

Masui, S., Ohtsuka, S., Yagi, R., Takahashi, K., Ko, M.S., and Niwa, H. (2008). Rex1/Zfp42 is dispensable for pluripotency in mouse ES cells. BMC Dev Biol 8, 45.

Medendorp, K., van Groningen, J.J., Vreede, L., Hetterschijt, L., van den Hurk, W.H., de Bruijn, D.R., Brugmans, L., and van Kessel, A.G. (2009). The mitotic arrest deficient protein MAD2B interacts with the small GTPase RAN throughout the cell cycle. PLoS One 4, e7020.

Meshorer, E., and Misteli, T. (2006). Chromatin in pluripotent embryonic stem cells and differentiation. Nat Rev Mol Cell Biol 7, 540-546.

Moshous, D., Callebaut, I., de Chasseval, R., Corneo, B., Cavazzana-Calvo, M., Le Deist, F., Tezcan, I., Sanal, O., Bertrand, Y., Philippe, N., et al. (2001). Artemis, a novel DNA double-strand break repair/V(D)J recombination protein, is mutated in human severe combined immune deficiency. Cell 105, 177-186.

Moynahan, M.E., and Jasin, M. (2010). Mitotic homologous recombination maintains genomic stability and suppresses tumorigenesis. Nat Rev Mol Cell Biol 11, 196-207. 
Nakaki, F., Hayashi, K., Ohta, H., Kurimoto, K., Yabuta, Y., and Saitou, M. (2013). Induction of mouse germ-cell fate by transcription factors in vitro. Nature 501, 222226.

Nakamura, T., Liu, Y.J., Nakashima, H., Umehara, H., Inoue, K., Matoba, S., Tachibana, M., Ogura, A., Shinkai, Y., and Nakano, T. (2012). PGC7 binds histone H3K9me2 to protect against conversion of $5 \mathrm{mC}$ to $5 \mathrm{hmC}$ in early embryos. Nature $486,415-419$.

Niimi, K., Murakumo, Y., Watanabe, N., Kato, T., Mii, S., Enomoto, A., Asai, M., Asai, N., Yamamoto, E., Kajiyama, H., et al. (2014). Suppression of REV7 enhances cisplatin sensitivity in ovarian clear cell carcinoma cells. Cancer Sci 105, 545-552.

Ohinata, Y., Payer, B., O'Carroll, D., Ancelin, K., Ono, Y., Sano, M., Barton, S.C., Obukhanych, T., Nussenzweig, M., Tarakhovsky, A., et al. (2005). Blimp1 is a critical determinant of the germ cell lineage in mice. Nature 436, 207-213.

Ohinata, Y., Sano, M., Shigeta, M., Yamanaka, K., and Saitou, M. (2008). A comprehensive, non-invasive visualization of primordial germ cell development in mice by the Prdm1-mVenus and Dppa3-ECFP double transgenic reporter. Reproduction 136, 503-514.

Ohnishi, Y., Huber, W., Tsumura, A., Kang, M., Xenopoulos, P., Kurimoto, K., Oles, A.K., Arauzo-Bravo, M.J., Saitou, M., Hadjantonakis, A.K., et al. (2014). Cell-to-cell expression variability followed by signal reinforcement progressively segregates early mouse lineages. Nat Cell Biol 16, 27-37.

Okamura, D., Hayashi, K., and Matsui, Y. (2005). Mouse epiblasts change responsiveness to BMP4 signal required for PGC formation through functions of extraembryonic ectoderm. Mol Reprod Dev 70, 20-29.

Ozeri-Galai, E., Schwartz, M., Rahat, A., and Kerem, B. (2008). Interplay between ATM and ATR in the regulation of common fragile site stability. Oncogene 27, 21092117.

Pacheco, S., Marcet-Ortega, M., Lange, J., Jasin, M., Keeney, S., and Roig, I. (2015). The ATM signaling cascade promotes recombination-dependent pachytene arrest in mouse spermatocytes. PLoS Genet 11, e1005017.

Padua, M.B., Fox, S.C., Jiang, T., Morse, D.A., and Tevosian, S.G. (2014). Simultaneous gene deletion of gata4 and gata6 leads to early disruption of follicular development and germ cell loss in the murine ovary. Biol Reprod 91, 24.

Pan, G.J., Chang, Z.Y., Scholer, H.R., and Pei, D. (2002). Stem cell pluripotency and transcription factor Oct4. Cell Res 12, 321-329.

Panier, S., and Boulton, S.J. (2014). Double-strand break repair: 53BP1 comes into focus. Nat Rev Mol Cell Biol 15, 7-18. 
Peterson, S.E., Li, Y., Chait, B.T., Gottesman, M.E., Baer, R., and Gautier, J. (2011). Cdk1 uncouples CtIP-dependent resection and Rad51 filament formation during $\mathrm{M}$ phase double-strand break repair. J Cell Biol 194, 705-720.

Pfleger, C.M., Salic, A., Lee, E., and Kirschner, M.W. (2001). Inhibition of Cdh1-APC by the MAD2-related protein MAD2L2: a novel mechanism for regulating Cdh1. Genes Dev 15, 1759-1764.

Pirouz, M., Pilarski, S., and Kessel, M. (2013). A critical function of Mad2/2 in primordial germ cell development of mice. PLoS Genet 9, e1003712.

Pirouz, M., Rahjouei, A., Shamsi, F., Eckermann, K.N., Salinas-Riester, G., Pommerenke, C., and Kessel, M. (2015). Destabilization of pluripotency in the absence of Mad212. Cell Cycle 14, 1596-1610.

Revelo, N.H., Kamin, D., Truckenbrodt, S., Wong, A.B., Reuter-Jessen, K., Reisinger, E., Moser, T., and Rizzoli, S.O. (2014). A new probe for super-resolution imaging of membranes elucidates trafficking pathways. J Cell Biol 205, 591-606.

Rosenberg, S.C., and Corbett, K.D. (2015). The multifaceted roles of the HORMA domain in cellular signaling. J Cell Biol 211, 745-755.

Rossetto, D., Truman, A.W., Kron, S.J., and Cote, J. (2010). Epigenetic modifications in double-strand break DNA damage signaling and repair. Clin Cancer Res 16, 45434552.

Saha, T., Rih, J.K., Roy, R., Ballal, R., and Rosen, E.M. (2010). Transcriptional regulation of the base excision repair pathway by BRCA1. J Biol Chem 285, 1909219105.

Saitou, M., and Yamaji, M. (2012). Primordial germ cells in mice. Cold Spring Harb Perspect Biol 4.

Sambrook, J., and Russell, D.W. (2006). Standard ethanol precipitation of DNA in microcentrifuge tubes. CSH Protoc 2006.

Schmittgen, T.D., and Livak, K.J. (2008). Analyzing real-time PCR data by the comparative C(T) method. Nat Protoc 3, 1101-1108.

Seki, Y., Yamaji, M., Yabuta, Y., Sano, M., Shigeta, M., Matsui, Y., Saga, Y., Tachibana, M., Shinkai, Y., and Saitou, M. (2007). Cellular dynamics associated with the genomewide epigenetic reprogramming in migrating primordial germ cells in mice. Development 134, 2627-2638.

Singer, Z.S., Yong, J., Tischler, J., Hackett, J.A., Altinok, A., Surani, M.A., Cai, L., and Elowitz, M.B. (2014). Dynamic heterogeneity and DNA methylation in embryonic stem cells. Mol Cell 55, 319-331.

Stower, M.J., and Srinivas, S. (2014). Heading forwards: anterior visceral endoderm migration in patterning the mouse embryo. Philos Trans R Soc Lond B Biol Sci 369. 
Stuart, H.T., van Oosten, A.L., Radzisheuskaya, A., Martello, G., Miller, A., Dietmann, S., Nichols, J., and Silva, J.C. (2014). NANOG amplifies STAT3 activation and they synergistically induce the naive pluripotent program. Curr Biol 24, 340-346.

Sulli, G., Di Micco, R., and d'Adda di Fagagna, F. (2012). Crosstalk between chromatin state and DNA damage response in cellular senescence and cancer. Nat Rev Cancer $12,709-720$.

Sung, P., and Klein, H. (2006). Mechanism of homologous recombination: mediators and helicases take on regulatory functions. Nat Rev Mol Cell Biol 7, 739-750.

Tajbakhsh, J., Stefanovski, D., Tang, G., Wawrowsky, K., Liu, N., and Fair, J.H. (2015). Dynamic heterogeneity of DNA methylation and hydroxymethylation in embryonic stem cell populations captured by single-cell 3D high-content analysis. Exp Cell Res 332, 190-201.

Thorslund, T., Ripplinger, A., Hoffmann, S., Wild, T., Uckelmann, M., Villumsen, B., Narita, T., Sixma, T.K., Choudhary, C., Bekker-Jensen, S., et al. (2015). Histone H1 couples initiation and amplification of ubiquitin signalling after DNA damage. Nature 527, 389-393.

Tomimatsu, N., Mukherjee, B., Catherine Hardebeck, M., Ilcheva, M., Vanessa Camacho, C., Louise Harris, J., Porteus, M., Llorente, B., Khanna, K.K., and Burma, S. (2014). Phosphorylation of EXO1 by CDKs 1 and 2 regulates DNA end resection and repair pathway choice. Nat Commun 5, 3561.

Tosolini, M., and Jouneau, A. (2016). Acquiring Ground State Pluripotency: Switching Mouse Embryonic Stem Cells from Serum/LIF Medium to 2i/LIF Medium. Methods Mol Biol 1341, 41-48.

Turinetto, V., Orlando, L., Sanchez-Ripoll, Y., Kumpfmueller, B., Storm, M.P., Porcedda, P., Minieri, V., Saviozzi, S., Accomasso, L., Cibrario Rocchietti, E., et al. (2012). High basal gammaH2AX levels sustain self-renewal of mouse embryonic and induced pluripotent stem cells. Stem Cells 30, 1414-1423.

Vastenhouw, N.L., and Schier, A.F. (2012). Bivalent histone modifications in early embryogenesis. Curr Opin Cell Biol 24, 374-386.

Vermeulen, M., Eberl, H.C., Matarese, F., Marks, H., Denissov, S., Butter, F., Lee, K.K., Olsen, J.V., Hyman, A.A., Stunnenberg, H.G., et al. (2010). Quantitative interaction proteomics and genome-wide profiling of epigenetic histone marks and their readers. Cell 142, 967-980.

Wang, H., Wang, M., Wang, H., Bocker, W., and Iliakis, G. (2005). Complex H2AX phosphorylation patterns by multiple kinases including ATM and DNA-PK in human cells exposed to ionizing radiation and treated with kinase inhibitors. J Cell Physiol 202, 492-502. 
Ward, I.M., and Chen, J. (2001). Histone H2AX is phosphorylated in an ATRdependent manner in response to replicational stress. J Biol Chem 276, 4775947762.

Watanabe, N., Mii, S., Asai, N., Asai, M., Niimi, K., Ushida, K., Kato, T., Enomoto, A., Ishii, H., Takahashi, M., et al. (2013). The REV7 subunit of DNA polymerase zeta is essential for primordial germ cell maintenance in the mouse. J Biol Chem 288, 10459-10471.

Weber, S., Eckert, D., Nettersheim, D., Gillis, A.J., Schafer, S., Kuckenberg, P., Ehlermann, J., Werling, U., Biermann, K., Looijenga, L.H., et al. (2010). Critical function of AP-2 gamma/TCFAP2C in mouse embryonic germ cell maintenance. Biol Reprod 82, 214-223.

Weterman, M.A., van Groningen, J.J., Tertoolen, L., and van Kessel, A.G. (2001). Impairment of MAD2B-PRCC interaction in mitotic checkpoint defective $t(X ; 1)$ positive renal cell carcinomas. Proc Natl Acad Sci U S A 98, 13808-13813.

Wu, G., Han, D., Gong, Y., Sebastiano, V., Gentile, L., Singhal, N., Adachi, K., Fischedick, G., Ortmeier, C., Sinn, M., et al. (2013). Establishment of totipotency does not depend on Oct4A. Nat Cell Biol 15, 1089-1097.

Xenopoulos, P., Kang, M., Puliafito, A., Di Talia, S., and Hadjantonakis, A.K. (2015). Heterogeneities in Nanog Expression Drive Stable Commitment to Pluripotency in the Mouse Blastocyst. Cell Rep.

Xu, G., Chapman, J.R., Brandsma, I., Yuan, J., Mistrik, M., Bouwman, P., Bartkova, J., Gogola, E., Warmerdam, D., Barazas, M., et al. (2015a). REV7 counteracts DNA double-strand break resection and affects PARP inhibition. Nature 521, 541-544.

Xu, X., Smorag, L., Nakamura, T., Kimura, T., Dressel, R., Fitzner, A., Tan, X., Linke, M., Zechner, U., Engel, W., et al. (2015b). Dppa3 expression is critical for generation of fully reprogrammed iPS cells and maintenance of Dlk1-Dio3 imprinting. Nat Commun $6,6008$.

Yamaji, M., Ueda, J., Hayashi, K., Ohta, H., Yabuta, Y., Kurimoto, K., Nakato, R., Yamada, Y., Shirahige, K., and Saitou, M. (2013). PRDM14 ensures naive pluripotency through dual regulation of signaling and epigenetic pathways in mouse embryonic stem cells. Cell Stem Cell 12, 368-382.

Yamazaki, S., Ishii, A., Kanoh, Y., Oda, M., Nishito, Y., and Masai, H. (2012). Rif1 regulates the replication timing domains on the human genome. EMBO J 31, 36673677.

Ying, Q.L., Wray, J., Nichols, J., Batlle-Morera, L., Doble, B., Woodgett, J., Cohen, P., and Smith, A. (2008). The ground state of embryonic stem cell self-renewal. Nature 453, 519-523. 
Zernicka-Goetz, M. (2005). Cleavage pattern and emerging asymmetry of the mouse embryo. Nat Rev Mol Cell Biol 6, 919-928.

Zha, S., Sekiguchi, J., Brush, J.W., Bassing, C.H., and Alt, F.W. (2008). Complementary functions of ATM and H2AX in development and suppression of genomic instability. Proc Natl Acad Sci U S A 105, 9302-9306.

Zhang, R.P., Shao, J.Z., and Xiang, L.X. (2011). GADD45A protein plays an essential role in active DNA demethylation during terminal osteogenic differentiation of adipose-derived mesenchymal stem cells. J Biol Chem 286, 41083-41094.

Zimmermann, M., and de Lange, T. (2014). 53BP1: pro choice in DNA repair. Trends Cell Biol 24, 108-117.

Zylicz, J.J., Dietmann, S., Gunesdogan, U., Hackett, J.A., Cougot, D., Lee, C., and Surani, M.A. (2015). Chromatin dynamics and the role of G9a in gene regulation and enhancer silencing during early mouse development. Elife 4. 


\section{Ali Rahjouei - Curriculum vitae}

\section{Personal data}

Name

Address

Phone

Birth

Place of birth

Nationality

Marriage

\section{Education}

2001-2010

2005

2006-2008

$2008-2010$

2010

since 2012
Email

\author{
Ali Rajouei, M.S. \\ Max Planck Institute for Biophysical Chemistry \\ Am Fassberg 11 \\ 37077 Goettingen \\ Germany
}

\author{
+495512011671 \\ ali.rahjouei@mpibpc.mpg.de \\ 20.09.1983 \\ Bandar-e Anzali \\ Iranian \\ Melina Rahjouei, M.S. Psychologist, born in 1986
}

Biology studies at the Islamic Azad University, Tehran, Iran Bachelor degree (B.S.) in Molecular and Cellular Biology Master degree (M.S.) program at Science and Research University, Tehran, Iran

Research in Royan institute for Stem Cell Biology and Technology, Iran

Master degree (M.S.) in Molecular and Cellular Biology

Science and Research University, Tehran, Iran

Research Advisor: Prof. Hossein Baharvand

Thesis title: "Induction and expansion of neural stem cells on nanofibers from human embryonic stem cells"

Enscription at the Georg August University, Goettingen, Germany member of the Goettingen graduate college GGNB research for $\mathrm{PhD}$ in the research group Developmental Biology Max Planck Institute for Biophysical Chemistry Thesis advisor: Prof. Dr. Michael Kessel provisional thesis title: The function of Mad2/2 in the epigenetic status of embryonic stem cells"

Honors and Awards

2010

2013-2016

Royan Institute research fellowship Max Planck fellowship

\section{Conference Abstracts:}

Rahjouei A, Zare N, Kiani S, Shahbazi E, Baharvand H. Optimization of RGDPeptide nano scaffolds with copolymerization method for axonal outgrowth in differentiated hESCeNeuralstem cells. Cell Journal, Volume 11 Supplement 1 ,Autumn 2009 (Presented at 5th Royan Congress on Stem Cell Biology and Technology)

Shahbazi E, Zare N, Kiani S, Hatami M, Hemmesi K, R ahjouei A, Gourabi H. S tepwise direct differentiation of human embryonic stem cells into functional motoneurons. Cell journal, Volume11 Supplement 1 ,Autumn 2009 (Presented at 5th Royan Congress on Stem Cell Biology and Technology)

Rahjouei A, Kiani S, Baharvand $\mathrm{H}$. A rapid protocol for isolation and expansion of neural stem 
cells from human embryoid bodies by new approach. Cell Journal, Volume 12 , Supplement 1,Summer 2010 (Presented at 6th Royan Congress on Stem Cell Biology and Technology)

Rahjouei A, Pirouz M and Kessel M. E ssential epigenetic regulation by Mad2/2 in embryonic stem cells and primordial germ cells. Development 2015 142: 27272729; doi: 10.1242/dev.124719 (Presented at EMBO workshop entitled Embryonic Extraembryonic Interfaces' took place in Göttingen, Germany, in May 2015)

Rahjouei A, Pirouz M, Kamin D, Kessel M. D NA damage response factor Mad2l2 is crucial for the epigenetic status of embryonic stem and primordial germ cells. ( Presented at cell symposia stem cell epigenetics, september 2015, Sitges, Spain)

\section{Original Articles:}

Rahjouei A, Kiani S, Zahabi A, Mehrjardi NZ, Hashemi M, Baharvand H. Interactions of human embryonic stem cellderived neural progenitors with an electrospun nanofibrillar surface in vitro. Int J Artif Organs 2011, 34(7): 559570, PMID : 21786255

Pirouz M, Rahjouei A, Shamsi F, Eckermann KN, SalinasRiester G, Pommerenke C, Kessel M. Destabilization of pluripotency in the absence of Mad2/2. Cell Cycle Volume 14, Issue 10, May 2015, pages 15961610 PMID: 25928475

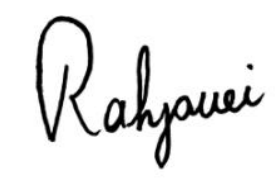

Ali Rahjouei, M.S.

Goettingen 04.0. 2016 
